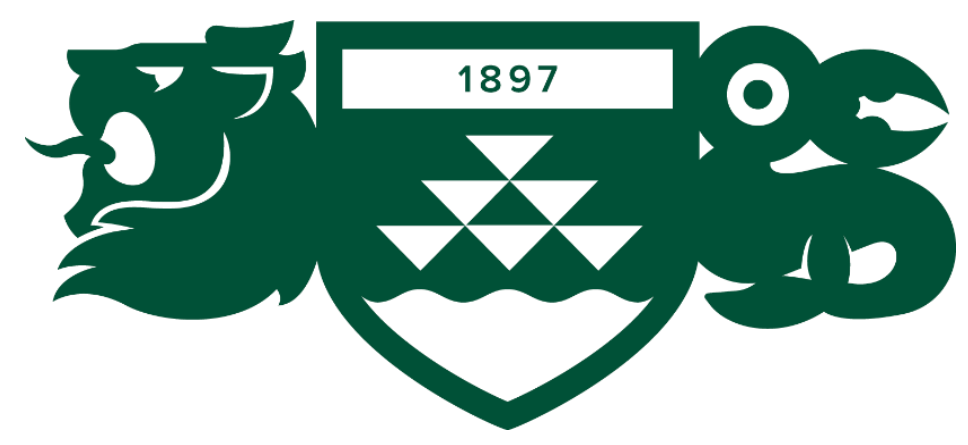

\title{
Exacerbating the privacy paradox: Investigating cognitive load's impact on disclosure
}

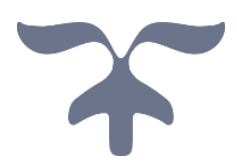

By

Paul Joseph Harrison

Supervisor: Associate Professor James E Richard

A thesis submitted to the Victoria University of Wellington in fulfillment of the requirements for the degree of Master of Commerce

Victoria University of Wellington

2020 


\begin{abstract}
Consumers have become the targets of a dual threat; more frequent requests for personal information and increased multitasking leading to distraction. This paper investigates the impact of cognitive load on the propensity to disclose personal information. A betweensubjects experimental design was employed wherein participants completed a fictitious company questionnaire which asked for personal information whilst participants simultaneously remembered a 7-digit (Cognitive load condition) or 2-digit (Control condition) number. Upon completion of the questionnaire participants were asked to recall their number before answering several additional surveys and demographic questions. The results suggest that cognitive load influences the level of personal information disclosure in such a way that individuals tasked to remember a 7-digit number were more likely to disclose their personal information. Results also demonstrated the impact of information sensitivity, perceived risk, perceived worry, and need for cognition on three dependent variables: absolute disclosure, quality of disclosure, and response latency. The research adds greater nuance to the privacy paradox literature by proposing cognitive load as a key factor. Moreover, the results provide implications for marketing practitioners and policymakers regarding the acquisition of consumer's personal information.
\end{abstract}




\section{Acknowledgements}

To my supervisor Dr. James Richard I must extend the greatest share of my appreciation and thanks. Despite my frequent bouts of maladaptive introspection and self-doubt, you were always able to set my mind back on the right track and pave a clear path to the successful completion of this thesis. Without your guidance and wisdom, your knowledge of statistics, and your patience to laboriously outline the seemingly pedantic nuances of a research paper's structure, this thesis would be of significantly diminished quality. Therefore, my success is indebted to your contribution as supervisor.

I would like to thank my parents for their ongoing support and encouragement throughout my years at University, especially as three years turned to four and then those four became six. I know it has not always been clear what I have been striving towards, but your support has continued unabated, and finally I at least have something tangible to present from this journey. Thank you for believing in me.

To my friends and family of whom there are too many to name, I thank you for always being there and keeping me within the bounds of sanity. I would also like to express gratitude to my colleagues, those numerous members of SMIB who offered their time, wisdom, and expertise to guide me, your advice was always heartily embraced. And to everyone on the eleventh floor, thank you for the kindness, for saying hello, and the small words of encouragement, you made me feel welcome beyond measure.

Finally, as I consider my next steps, moving forward to further academic endeavours, or perhaps finally entering that 'real world' I so often hear about, I am eternally grateful to everyone's support, and can march hopeful into the future knowing I have been guided by the finest party of family, friends, and colleagues that I could ever ask for. 


\section{Table of contents}

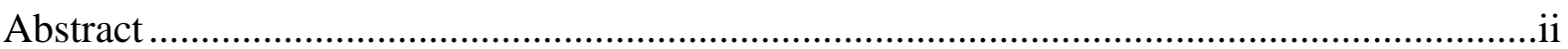

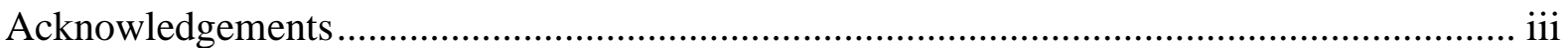

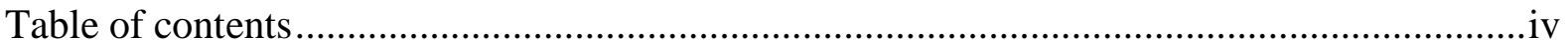

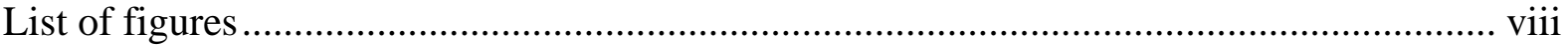

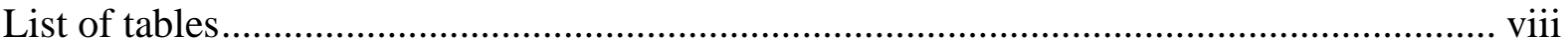

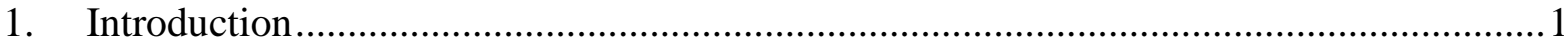

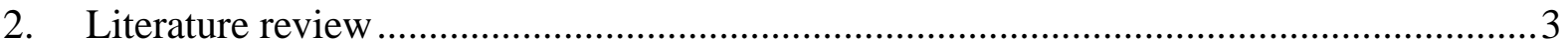

2.1 Privacy paradox and disclosure of personal information............................................

2.1.1 Disclosure differences between groups ....................................................... 6

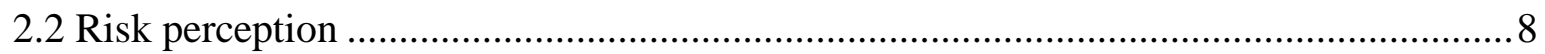

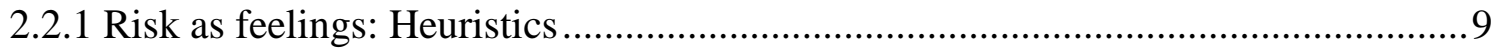

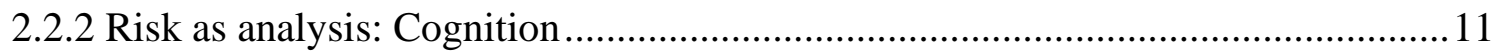

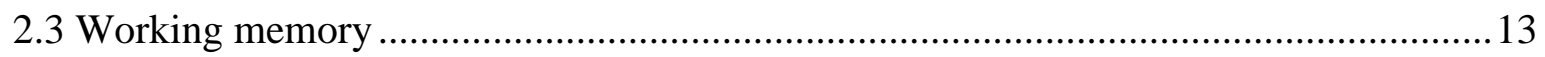

2.3.1 Limitations of working memory capacity .................................................... 14

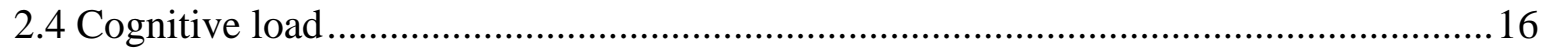

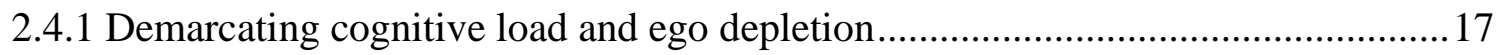

2.4.2 Cognitive load in the Marketing literature ........................................................ 18

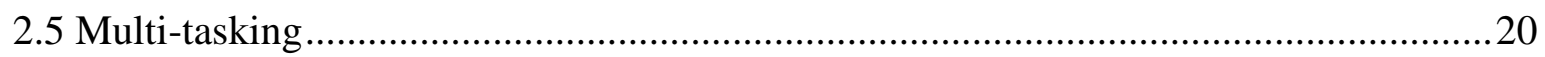

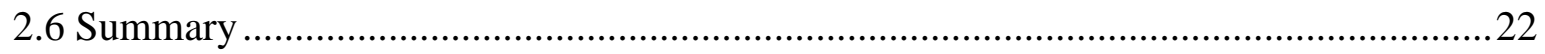

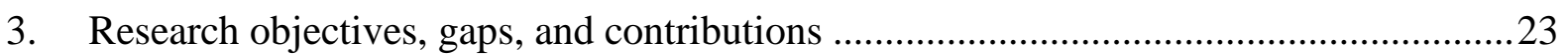

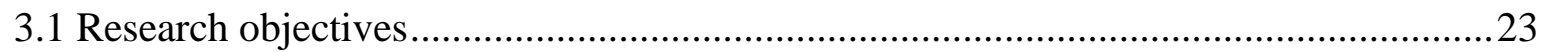

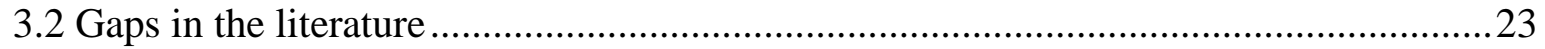

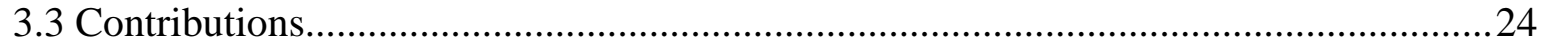

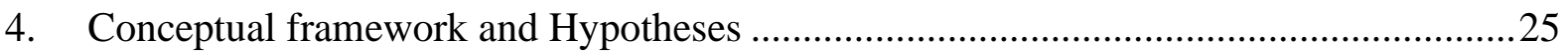

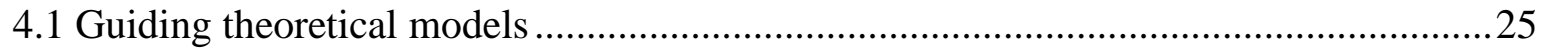

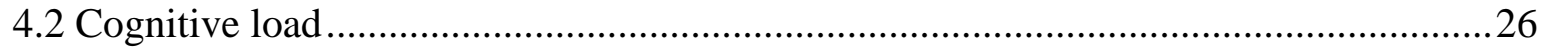




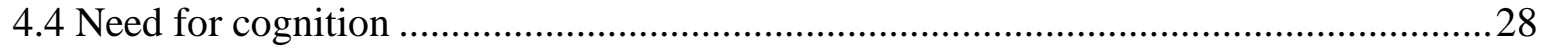

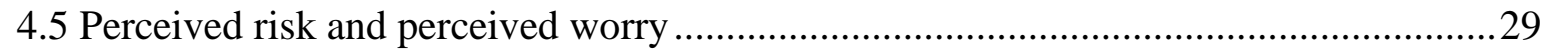

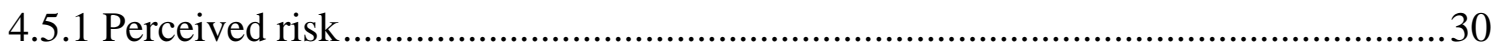

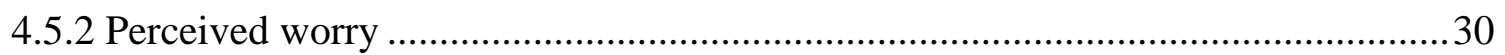

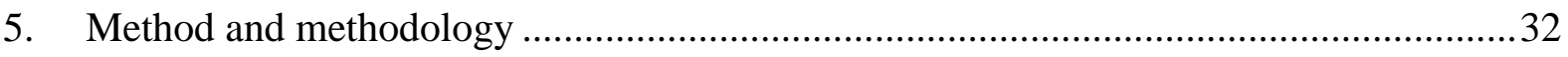

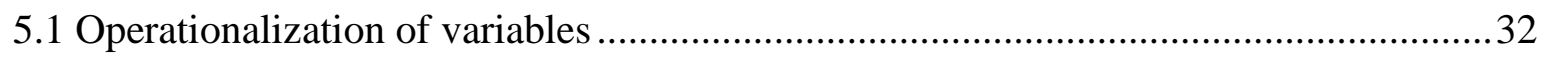

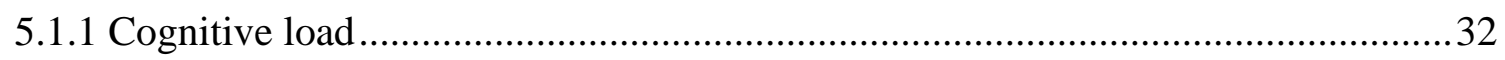

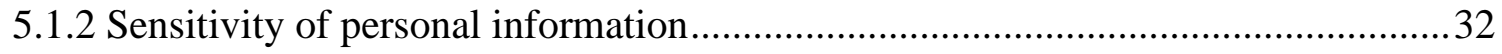

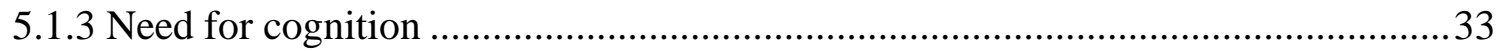

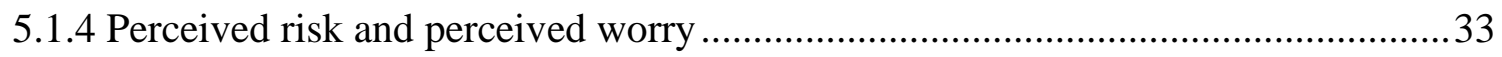

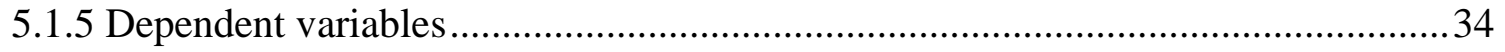

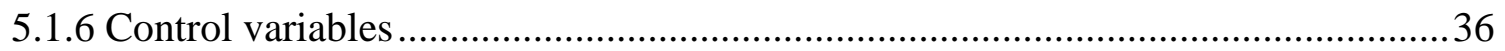

5.2 Pre-tests: Scenario development and question selection ......................................... 39

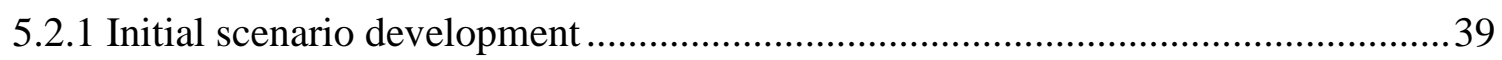

5.2.2 Pre-test one

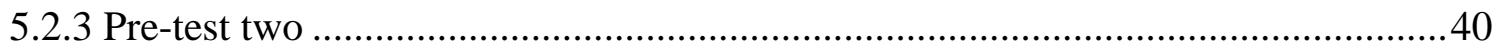

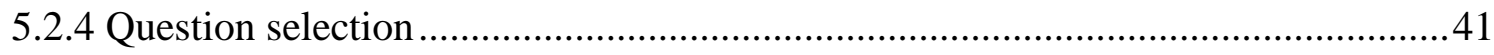

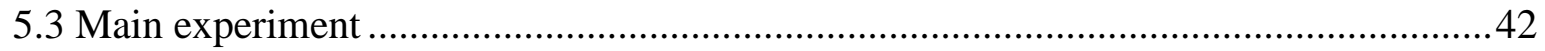

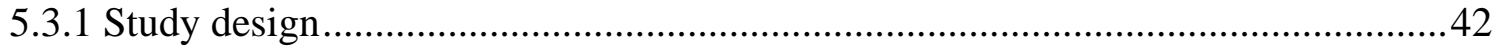

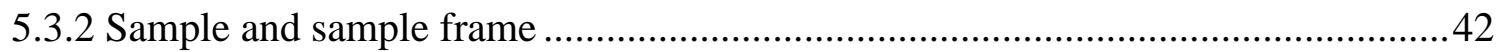

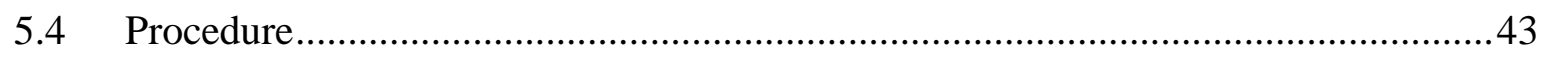

5.4.1 Phase one: Introduction of the study and scenario..............................................4

5.4.2 Phase two: Company questionnaire and manipulation ........................................46

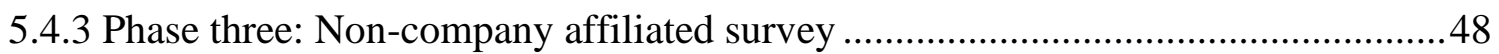




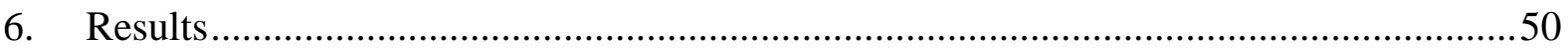

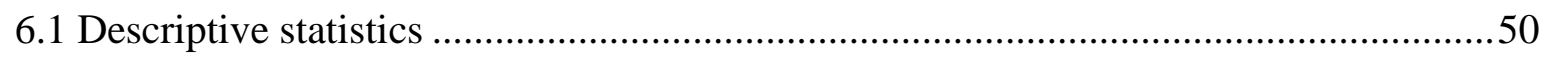

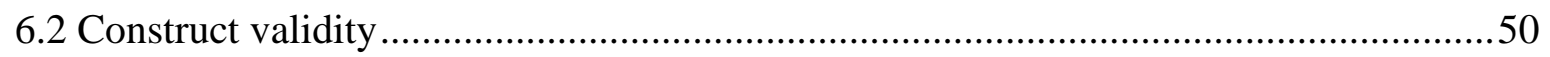

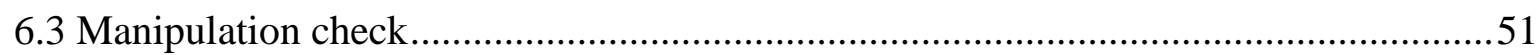

6.4 Comparing the cognitive load and control condition...............................................52

6.5 Cognitive load and sensitivity of personal information ...........................................53

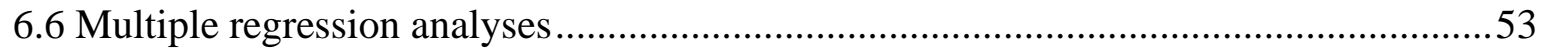

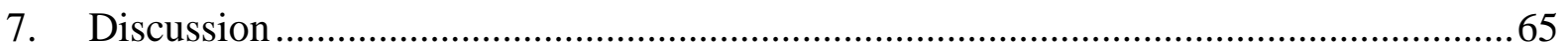

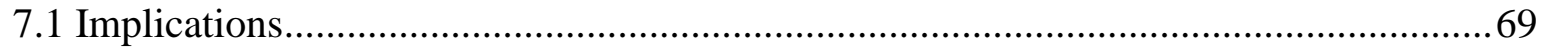

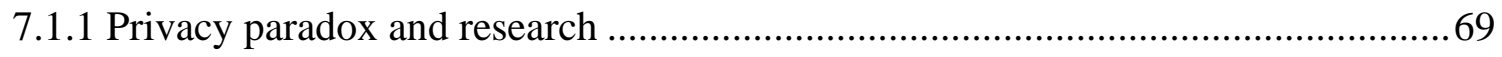

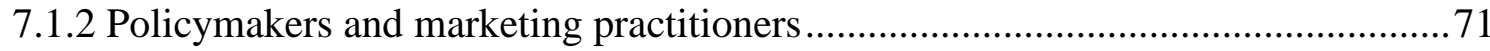

7.1.3 Perceived risk and perceived worry under cognitive load .................................. 73

7.1.4 Absolute disclosure, quality of disclosure, and response latency ......................... 73

7.1.5 Broader implications considering the trends of society .................................... 74

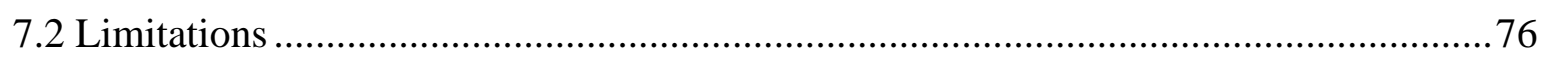

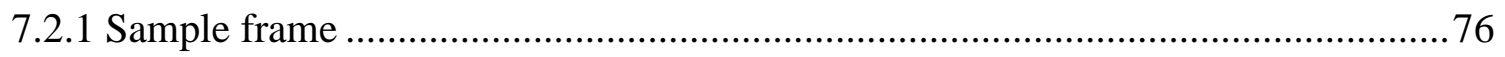

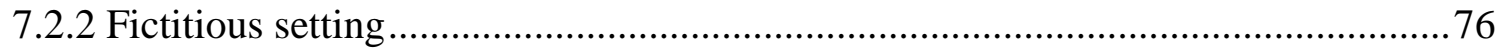

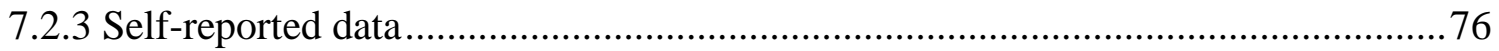

7.2.4 Demarcating refusal to disclose and inability to recall ....................................... 77

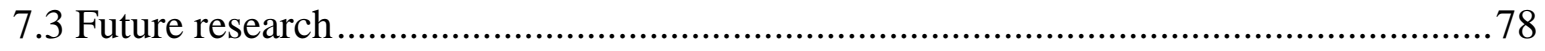

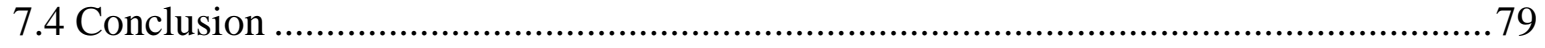

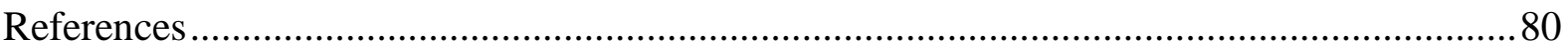

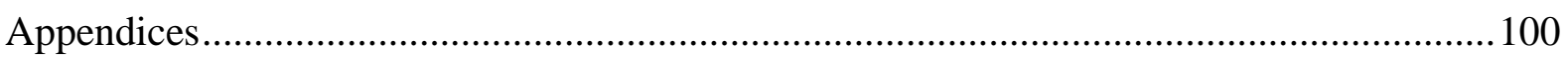

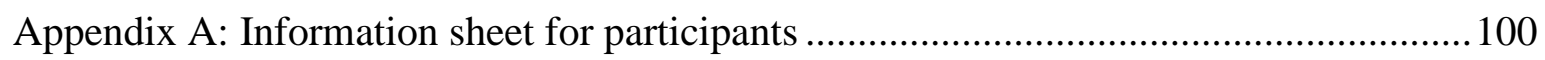

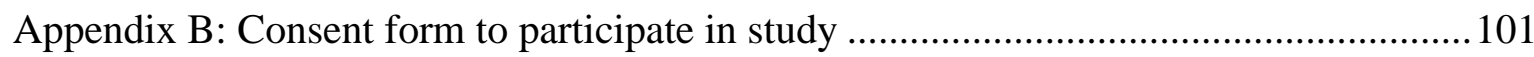




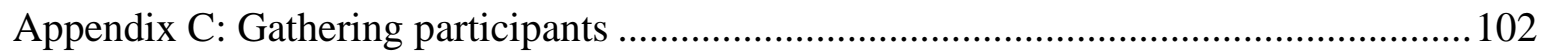

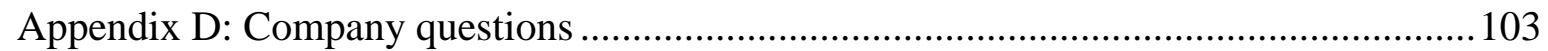

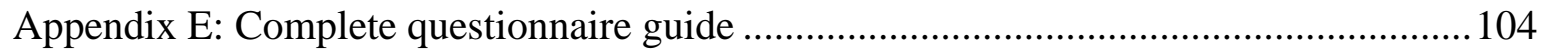

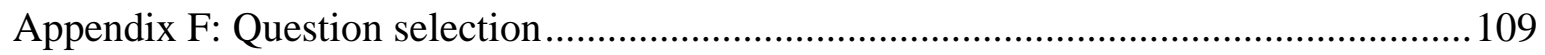

Appendix G: Pre-test 1 and 2 demographic and scenario data ..................................... 110

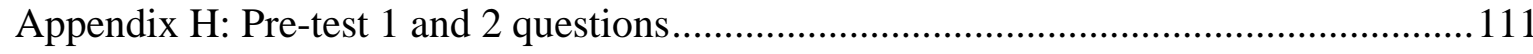

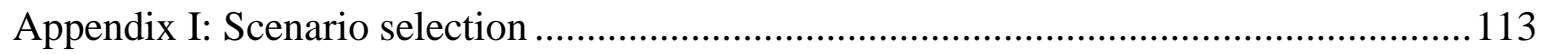

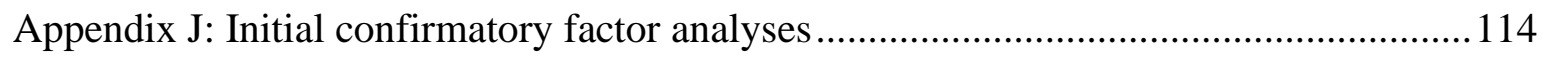

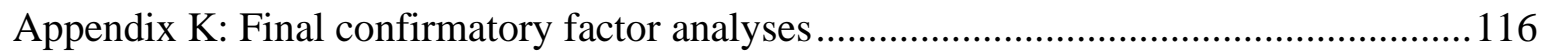

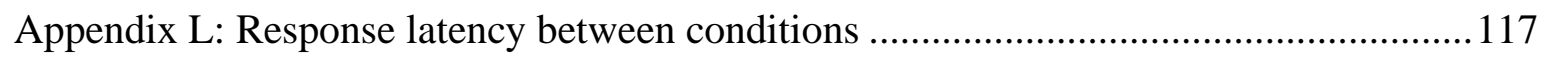




\section{List of figures}

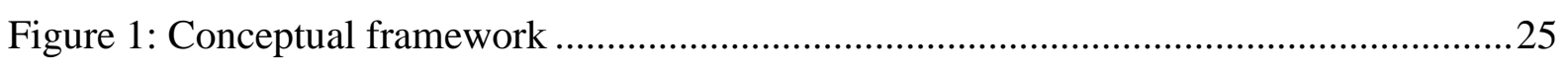

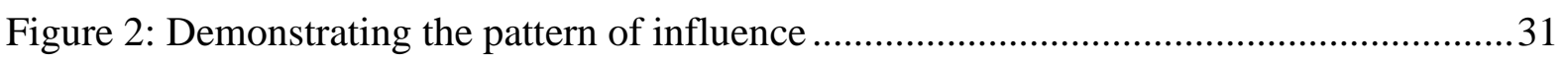

\section{List of tables}

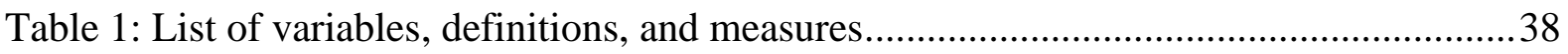

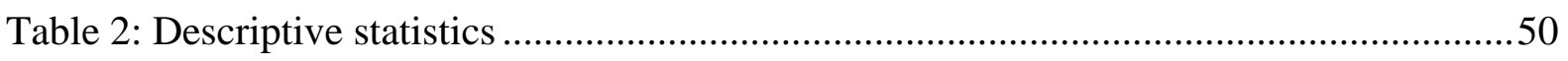

Table 3: Cognitive load and sensitivity of personal information..........................................54

Table 4: Regression model with absolute disclosure as dependent variable ..........................57

Table 5: Regression with number of false responses as dependent variable ..........................58

Table 6: Regression model with number of incomplete responses as dependent variable ......59

Table 7: Regression model with combined protective strategies as dependant variable .........60

Table 8: Regression model with time taken as dependant variable .......................................62

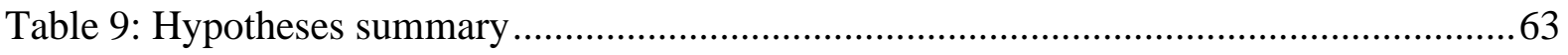




\section{Introduction}

Technology has helped improve many facets of life. Smartphones provide access to endless information and entertainment, instant communication, and a myriad of personal accessories from calculators to cameras. But, this intimate relationship with technology also provides companies and businesses with a direct avenue to ask consumers questions and gain access to personal information.

Marketers require consumer insights to drive improved decision making, thus as businesses aim to accumulate as much customer data as possible, consumers have steadily became the target of increased requests for personal information (Martin, 2016). The privacy paradox attempts to explain the discrepancy between an individual's privacy concerns with that of their actual indiscriminate privacy disclosure behaviour (Norberg, Horne, \& Horne, 2007). Prominent examples of excessive disclosure include oversharing on social media and disclosing purchasing habits to companies in exchange for small rewards and conveniences (Beresford, Kübler, \& Preibusch, 2012; Tufekci, 2008). These instances reflect the problem at hand; consumers' disclosure behaviour is undermining their privacy, despite the privacy concerns they themselves may hold.

Alongside this privacy paradox, individuals are distracted by their smart devices. It is not rare to stumble upon a story of someone coming to an untimely death by walking into oncoming traffic or falling from a cliff whilst enthralled by their phones (Appel, Krisch, Stein, \& Weber, 2019). Consumers are also multi-tasking more frequently, for example switching between devices whilst consuming media, and students incessantly using phones for nonlearning related purposes in classroom settings (McCoy, 2016). Moreover, an individual working whilst in the vicinity of their smartphone is prone to experiencing diminished cognitive ability (Ward, Duke, Gneezy, \& Bos, 2017). Thus, consumers are both more frequently being asked to disclose personal information whilst they are also likely to be in a state of divided attention. Whether this interaction exacerbates the privacy paradox, increasing individual's personal information disclosure, is currently unknown. If distracted consumers are susceptible to over-disclosure this may undermine their ability to align disclosure behaviour with privacy concerns, potentially putting the consumer at greater risk of their personal information being misused. An additional problem could also arise if companies develop techniques to target consumers with requests for personal information whilst the consumer is distracted, threatening the consumers' autonomy. 
Previous Marketing research has yet to investigate the impact of cognitive load on an individual's personal information disclosure despite prior research demonstrating a negative impact of cognitive load on an individuals' ability to self-regulate their behaviour to align with their goals (Shiv \& Fedorikhin, 1999). The present paper addresses the potential problems listed above by conducting an experiment to investigate the impact of cognitive load on an individuals' propensity to disclose personal information. The study reveals that participants under cognitive load are more likely to disclose more personal information than those in greater control of their cognitive faculties. Additional nuances such as whether the impact of determinant variables of disclosure: perceived risk, perceived worry, need for cognition, and sensitivity of information, are moderated by the presence of cognitive load is also explored. Theoretical and managerial implications of the results are also discussed. 


\section{Literature review}

The literature review delves into extant research primarily from the fields of Marketing and Psychology. The privacy paradox literature is explored first. A broad analysis into risk perception is then undertaken, identifying key conceptual frameworks regarding heuristic and cognitive processing. Literature, primarily from the field of Psychology, provides a foundation of working memory knowledge, and both Psychology and Marketing literature is drawn upon to explore cognitive load and its impact on behaviour. The current research extensively covers the privacy paradox, disclosure of personal information, and the impact of cognitive load, although the search is not exhaustive beyond the field of Marketing.

\subsection{Privacy paradox and disclosure of personal information}

Acquisti (2004) explains how privacy used to primarily refer to an individual's right to not be disturbed, but the idea of privacy has morphed and informational privacy now takes a greater focus. Acquisti, Gritzalis, Lambrinoudakis, and di Vimercati (2007) takes this transition into consideration and provides a clear definition of privacy as the "right of an individual to control the ways in which personal information is obtained, distributed, shared, and used by any other entity". Privacy is a multifaceted construct comprising three components; territorial privacy, privacy of a person, and informational privacy, which focuses on how personal data can be used and managed (Kokolakis, 2017). The privacy paradox investigates the discrepancy between individuals' concerns to maintain their privacy, with that of their actual behaviour, which often shows a rampant disregard for these concerns (B. Brown, 2001).

Norberg et al. (2007) undertook an exploratory study to examine the privacy paradox. A tactical two-phase study was used, each phase was spaced 12 weeks apart, and this enabled the authors to match participants' intention to disclose personal information with their actual disclosure behaviour. The results supported the existence of a privacy paradox as participants' actual disclosure was significantly greater than their reported willingness to disclose, however their two proposed antecedents, risk and trust, did not provide an explanation for the phenomena. Spiekermann, Grossklags, and Berendt (2001) also found participants actual disclosure behaviour during an online shopping episode exceeded their privacy concerns, and Beresford et al. (2012) found participants with a strong interest in privacy still likely to provide sensitive personal information, date of birth and monthly income, to a DVD store for a $\$ 1$ discount, despite a less intrusive competitor being available. Moreover, Tufekci (2008) using a sample of 704 college students found no relationship between privacy concerns and information disclosure on social network sites, although 
individuals with high privacy concerns did minimize the visibility of their profiles. Tufekci (2008) suggested that, even though participants may hold strong privacy concerns these are not exhibited through their actual behaviour. Instead, personal information is often quickly divulged.

The value people place on their personal information can be very low. Sayre and Horne (2000) undertook a phenomenological study examining actual disclosure which involves participants disclosing personal information rather than simply expressing privacy concerns. The findings showed that consumers would freely give up personal information in exchange for discounts at a grocery store. Additionally, Carrascal, Riederer, Erramilli, Cherubini, and de Oliveira (2013) found that participants valued their online browsing history at only 7 euros. People appear to be more concerned about the secondary use of their personal data which refers to how data is treated and used after it is collected. The fear that a company may share their personal information with a third party leads to cautious behaviour (Carrascal et al., 2013; D'Souza \& Phelps Joseph, 2009). D'Souza and Phelps Joseph (2009) found that data collecting practices which did not include secondary disclosure had a similar impact on purchase intentions as decreasing the price of a product by $25 \%$.

Numerous studies have attempted to offer explanatory insights for the privacy paradox. Norberg et al. (2007) examined the impact of risk and trust. Risk demonstrated a significant negative relationship with disclosure-intention, but no relationship was found between risk and actual disclosure. Contrary to expectations, trust did not significantly impact either of the dependent variables (disclosure intention and actual disclosure). Norberg et al. (2007) suggest that because the participants were not aware of the actual organization used in the study, trust levels may not have been salient enough to impact disclosure. However, this nonsignificant relationship between trust and privacy disclosure was also demonstrated by Spiekermann et al. (2001) wherein participants disclosed large amounts of personal information even when they were presented with a harsh privacy statement. However, Kokolakis (2017) argues that because these studies were undertaken in a familiar environment, the impact of trust may be negated as students feel 'protected'.

Norberg et al. (2007) also suggested that the discrepancy between intentions and behaviour may be impacted by influences such as trust and routinization. Firstly, a trustworthiness heuristic may make consumers more willing to provide personal information to trusted brands. Even an individual's familiarity towards the computer they are using to disclose 
information has been demonstrated to impact levels of personal information divulgence (Moon, 2000). Secondly, due to the bombardment of requests for information that consumers receive which often do not result in personal harm, this may make consumers more likely to part with information during successive requests. Additionally, several studies have used privacy calculus theory to provide insight into the privacy paradox. Privacy calculus theory proposes that an individual's behaviour is determined by a trade-off between expected privacy losses and potential gains, thus privacy disclosure occurs when the gains exceed the costs (Dinev \& Hart, 2006; Jiang, Heng, \& Choi, 2013). Debatin, Lovejoy, Horn, and Hughes (2009) found active participation on social networks was associated with three needs: a need for entertainment, social relationships, and identity construction. Disclosing personal information and hence putting ones' privacy at risk can often be viewed as a worthy trade-off for these alluring benefits.

Consumers employ a myriad of strategies to protect their privacy. Son and Kim (2008) develop a taxonomy of information privacy-protective responses which they define as a set of behaviours individuals employ in the face of privacy threats, such as companies requesting personal information. Six behavioural responses to privacy threats are provided: Refusal to provide information, misrepresentation of information, removal of information, negative word-of-mouth, complaining directly to online companies, and complaining indirectly to third-party organizations. The first two responses, refusal and misrepresentation, fall under the category 'information provision', and numerous studies have found evidence of these behaviours. Sheehan and Hoy (1999) for example reported that on average respondents provided incomplete information during half of all online registrations whilst Tufekci (2008) noted that individuals often withhold disclosing personal information to social networks such as Facebook with less than a third of users providing their phone number or address. However, Tufekci (2008) found that users were more likely to control their privacy by reducing the availability of their profiles rather than decreasing disclosure. Jiang et al. (2013) also found evidence of misrepresentation where individuals in some cases misrepresented themselves, even when an option of non-disclosure was available. Nonetheless, Jiang et al. (2013) argue that rather than misrepresentation being perceived as a negative and nonnormative behaviour, they posit misrepresentation as a protective strategy, and a means to provide some data despite privacy concerns. Joinson, Paine, Buchanan, and Reips (2008) demonstrated how responses to personal information requests vary in breadth and depth. Breadth refers to whether the information is provided or not, and depth refers to how accurate 
and detailed the provided information is. Joinson et al. (2008) detailed how avoiding questions is a protective strategy that would impact the breadth of information provided and a technique termed blurring which limits the accuracy of a response, is used as a protective strategy to impair the depth of information provided.

Finally, there is a key difficulty present when investigating personal information disclosure, particularly that personal information is not homogenous, but instead bound by an individual's own attitudes and subjective experiences (Kokolakis, 2017). Horne and Horne (1998) demonstrate that consumers are more concerned about medical, financial and family information rather than product, brand or media usage. Similarly, Phelps, Nowak, and Ferrell (2000) found consumers were more willing to provide demographic, media and lifestyle information, and suggested that marketers use this information to estimate sensitive details such as income. White (2004) highlights a distinction between information that causes embarrassment and information that causes a loss of privacy. These domains differ on the perceived disclosure consequences that they conjure within individuals such that loyal customers found the exchange of embarrassing information for more customized offerings as unattractive whilst customers with shallow loyalties were less reluctant to share (White, 2004). Moreover, Mothersbaugh, Foxx, Beatty, and Wang (2012) found the effects of online privacy concern and information control had a greater impact on information disclosure when the information desired was more sensitive, subsequently they proposed that information sensitivity needs to be considered as a moderator when investigating online disclosure models. A key consideration is whether these disclosure behaviours and even privacy perceptions themselves, remain consistent across different populations.

\subsubsection{Disclosure differences between groups}

Mathews, Derlega, and Morrow (2006) found no significant difference in personal topic disclosure levels between males and females towards four relationship targets: mother, father, same-sex friend, and dating partner, across any of the personal questions they posed (e.g., sex, abuse, and moral issues). In contrast, Dindia and Allen (1992) conducted a meta-analysis of 205 studies involving 23,702 subjects and found a significant difference between male and female disclosure levels. Women were more likely to disclose personal information than men to a recipient whom they had a relationship with (i.e. friend, partner, or parent). However, this difference disappeared when the target of disclosure was a stranger. 
Christofides, Muise, and Desmarais (2012) explore the differences in Facebook use between adolescents and adults for information sharing and the use of privacy settings. Adolescents reported disclosing more and using privacy settings less than adults, however the results indicated that the factors predicting disclosure and use of controls were similar across both age groups. The two significant predictors included time spent on the platform and levels of self-esteem. Individuals who spent more time on the platform had greater levels of disclosure, adolescents spend more time on Facebook than adults, which partially explains the greater disclosure levels for that group. Individuals with greater self-esteem showed increased use of privacy controls, self-esteem generally increases with age (Trzesniewski, Donnellan, \& Robins, 2003), thus contributing towards the increased use of privacy controls and decreased disclosure in adults. Lastly, older adolescents also showed greater levels of disclosure which the authors presented as a result of these adolescents "developing their identity" and wanting to share this development with friends (Christofides et al., 2012).

There is evidence to suggest that adolescents and adults hold different perceptions of privacy. Livingstone (2008) found that teenagers did not view information such as religion, politics, and sexual preference as private. Moreover, Richard and Ralphs (2018) undertook a qualitative study applying Maslow's hierarchy of needs as a framework to understand social media risk perception and disclosure. Older generations were found to be more concerned with safety and survival needs, whereas younger generations were more concerned with selfactualization and esteem needs. Richard and Ralphs (2018) suggested several possible explanations for this pattern, such as generation $\mathrm{Z}$ individuals being more sheltered from financial hardships making safety and income concerns an unknown concept. Additionally, younger generations may not perceive the large risks of social media disclosure to their safety as they rationalize that if everyone else is on social media then it must be fine (Richard \& Ralphs, 2018).

Whilst perceptions of privacy and risk may differ across generations, the underlying cognitive mechanisms driving the formation and activation do not differ, being guided by either automatic or deliberative processing (Epstein, 1994; Slovic \& Peters, 2006). The following section delves into how humans perceive risk, considering both the influence of heuristics and deliberative cognition. 


\subsection{Risk perception}

Consumers perceive a degree of risk when disclosing personal information online and to institutions such as Governments and businesses. Disclosing personal information on social networks can open individuals to spam, identity theft, and stalking (Hogben, 2007), whilst disclosing to brands often facilitates secondary disclosure wherein the brand can 'share' your data with other parties, often allowing the brand to profit from your personal information and increasing the risk of subsequent mistreatment (D'Souza \& Phelps Joseph, 2009). However, individuals often need to disclose personal information to gain access to products and services, thus necessitating them to partake in risk assessment to evaluate when disclosure would be worth the potential risk of mistreatment.

Risk perception refers to an individual's subjective understanding of an activity's risk characteristics and the potential impact the activity has towards themselves or society (Slovic, 1987). Cases (2002) splits the conceptualization of perceived risk into two components: uncertainty, and the potential seriousness of the consequences. However, Loewenstein, Weber, Hsee, and Welch (2001) examined the gap within decision making research regarding the role of emotions, and demonstrated the limitations of being bound by a cognitive, consequentialist perspective to decision making. The term consequentialist refers to the making of decisions based upon the consequences of choices and their alternatives and has formed the basis of much early decision making research (Harless \& Camerer, 1994; Loewenstein et al., 2001). Loewenstein et al. (2001) propose that risk perception is not solely the result of cognitive evaluations of possible outcomes, instead affective components such as an individual's emotional state in the moment of evaluating risk can also be an influencing factor, if not the primary factor, driving the individual's final perception of risk.

The current sphere of decision making research is amenable to both cognitive and affective perspectives of risk perception. Slovic and Peters (2006) delineate the perception of risk into two categories; risk as feelings, and risk as analysis, wherein risk as analysis is deliberative and based upon logic, and risk as feelings is intuitive, generally being processed quicker and with more efficiency to guide decision making, especially under time-pressure. Along a similar conceptual vein Sjöberg (1998) demarcates perceived risk and perceived worry as independent constructs, finding a weak correlation between the two. In this case worry refers to the rumination of uncertain and negative events and has a stronger visceral connection with the individual (Sjöberg, 1998). In contrast, cognitive evaluations of risk are influenced by factors such as probabilities and outcome valences (Loewenstein et al., 2001). 


\subsubsection{Risk as feelings: Heuristics}

Heuristics refer to quick, intuitive judgements that occur when an individual doesn't have the motivation or resources available to enlist more deliberative processing (Drolet, Simonson, \& Luce, 2008; Pocheptsova, Amir, Dhar, \& Baumeister, 2009). Tversky and Kahneman (1974) demonstrate that people rely on a relatively limited number of heuristics to reduce the complexity of tasks such as assessing probabilities and estimating values. Examples of heuristics include the representativeness heuristic wherein probabilities are estimated by the degree that A is representative of B (e.g., is Steve representative of the stereotypical librarian?), such that high representativeness corresponds with higher probability (e.g., Steve is representative of the stereotype therefore Steve is probably a librarian), and dissimilarity with low probability (Tversky \& Kahneman, 1974). The use of this type of heuristic shows a disregard of individuals towards prior probabilities of outcomes, sample sizes and predictability (Tversky \& Kahneman, 1974).

The availability heuristic refers to the subjective experience of greater ease of retrieval which consequently influences an individual's risk perception (Tversky \& Kahneman, 1974). Schwarz et al. (1991) conducted three experiments providing evidence that individuals consider not only what they recall, but also the ease at which that information comes to mind, when evaluating judgements. Thus, difficulty in recall decreases how often an individual judges the frequency of an event occurring, whilst ease of recall increases frequency judgements. Tversky and Kahneman (1974) suggest that this availability can be influenced both by the retrievability of instances and through imaginability, the latter refers to our ability to conjure relevant instances that may not be stored in memory but can be generated through our imagination.

Objectively risk and benefits are distinct concepts, usually being independent of one another. However, Alhakami and Slovic (1994) demonstrated evidence of the affect heuristic by identifying that an inverse relationship between perceived risk and benefit was associated to the strength of the positive or negative affect held towards the activity. For example, if feelings towards an activity are positive then the individual tends to view the risks as low, and vice versa. Moreover, Finucane, Alhakami, Slovic, and Johnson (2000) were able to manipulate an individual's perception of risk by emphasizing either the costs or benefits, such that emphasizing the benefits resulted in a decreased perception of risk. 
People also believe that they are more immune to risks than others, for example the majority of people think that they will live past the age of eighty reflecting an optimism bias for positive events (Weinstein, 1989). Regarding immunity to risk, people are often lulled into a false sense of security. They view their personal experience as demonstrating their own competence, whilst in contrast whenever they hear about accidents occurring, they are impacting someone else. The notion of a self/other distance wherein the individual believes they are more immune to risks than others is then solidified (Kahneman, Slovic, Slovic, \& Tversky, 1982).

People observe others indulging in potentially risky behaviour and as a result consider the behaviour as less risky. Herding represents the learning heuristic whereby an individual seeks to acquire information about something unknown or to behave correctly by observing others rather than deliberatively thinking for themselves (M. Baddeley, 2010). Herding can have a significant impact on an individual's perception of risk, particularly in regards to the disclosure of personal information. Acquisti, John, and Loewenstein (2012) demonstrates that if people are led to believe that others have disclosed personal information then there may not be such a large risk in doing so and they will in turn be more likely to disclose sensitive information. The impact of a herding mentality is pervasive and can encourage people to behave counter to their own rational perception of the facts presented before them (Asch, 1955).

Finally, another heuristic relevant to the disclosure of sensitive information is anchoring. Anchoring refers to the process of making decisions based upon the observation of an initial stimuli (Tversky \& Kahneman, 1974). Acquisti et al. (2012) demonstrated that participants presented with a highly sensitive question at the start of a survey are likely to perceive subsequent questions as being less sensitive than they otherwise may have if the individual was not exposed to the initial sensitive question. Acquisti et al. (2012) also found that beginning the survey with innocuous questions anchored participants to expect these less sensitive questions, thus when exposed to sensitive questions at the end of the survey, they were rated as being significantly more sensitive than if sensitive questions were presented earlier in the survey. The research into heuristics details how people are easily influenced by irrelevant information. 


\subsubsection{Risk as analysis: Cognition}

Whereas evidence of the above contradicts the concept of the mythologised homo economicus, it would nevertheless be irrational to ignore the literature surrounding how and when humans are able to employ deliberative thought. The elaboration likelihood model details two routes to attitude formation, the central route which is deliberative and considers the relevant information available, and the peripheral route which is more intuitive and based on simple cues (Petty, Cacioppo, \& Schumann, 1983). Levels of involvement influences an individual's attitude formation by directing individuals to process information via one of the two routes. Highly involved individuals process information via the central route and low involvement individuals via the peripheral route. Thus, because people are constantly faced with a plethora of stimuli it is clear that involvement cannot be high for each instance, therefore the majority of attitude formations will be made via the peripheral route. Drolet et al. (2008) supports this as they found high motivation to use self-goals decreased the use of the compromise heuristic, this was compared with individuals who were less motivated to maintain their self-goals and therefore less involved with the choice. Thus, indicating the importance of involvement on attitude formation and decision making even in the presence of minimal influencing stimuli.

The elaboration-likelihood model has a motivational component (Petty, Cacioppo, \& Goldman, 1981). Cacioppo and Petty (1982) posit the need for cognition construct as a means to operationalize this component as it is considered a motivational factor. Haugtvedt, Petty, and Cacioppo (1992) undertook a series of experiments to assess the use of need for cognition in this context, particularly during short exposures. Student participants completed an "Advertising Evaluation Study" and were split into two groups of high or low need for cognition based upon their scores on the Cacioppo, Petty, and Feng Kao (1984) 18-item need for cognition scale. The results followed the usual pattern supporting the hypothesis that individuals with a high need for cognition follow the central route even under short exposure times and without explicit instructions to focus on evaluating the product or the brand.

Another pertinent model that seeks to understand how we cognitively react to stimuli, guiding attitudes and decision making, is the persuasion knowledge model. Whereas the elaboration likelihood model focuses more upon the dual systems of deliberation and intuition, the persuasion knowledge model seeks to understand how activation of analytical cognition occurs with less concern regarding heuristic processing. A key tenet of the persuasion knowledge model proposed by Friestad and Wright (1994) is that individuals exposed to 
persuasive messages may activate and employ strategies to defend against the persuasive message. The activation of persuasion knowledge and the acquisition of strategies to employ are vital points of understanding, which are explored within a conceptual model developed within Evans and Park (2015). Their paper focuses on the persuasion knowledge model and schema theory to build the underlying framework which they use to help explain how consumers cope with covert marketing practices.

Friestad and Wright (1994) suggest the employment of protective strategies is garnered by cumulative knowledge and experience. Evans and Park (2015) provide the example that consumers viewing traditional advertisements have typically acquired enough knowledge to recognise the persuasive intent behind the message. However, consumers may have less experience of covert advertisements, delaying activation of defensive strategies. Evans and Park (2015) suggest that schema theory, our active organisation of past experiences which helps us guide and interpret subsequent situations (Brewer \& Nakamura, 2000), can explain when persuasion knowledge will be activated. Evans and Park (2015) posit that the activation of advertising schema depends on the match between past experiences and the current information at hand. If the content clearly looks like an ad, such as banner advertisements, then the content will be processed as such and persuasion knowledge will be activated. However, if the ad took the form of sponsored content and initially activated the schema for an editorial and upon examination the match persisted, then persuasion knowledge would not be activated. Alternatively, if upon examination the individual recognises the persuasive intent of the sponsored content this may lead to an update or activation of alternative schema which may consequently activate defensive strategies and predispose the individual to recognising similar persuasion attempts in the future (Evans \& Park, 2015).

Evans and Park (2015) also suggest that despite the potential activation of advertising schema, the subsequent decrease in attitudes due to persuasion knowledge activation is not assured. For example, Nelson (2002) explored the reactions of gamers who were exposed to covert advertising in a racing game. The study indicated that participants were generally favourable towards the product placement, perceiving it as non-deceptive and noninterruptive of the gameplay. Evans and Park (2015) postulate that if the ad is placed in a context, such as a videogame, that elicits positive attitudes then this may subsume and negate the negative perceptions towards the ad, especially if the ads embedded in the content are not trying to actively persuade consumers but instead simply position the brand in a more favourable light. Additionally, Evans and Hoy (2016) found that adults playing an ad- 
sponsored-game under cognitive load showed less persuasion knowledge activation even when the commercial connection was disclosed. The persuasion knowledge model highlights the importance of individuals having the required ability and resources available to employ more cognitive processing, which is managed by working memory.

\subsection{Working memory}

When individuals attempt to calculate an equation, remember a new person's name, or assess whether an action is responsible, working memory is used. Working memory is a similar, but distinct concept to short-term memory which focuses on the input and storage of new information (Radvansky \& Ashcraft, 2014). Working memory refers to a more comprehensive process whereby information is not only stored but also manipulated and supplemented by internal resources such as episodic memory (Baddeley, 1992).

Initial conceptualizations of working memory were posed as a unitary system with a single short-term store of information, however subsequent research found evidence suggesting greater complexity (Baddeley, 1992). The most renowned model of working memory is Baddeley's multicomponent model consisting of an attentional controller which orchestrates the central executive and two slave systems: the phonological loop and the visuospatial sketchpad (Baddeley, 1992).

The central executive is the main processing unit of working memory and is posited to have three main functions: to focus attention, to divide attention, and to switch attention (Baddeley, 2001). The phonological loop deals with speech-based information and itself comprises two components: a phonological store and an articulatory rehearsal system (Baddeley, 1992). On the other hand, the visuospatial sketchpad focuses on storing and manipulating visual information gathered through either the senses or long-term memory (Baddeley, 1992). The tripartite model itself, however, had several gaps that necessitated reevaluation leading to the addition of an episodic buffer to the model (Baddeley, 2001). The basic function of the episodic buffer is to integrate information within working memory with information retrieved from long-term memory (Baddeley, 2000).

Together these four systems constitute a commonly held conceptualization of working memory. Unlike long-term memory which has no known limits to its capacity (Bahrick, Bahrick, \& Wittlinger, 1975), working memory, as proposed by Baddeley's model, is severely bound by two limitations: capacity and holding time. Miller (1956) suggested working memory capacity at seven plus or minus two units, whilst Brown (1958) and 
Peterson and Peterson (1959) demonstrated quick forgetting by decay, and a later study by Waugh and Norman (1965) demonstrated the dual impact of interference on holding time. Capacity and holding time therefore represent the severe limitations of working memory, our tool of interacting with and understanding each passing moment.

Other notable frameworks of working memory include Cowan's embedded processes model (Cowan, 1988), and Engle's controlled attention model (Kane, Engle, \& Review, 2002). These two models take a more homogenous approach to working memory incorporating it within long-term memory and doing away with separate components for stimuli such as a phonological loop for speech-based information or a visuo-spatial sketchpad.

Cowan's embedded processes model conceptualizes working memory as a subset of longterm memory, wherein working memory concerns the information that is currently active and in the focus of our attention (Cowan, 1988). In other words, our working memory is what we are currently thinking about, alongside a larger subset of activated memory that is readily accessible. As our focus of attention shifts, so too does the activated memories of the larger, long-term memory superset. Engle's controlled attention model is similar to Cowan's model, but instead conceptualizes working memory as the controller of thought processes (Radvansky \& Ashcraft, 2014).

\subsubsection{Limitations of working memory capacity}

The working memory literature is far from reaching a consensus regarding a unified model of working memory, with much debate still centred on the limits and dynamics of working memory capacity. Miller (1956) suggested that working memory capacity was seven plus or minus two units, however Cowan (2001) suggests this number is not to be taken literally as the capacity limit, but instead as a common compound capacity limit. Cowan (2001) suggests that participants were utilizing chunking techniques within the study, resulting in higher numbers of recall. Chunking is defined by Cowan (2001) as a collection of strongly associated concepts which is simultaneously weakly associated to other chunks concurrent in working memory. Chunking occurs when we group data points together, thus it is possible to turn three data points, "1", “2”, and “ 3 ” for example, into one data-point, " 123 ”. In doing so we can decrease the strain on our cognitive function and 'free-up' more memory space. This technique is likely subconscious in nature, and thus it is difficult to determine when a person is chunking or not (Gobet et al., 2001). Cowan (2001) suggests that working memory is comprised of around four chunks. 
Whilst early advocates of working memory suggested this capacity was reached via temporal limitations (Baddeley, Thomson, \& Buchanan, 1975), it is difficult to measure this with any degree of certainty. Delineating between the effect of various proactive and retroactive interferences on forgetting, with the possible effect of time passing is limited. What appears to be forgetting based upon decay may instead occur due to displacement of items within a store of limited-capacity as new data points arise, switching and interfering with those currently held in memory (Oberauer, Farrell, Jarrold, \& Lewandowsky, 2016). Three core theories of working memory capacity: the decay theory, the resource model, and the interference model, consider this issue.

The decay model posits that items held in working memory will disappear over time unless this decay is prevented by a restorative measure such as repetition (Baddeley et al., 1975). The decay theory received support from Baddeley et al. (1975) which found longer words were harder to recall in order than short words, suggesting that the length of time required to continually rehearse these longer words was too great, resulting in diminished recall accuracy. Subsequent research has found evidence undermining this conclusion, Service (1998) found that the length of the words was not the main factor causing quicker forgetting, but rather the underlying complexity of the word itself.

The resource model provides an alternative view of working memory as comprising a limited resource that needs to be shared amongst the items and processes being held and undertaken simultaneously (Ma, Husain, \& Bays, 2014). A resource in this case is defined as a limited quantity that enables cognitive functioning and processing, thus if more resources are allocated to the task, its processing and outcome will be more efficient (Oberauer et al., 2016). Thus, this limited resource is shared amongst the cognitive demands of an individual, where at each moment they are prioritizing a set of tasks at the expense of others. Vogel and Machizawa (2004) found electrophysiological evidence that supports the four-item capacity limit of working memory. Results showed that electrophysiological activity varied by the number of items held in memory (more items equalled greater activity), but this reached an asymptotic limit for datasets that matched or exceeded the storage capacity of four items.

Thirdly, an interference model has been proffered, suggesting that forms of interference diminish capacity rather than decay or a limited resource (Oberauer \& Kliegl, 2006). Representations, conceptualized as a set of features, are characterized by two aspects: feature dimensions, and similarity of common features (Oberauer et al., 2016). Oberauer et al. (2016) gives the example of a red circle and blue square, both items share two feature dimensions: 
colour and shape, but there is no similarity between these common features (the items are both different shapes and different colours). An example of two items that do not share feature dimensionality would be a blue square and an audio recording of a dog barking. The bark does not share any features with the blue square, it does not have a colour or a shape, and it is auditory rather than visual. Proportional variation of similarity between feature dimensions and similarity of common features impacts the outcome of interference by confusion, interference by superimposition, and interference by overwriting. It is this framework that allows the interference model to best explain why mixing different content domains can lead to greater recall compared to a similar sized homogeneous set of data (Oberauer et al., 2016). The interference model comes with its own array of limitations. However, the strengths and weaknesses of the interference model and resource model are mostly complementary. Suggesting a combined model of interference with a domain-general resource limit may be better able to explain the myriad of results observed within working memory (Oberauer et al., 2016).

\subsection{Cognitive load}

Because working memory is bound by capacity limitations, overloading the system with information will result in impaired working memory function, referred to as cognitive load (Barrouillet, Bernardin, Portrat, Vergauwe, \& Camos, 2007).

Cognitive load is explored in education and learning literature to help guide effective teaching practice (de Jong, 2010). Sweller (2010) demarcates cognitive load into three categories: intrinsic cognitive load refers to the natural complexity of information, extraneous cognitive load is concerned with the instruction design conveying the information, and germane cognitive load concerns the acquisition of knowledge. Whilst intrinsic load cannot be simply manipulated without additional learning or via methods of chunking, extraneous load is more malleable by altering the instructions of a task (Moos \& Pitton, 2014). Extraneous cognitive load has been operationalized in three main ways, by changing: the amount of information, the number of alternative outcomes, and the diversity of information (Speier, Valacich, \& Vessey, 1999).

Cognitive load is also used in Psychology research to gain a better understanding of working memory and how it functions (Colle \& Welsh, 1976; Elsley \& Parmentier, 2009; Jefferies, Lambon Ralph, \& Baddeley, 2004). In these cases a dual-task method is employed, and involves two tasks being performed concurrently as a means of inducing cognitive load 
(Brunken, Plass, \& Leutner, 2003). Participants within the cognitive load condition will perform a primary task with an added secondary task to be performed simultaneously. The performance of the primary task is the variable under investigation, and this will usually be compared with participants' performance of the primary task without the concurrent performance of the secondary task. When two tasks are done simultaneously, they may function independently, dependently or with various in-between levels of dependency (Radvansky \& Ashcraft, 2014). It is when two tasks interfere with one another and draw upon the same resources that cognitive load will arise. Colle and Welsh (1976) demonstrated the limited capacity of resources by employing a dual-task method, participants were asked to perform a serial recall task whilst listening to a foreign language using headphones. The results revealed an irrelevant speech effect whereby it is harder to keep track of information when exposed to irrelevant speech in the background.

Whilst the dual task method is often used as a tool to help psychologists explore the mechanisms of working memory, it is also employed in other disciplines to explore the impact of cognitive load on behaviour in general. A review of cognitive load within the marketing literature will be provided below, but firstly the distinction between cognitive load and the conceptually similar theory of ego-depletion must be made.

\subsubsection{Demarcating cognitive load and ego depletion}

A state of impaired cognition can arise from both cognitive load and ego-depletion, with it often being difficult to differentiate between the two (Maranges, Schmeichel, \& Baumeister, 2017). The basic theory behind ego-depletion is that volitional action from the self draws upon a shared resource pool that is finite, and once drawn upon, inhibits subsequent acts of volition (Baumeister, Bratslavsky, Muraven, \& Tice, 1998). This inhibition refers to the state of ego depletion wherein the self's ability to volitionally control the environment, make choices, or control the self, is reduced temporarily (Baumeister et al., 1998). A typical example of ego depletion is how an individual trying not to think about a white bear is more likely to give up quicker on a subsequent, unrelated anagram task than someone who was not given the bear task beforehand (Muraven, Tice, \& Baumeister, 1998).

Cognitive load and ego-depletion both concern the impact of cognitive scarcity on behaviour, however there are several key distinctions that set them apart. Firstly, the two concepts differ temporally; ego depletion refers to a hang-over effect wherein a task undertaken earlier creates the state of ego depletion which impairs subsequent tasks, whilst cognitive load refers 
to a concurrent effect wherein a simultaneous primary and secondary task impairs task functioning in the moment (Maranges et al., 2017). Additionally, where ego-depletion likely requires time for mental rest before ego depletion can be lifted, cognitive load can be removed instantly (Tyler \& Burns, 2009).

Alongside temporal differences, these two concepts also differ between which areas of cognition they impair. Simply put, cognitive load distracts attention away from key areas, diminishing short-term memory maintenance and attention to peripheral information (Lavie, Hirst, De Fockert, \& Viding, 2004). Ego depletion however, does not interfere with attention or short-term memory, but instead diminishes an individual's capacity to control their attention effectively (Maranges et al., 2017). The present research concerns itself with cognitive load.

\subsubsection{Cognitive load in the Marketing literature}

Cognitive load has featured in the Marketing literature primarily in connection to decision making, persuasion knowledge activation, and self-regulation. Malhotra (1984) provided a prophetic piece in the 80 's, identifying the rise of attention demanding stimuli, which has only become more pronounced in the digital era with the presence of smartphone notifications and social media. The paper provided an initial literature review of cognitive load within the fields of Psychology and Marketing whilst drawing comparisons and insights with previous research, notably Malhotra (1982).

Malhotra (1982) investigated the impact of cognitive load on consumer decision making when participants were provided with between 10 and 25 choice alternatives or with information on 15 to 25 attributes; intrinsic load was being manipulated. Participants were asked to rank the profile of houses in order of their purchase preference and asked whether too much information had been provided impairing their ability to make the best choice. The results indicated that decision making was impaired if participants were provided with 15 or more alternatives or attributes. Moreover, the effect remained constant from 15 to 25 alternatives or attributes. Malhotra (1982) suggested that participants may have adopted simplifying strategies to cope with the ranking task at these higher levels.

Menon and Raghubir (2003) consider ease of retrieval and whether the effect is automatic. Their first study demonstrated that the more difficult a task was to recall, the less favourable were one's judgements. Moreover, the study demonstrates that the ease of retrieval effect held whilst participants were under cognitive load, indicating that the process is automatic 
and not reliant on deeper processing. Similarly, Brenner, Sood, and Rottenstreich (2007) found support that the act of remembering causes cognitive strain, inhibiting our ability to deliberate over choices based from memory.

Cognitive load also influences the outcome of social labelling. Cornelissen, Dewitte, Warlop, and Yzerbyt (2007) found that individuals given a cognitive load task were more likely to reattribute their product choice of a TV to align with the social label of environmental consciousness, despite most likely making the choice because it had the highest rated image and sound quality. A subsequent task supported this re-attribution as consumers in the load condition were willing to spend money on environmentally friendly products than those in the non-load condition. Moreover, the study finds that the same effect is found even if consumers are able to fully access persuasion knowledge during the presentation of the social label, but are subsequently placed under cognitive load when it comes to making decisions at the time of purchase.

Meyers-Levy and Malaviya (1999) posits that the strategies for processing persuasion attempts are determined by the availability of cognitive resources. Craig, Loureiro, Wood, and Vendemia (2012) use neuroimaging methods to explore these cognitive processes, notably, what transpires when we are told claims of varying levels of deception? The results indicated that consumers under cognitive load were not able to engage in expanded processing and thus moderately deceptive claims were evaluated similarly to believable claims. Shu and Carlson (2014) supports this by finding evidence that consumers were less able to enlist relevant coping strategies to identify dubious claims whilst under cognitive load.

A pertinent area of cognitive load research in marketing literature surrounds its impact on self-regulation. Self-regulation refers to the ability of individuals to maintain long-term goals by controlling their behaviour and thoughts (Bandura, 1991). Shiv and Fedorikhin (1999) provide a seminal experiment demonstrating the impact of cognitive load on decision making within a self-regulatory situation. The study examines stimulus-induced affect using a binary choice task where the positive affect is elicited by the alternative of chocolate cake more so than the choice of a fruit salad, but cognitively the former choice is more negative. The task had one group remember a seven-digit number (Cognitive load condition) whilst another group was asked to remember a two-digit number (Control condition) as they walked between rooms and were consequently presented with a choice of either the cake or fruit 
salad. Afterwards they were asked to recall the number. The results indicated that individuals under cognitive load (as opposed to the control condition) were more likely to choose the affective alternative (chocolate cake) than the cognitive choice (fruit salad). Additionally, this result was more pronounced for individuals in a 'real' condition, when exposed to the actual food, rather than a symbolic condition where only photos were shown. The post-choice questions suggested that individuals in the high processing condition also showed strong affective responses to the chocolate cake but were able to overcome this through better use of their cognitions.

Drolet and Frances Luce (2004) and Argo and White (2012) also demonstrate the detrimental impact of cognitive load on self-regulation. Drolet and Frances Luce (2004) show that cognitive load impacts an individual's self-regulation such that they are unable to monitor themselves and keep their actions aligned with their goals. The study suggests consumers avoid making difficult attribute trade-offs to cope with the negative emotions resulting from such choices. Argo and White (2012) however, demonstrate a counter-intuitive result whereby high cognitive load decreases consumption of candy-coated chocolate contained in small packages for participants low in appearance self-esteem (ASE). In an earlier study within Argo and White (2012), low ASE participants were shown to consume more candycoated chocolate when presented within small packages in a bowl compared to candy-coated chocolate presented in the bowl in no package, their reasoning for this being that participants would project their self-control onto the package itself, which is seen as containing an acceptable quantity of candy-coated chocolate for consumption. Argo and White (2012) hypothesized that this projection of self-control relied upon the availability of cognitive resources, this was supported by their results as low ASE participants in the cognitive load condition consumed less from the small packets than those in the no load condition, moreover their consumption equalled that of the no package group. This highlights the nuanced, yet vital role of cognitive load in coordinating self-control.

\subsection{Multi-tasking}

Multitasking involves the simultaneous performance of two or more independent tasks (Sanbonmatsu, Strayer, Medeiros-Ward, \& Watson, 2013), and it is this act which can result in cognitive load. Whilst multitasking behaviour can be beneficial for an individual, enabling them to complete more tasks and broaden their intake of experiences, it can also diminish the performance of one or more of the tasks being undertaken, with increased multitasking resulting in an inverted-U curve for performance efficiency and steadily decreasing levels of 
accuracy (Adler \& Benbunan-Fich, 2012). Therefore, it is important to step-back and broadly assess why people multitask, and whether there are particular groups more likely to indulge in the behaviour.

Decision theory suggests that optimally people should multi-task when they expect benefits from their behaviour and are good at it (Einhorn \& Hogarth, 1981), however there is often a discrepancy between peoples actual and perceived task competence (Dunning, Heath, \& Suls, 2004). Sanbonmatsu et al. (2013) found that multitasking performance during a working memory task was negatively correlated with self-reported multi-tasking ability. Moreover, their study found that this perceived multitasking ability was positively correlated with the individual's media related multitasking behaviour, and their use of a cell phone whilst driving. Additionally, Sanbonmatsu et al. (2013) demonstrated that people with higher levels of impulsitivity and sensation seeking were more likely to report multitasking behaviour, suggesting that people may be inclined towards multitasking when they are less able to focus on a singlular task or to ignore distractions.

Additional research investigating multitaskers reveals that the most prolific multitasking individuals are likely to be younger. Foehr (2006) found that only one-fifth of 8 to 18 year olds devoted almost no time to multitasking. Jeong and Fishbein (2007) investigated 14 to 16 year olds and found that multitasking was common with the most common combinations being listening to audio while travelling, listening to audio whilst interacting with friends, and watching television while eating. Carrier, Cheever, Rosen, Benitez, and Chang (2009) reveal a significant difference in levels of multitasking between the Net generation (born after 1980), and older generations such as Gen X (Born between 1960 and 1980) and Baby Boomers (Born between 1950 and 1960). Nonetheless, the combination of multitasked activities did not differ significantly across the generational groups. Carrier et al. (2009) suggested that the combination of activities which are often multitasked is limited by the cognitive demands of each individual task, thus combinations that would exceed the individuals store of available cognitive resources will not be undertaken. A pertinent limitation of Carrier et al. (2009) is the inability to discern generational differences from agebased differences. Notably, the ease and prevalence of multitasking in younger generations could simply be a factor of youth, rather than qualitative generational differences. However, evidence to support a widening generational gap was recently provided by McCoy (2016) which found that the number of times a student used a digital device for non-class purposes had increased from 10.93 times a day in a 2013 survey to 11.43 times a day in their 2015 
survey. Additionally, the 2015 survey found that these digital distractions accounted for roughly $21 \%$ of a student's time in class on average.

Thus, the literature outlines generational differences in both aspects of risk perception and multitasking behaviour. In both cases the younger generations are multitasking and disclosing personal information in excess (Christofides et al., 2012; McCoy, 2016).

\subsection{Summary}

The privacy paradox and the disclosure of personal information comprise the central focus of the current work. A combination of the elaboration likelihood model (ELM) (Evans \& Park, 2015; Friestad \& Wright, 1994), and the persuasion knowledge model (PKM) (Petty \& Cacioppo, 1986) are the primary theories guiding the conceptual framework, helping to explain the impact of cognitive load on personal information disclosure. Cowan's embedded processes model (Cowan, 1988), and Engle's controlled attention model (Kane et al., 2002) provide the working memory lens which informs the dynamics of cognitive load. Additionally, Sjöberg (1998) demarcates perceived risk and perceived worry into two independent constructs and this distinction is expected to help explain potential differences in privacy protection strategies. These constructs and their relevance to the current work are discussed in greater depth below in the section pertaining to the conceptual framework and hypotheses. 


\section{Research objectives, gaps, and contributions}

\subsection{Research objectives}

The objectives outlined below guide the present research.

Primary Objective:

- To investigate the impact of cognitive load on consumers' propensity to disclose personal information.

Secondary Objectives:

1. To examine how cognitive load impacts the disclosure of sensitive and nonsensitive information.

2. To investigate which factors influence a consumers' propensity to disclose personal information, and to observe whether these factors are moderated by the presence of cognitive load.

3. To evaluate the effectiveness of using the construct "quality of information" to explore nuances in disclosure patterns.

4. To evaluate the effectiveness of using response latency to explore nuances in disclosure patterns.

\subsection{Gaps in the literature}

There is an abundance of research concerning the privacy paradox, however a review of the literature revealed several pertinent gaps. Firstly, despite cognitive load being frequently investigated within the fields of both Psychology (Colle \& Welsh, 1976; Elsley \& Parmentier, 2009; Jefferies, Lambon, Ralph, \& Baddeley, 2004; Sweller, 2010) and Marketing (Argo \& White, 2012; Brenner, Sood, \& Rottenstreich, 2007; Cornelissen, Dewitte, Warlop, \& Yzerbyt, 2007; Craig, Loureiro, Wood, \& Vendemia, 2012; Shiv \& Fedorikhin, 1999; Shu \& Carlson, 2014), it has yet to be considered as a potential contributor to personal information disclosure. Moreover, investigation into cognitive loads relationship with risk perception is scarce with no published research yet seeking to understand the underlying processes at work. The second gap identified concerns the dearth of actual disclosure as a measurement within the privacy paradox research, wherein disclosure intention is primarily used as a dependant variable due to the ease of collection. Furthermore, studies that have used actual disclosure have been content to only use absolute disclosure 
without consideration for other outcome variables such as quality of disclosure or response latency (Norberg et al., 2007; Spiekermann, Grossklags, and Berendt, 2001). The present research will address these gaps by including three outcome variables: absolute disclosure, quality of disclosure, and response latency. Lastly, the current research seeks to demarcate perceived risk and perceived worry to investigate whether the use of the two constructs individually will reveal differential interactions with levels of disclosure. Previous research has primarily treated these two constructs as singular (Norberg et al., 2007), under a general 'privacy concern' construct, thus a gap exists to explore the relationship between them.

\subsection{Contributions}

The current research contributes to the privacy paradox literature by introducing cognitive load as a potential predictor of information disclosure. It is conceivable that a significant amount of the discrepancy between privacy attitudes and behaviours could be explained by the impact of cognitive load during the process of personal information disclosure. Whilst the current research does not advocate for cognitive load as the sole determinant of the privacy paradox, the current research seeks to highlight the potential role of cognitive load upon disclosure levels within day-to-day interactions, and within past, present, and future research. Additionally, the present research adds to the methodological toolkit of future disclosure studies by providing quality of disclosure and response latency as additional measurements of actual disclosure, potentially allowing for more nuanced explanations of disclosure patterns. The research also contributes to our theoretical understanding of risk perception as a distinct construct to that of worry.

Practically the research helps determine when consumers may be most susceptible to disclosing excess personal information, allowing for adequate privacy protection policy to be developed to help consumers make more informed decisions and to protect them from overdisclosure during potential moments of weakness. Marketers could also use the results to increase perceptions of trust and transparency with consumers by being open about their data collection practices. 


\section{Conceptual framework and Hypotheses}

Before proceeding it is important to note that the proposed research will employ a betweensubjects experimental design, wherein participants will be randomly assigned to either a cognitive load or control condition. The guiding theory and key constructs that will be used to investigate and respond to the objectives above will now be explored.

\subsection{Guiding theoretical models}

The research utilizes a combination of the elaboration likelihood model (ELM) (Evans \& Park, 2015; Friestad \& Wright, 1994), and the persuasion knowledge model (PKM) (Petty \& Cacioppo, 1986), to guide the current theoretical framework. No single model can explain the decision-making process involved in choosing to disclose or withhold personal information to businesses, however, the ELM and PKM provide the most comprehensive understanding of decision-making processes whilst also considering the limitations of cognitive load.

The working memory lens that will guide the present research constitutes the homogenous approaches of Cowan's embedded processes model (Cowan, 1988), and Engle's controlled attention model (Kane et al., 2002). This approach does not perceive working memory as comprising separate components for stimuli in the same manner as Baddeley's multicomponent model (Baddeley, 1992). Instead, distractions are expected to impair cognitive functioning, and cognitive resources are expected to be limited to around four chunks of information, regardless of stimuli modality.

The figure below displays the conceptual framework, the expected relationship between each of the constructs will be discussed below.

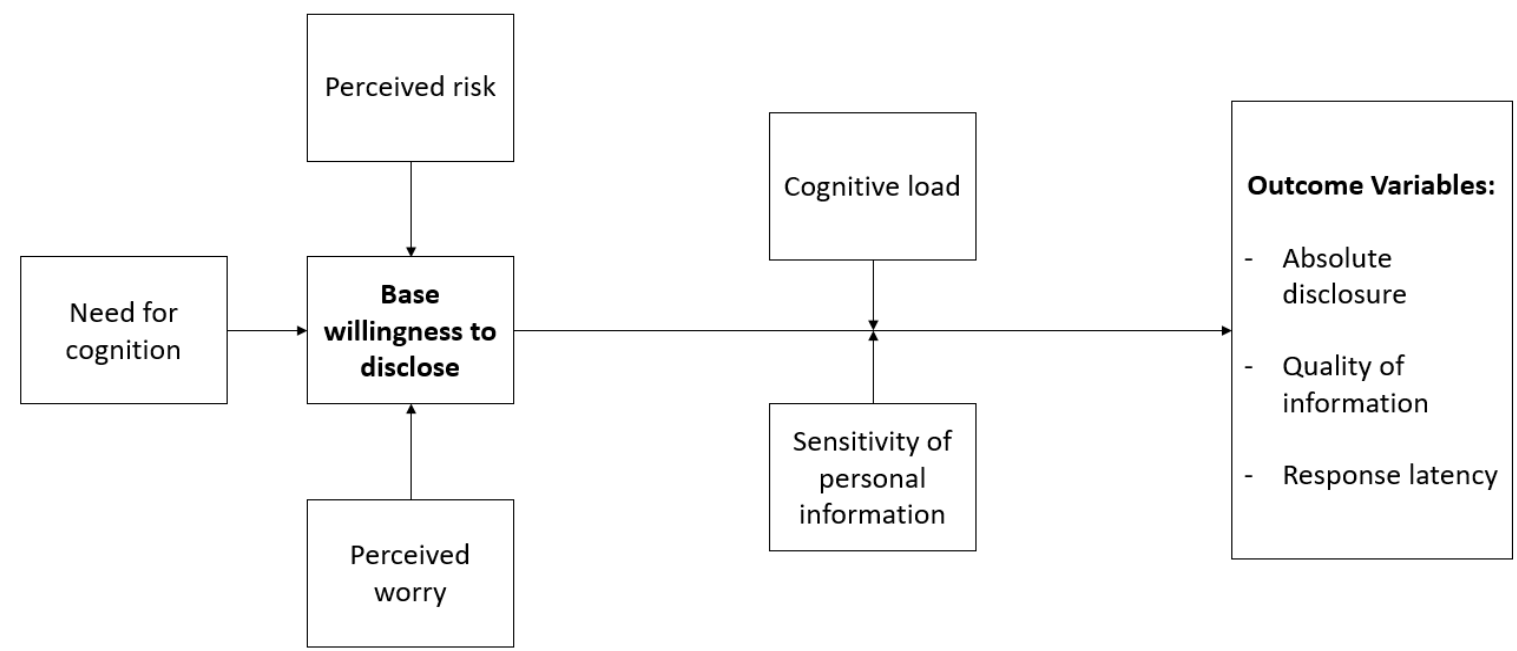

Figure 1: Conceptual framework 


\subsection{Cognitive load}

The current research focuses on the impact of extraneous cognitive load on personal information disclosure. Through altering the amount of information provided to an individual to consider, they will experience more or less strain on their cognitive resources, which are needed to make sense of both incoming information and information within working memory (Barrouillet et al., 2007).

Whilst the full extent of an individual's privacy protection goals are often disregarded when it comes to their actual disclosure behaviour (Norberg et al., 2007), they will still employ a myriad of strategies to protect aspects of their privacy (Sheehan \& Hoy, 1999; Son \& Kim, 2008; Tufekci, 2008). Individuals in control of their cognitive resources are expected to be better equipped to access and utilize these protective strategies. The persuasion knowledge model posits that individuals exposed to persuasive messages may activate and employ strategies to defend against the persuasive message (Friestad \& Wright, 1994). The current research proposes that when individuals are exposed to stimuli such as a firm asking for personal information this may trigger the individual's awareness of their own privacy protection goals, and they may then activate and employ strategies to protect their privacy. In contrast, individuals under cognitive load are expected to be unable to easily access privacy protection goals (Evans \& Hoy, 2016). The elaboration likelihood model demonstrates how an individual's ability to process a message impacts the route of elaboration taken. Distracted individuals, those under cognitive load, are more likely to take the peripheral route which is more intuitive, rather than the central route which is deliberative (Petty \& Cacioppo, 1986). It is this ability to deliberatively consider the question and information being asked, which allows the individual to decide whether disclosing the information coincides with their privacy protection goals.

H1a: Participants in the cognitive load group will answer significantly more questions than participants in the control group.

Whilst absolute disclosure is expected to increase under cognitive load, there will also be a greater quality of information disclosed. Few studies have considered the quality of information disclosed as an outcome variable despite deception being a known strategy used by individuals for protecting their privacy (Jiang et al., 2013). The construct quality of information disclosed refers to the richness of personal information provided in response to the question posed. Taddicken (2014), for example, recognizes the importance of information quality but does so by assessing whether more sensitive information is posted on social 
media, rather than whether more sensitive information is provided in response to a specific question.

An increase in the quality of information disclosed is expected to occur as the cognitive load task should diminish the individual's ability to utilize privacy protection strategies such as providing a false or incomplete response. However, the predicted effect size is likely to be partially mitigated by competing cognitive resources, which may diminish the individuals' ability to provide a thorough and complete response (Adler \& Benbunan-Fich, 2012).

Additionally, there is a dearth of marketing literature that uses latency within cognitive load research despite the measure being readily utilized within Psychology research (Bonner \& Newell, 2010; Suchotzki, Verschuere, Van Bockstaele, Ben-Shakhar, \& Crombez, 2017; Suter \& Hertwig, 2011; Verschuere, Köbis, Bereby-Meyer, Rand, \& Shalvi, 2018). Individuals under cognitive load are expected to take longer to understand the question, formulate a response, and type their response due to competing available cognitive resources.

H1b: Participants in the cognitive load group will provide significantly less false, incomplete, and combined protective strategy responses than participants in the control group.

H1c: Participants in the cognitive load group will take significantly longer to respond to questions than participants in the control group.

For a discussion of the outcome variables: absolute disclosure, false responses, incomplete responses, combined protective strategies, and latency, refer to chapter 5.1.5 below.

\subsection{Sensitivity of personal information}

Several studies have demonstrated that personal information can either be perceived as low or high in sensitivity, with consumers being less willing to disclose information that is more sensitive in nature (Horne \& Horne, 1998; Mothersbaugh et al., 2012; Phelps et al., 2000; White, 2004). Utilizing the persuasion knowledge model as a guide helps explain how different levels of information sensitivity may impact disclosure. Evans and Park (2015) demonstrated how more overt ads are more likely to trigger persuasion knowledge activation than covert advertisements. The current research proposes a similar dichotomy between information sensitivity levels wherein questions of higher sensitivity, such as "what is your parents income?" or "what is your address?", share the persuasion knowledge activation properties of overt ads, whilst questions of lesser sensitivity, such as "what is your name?", share the properties of covert ads. Demanding sensitive information from consumers is expected to bring their privacy protection goals to the fore, thus eliciting subsequent 
strategies such as withholding disclosure to protect their privacy and align their behaviour with their goals. Within the present study individuals may employ two strategies to help protect their privacy. They may either completely refuse to respond to the question, and secondly, they may choose to provide false or incomplete information (Son \& Kim, 2008).

Cognitive load has been demonstrated to decrease persuasion knowledge activation (Evans \& Hoy, 2016). Therefore, it is expected that participants under high cognitive load when exposed to questions with greater information sensitivity will be less likely to trigger persuasion knowledge activation, thus decreasing the likelihood of defensive strategies such as withholding disclosure being used by participants (Friestad \& Wright, 1994). Participants exposed to non-sensitive questions do not require the activation of persuasion knowledge as individuals are more open to disclosing this type of information, thus in this situation no difference in absolute disclosure is expected between participants responding to sensitive and non-sensitive questions

H2a: Participants in the control group will answer significantly fewer sensitive questions than non-sensitive questions.

H2b: Participants in the cognitive load group will not significantly differ in their disclosure between sensitive and non-sensitive questions.

H2c: Participants in the control group will provide significantly more false (f), and incomplete (i) responses to sensitive questions than non-sensitive questions.

H2d: Participants in the cognitive load group will not significantly differ in the number of false (f), and incomplete (i) responses provided between sensitive and non-sensitive questions.

\subsection{Need for cognition}

Need for cognition (NFC) refers to an individual's tendency to engage in, and enjoy thinking, and has been operationalized as a motivational factor, primarily for use within the elaboration likelihood model (Cacioppo \& Petty, 1982; Haugtvedt et al., 1992; Petty et al., 1981). In this context NFC serves to predict whether an individual will undertake the central or peripheral route to attitude formation, with individuals high in NFC showing a tendency towards the central route whilst those low in NFC use the peripheral route (Haugtvedt et al., 1992; Petty et al., 1983). The current research proposes that questions may be analysed in the same manner, whereby individuals with a greater NFC are able to better understand the privacy implications of providing a response to sensitive questions. Understanding the privacy 
implications of providing a response will result in greater deliberation over how to respond and increase the likelihood of employing privacy protection strategies.

The persuasion knowledge activation model refers to the process wherein an individual reaches an understanding that they are being persuaded in some manner (Friestad \& Wright, 1994). In the absence of high NFC, individuals are expected to be less aware of the privacy implications of the sensitive questions posed and as such are less likely to employ protective strategies such as withholding disclosure. However, NFC is only expected to impact disclosure patterns when individuals have cognitive resources available (Drolet et al., 2008).

H3a: In the control group participants need for cognition will have a significant negative relationship with absolute disclosure

H3b: In the cognitive load group participants need for cognition will not have a significant relationship with absolute disclosure

H4a: In the control group participants need for cognition will have a significant positive relationship with the number of false (f), incomplete (i), and combined protective strategy (cps) responses provided.

H4b: In the cognitive load group participants need for cognition will not have a significant relationship with the number of false (f), incomplete (i), and combined protective strategy (cps) responses provided.

H5a: In the control group participants need for cognition will have a significant positive relationship with the time taken to complete the questionnaire.

H5b: In the cognitive load group participants need for cognition will not have a significant relationship with the time taken to complete the questionnaire.

\subsection{Perceived risk and perceived worry}

Sjöberg (1998) demonstrates a key distinction between perceived worry which is an affective and intuitive awareness towards possible danger, and perceived risk which utilizes intellectual judgements as a guide to decision making. High ratings for both constructs are expected to increase an individual's privacy protection strategies (Mathews, 1990; Slovic, 1987), however due to the affective/cognitive distinction a differential impact is expected (See figure 2). When an individual's ability to process information is compromised this inhibits their ability to process information deliberatively through the central route, instead the peripheral route is taken and affective cues are more influential (Petty \& Cacioppo, 1986). 
Thus, when participants are faced with a sensitive question and in control of their cognitive capacity it is expected that perceived risk will be more likely to influence participants' use of privacy protection strategies. In contrast when participants are faced with a sensitive question whilst under cognitive load it is expected that perceived worry will be more likely to influence participants' use of privacy protection strategies.

\subsubsection{Perceived risk}

H3c: In the control group participants perceived risk will have a significant negative relationship with absolute disclosure.

H3d: In the cognitive load group participants perceived risk will not have a significant relationship with absolute disclosure.

H4c: In the control group participants perceived risk will have a significant positive relationship with the number of false (f), incomplete (i), and combined protective strategy (cps) responses provided.

H4d: In the cognitive load group participants perceived risk will not have a significant relationship with the number of false (f), incomplete (i), and combined protective strategy (cps) responses provided.

H5c: In the control group participants perceived risk will have a significant positive relationship with the time taken to complete the questionnaire.

H5d: In the cognitive load group participants perceived risk will not have a significant relationship with the time taken to complete the questionnaire.

\subsubsection{Perceived worry}

H3e: In the control group participants perceived worry will not have a significant relationship with absolute disclosure.

H3f: In the cognitive load group participants perceived worry will have a significant negative relationship with absolute disclosure.

H4e: In the control group participants perceived worry will not have a significant relationship with the number of false (f), incomplete (i), and combined protective strategy (cps) responses provided. 
H4f: In the cognitive load group participants perceived worry will have a significant positive relationship with the number of false (f), incomplete (i), and combined protective strategy (cps) responses provided.

H5e: In the control group participants perceived worry will not have a significant relationship with the time taken to complete the questionnaire.

H5f: In the cognitive load group participants perceived worry will have a significant positive relationship with the time taken to complete the questionnaire.

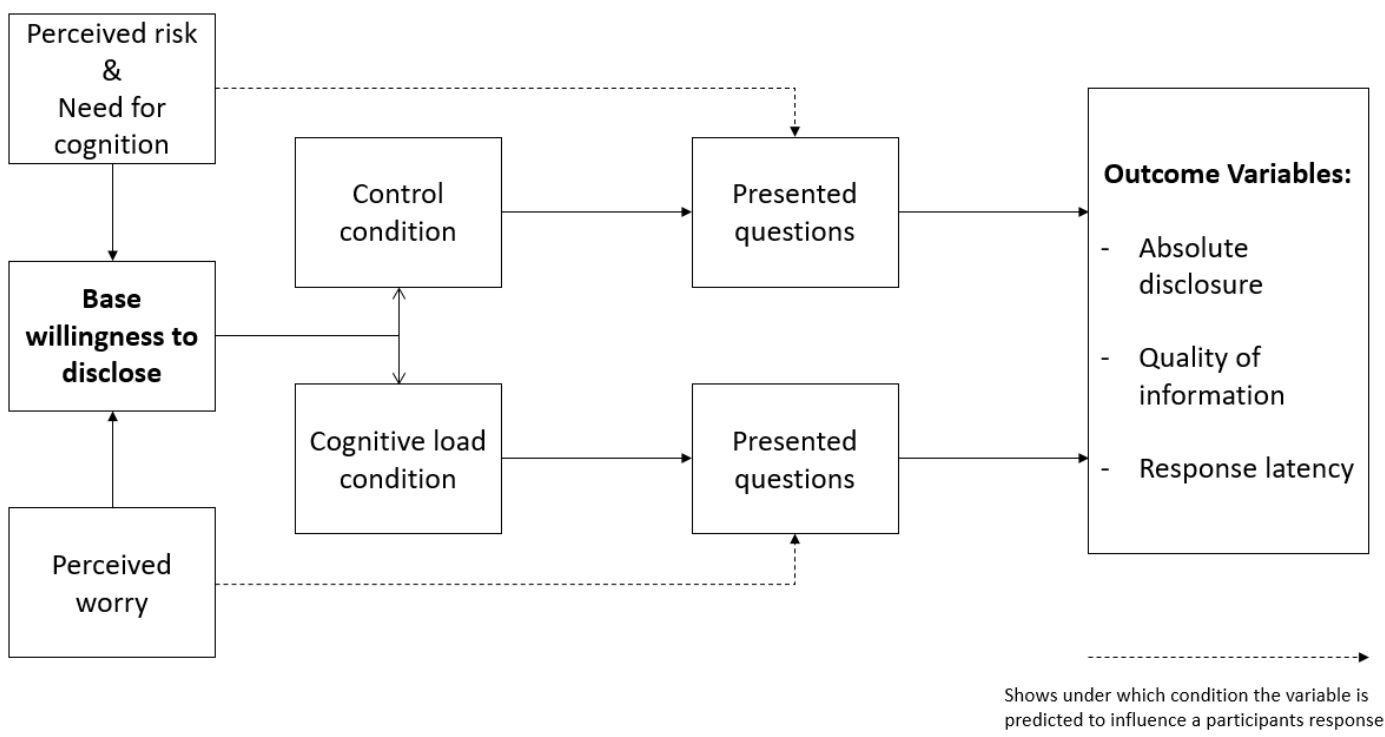

Figure 2: Demonstrating the pattern of influence 


\section{Method and methodology}

\subsection{Operationalization of variables}

\subsubsection{Cognitive load}

The present study uses an extraneous cognitive load task to understand the impact of a distractor task on an individual's disclosure of personal information. Cognitive load is defined as the impairment of working memory function as a result of remembering a sevendigit number. Cognitive load was induced by asking participants to remember a seven-digit number, the control group was asked to remember a two-digit number (Shiv \& Fedorikhin, 1999). Retaining numbers in memory requires rehearsal which impairs working memory function, with the more digits to remember necessitating more constant rehearsal and greater cognitive impairment. The manipulation was checked by asking participants how hard they thought it was to hold the number in their mind (Goode, Dahl, \& Moreau, 2010; Shiv \& Fedorikhin, 1999). If the participants stated they found holding the seven-digit number harder, the manipulation was a success (Refer to Appendix E to see how the manipulation is employed).

\subsubsection{Sensitivity of personal information}

Sensitivity of personal information is defined as the degree of intimacy linked to information, wherein individuals perceive more risk of loss when disclosing information of greater intimacy (Mothersbaugh et al., 2012).

This construct was operationalized by developing a set of questions that varied in their levels of sensitivity. Previous literature provided a framework for this task, alongside a pre-test to identify and validate the initial selection of questions. Firstly, Mothersbaugh et al. (2012, p. 85 ) provided a set of criteria to guide the formulation of questions, these criteria are listed below:

a) Have a foundation in prior privacy disclosure and marketing research.

b) Reflect typical online disclosure questions.

c) Reflects specific types of information and varies from higher to lower levels of sensitivity.

Mothersbaugh et al. (2012) examined 30 websites across a variety of retail categories, along with previous literature (e.g. Phelps et al., 2000; Xie, Teo, \& Wan, 2006) to generate their initial 45 questions. The current research drew heavily upon Mothersbaugh et al. (2012), but 
also, Norberg et al. (2007), Phelps et al. (2000), and White (2004) (See Appendix F). However, the number of highly sensitive questions was outnumbered by those of lesser sensitivity. Therefore several sensitive questions were extrapolated from the existing categories, for example the question "What is your yearly income?" (Norberg et al., 2007; Phelps et al., 2000) led to the sensitive question “Are you in any debt?", additionally the sexually related question "have you bought condoms this year?" (White, 2004) led to the question "What is your sexual orientation?". Several questions were updated to reflect the behaviours of contemporary society such as changing the question "have you purchased playboy/playgirl magazines?" (White, 2004) to "how frequently do you view porn?".

Finally, the pre-tests validated the initial questions and two categories of question sensitivity: non-sensitive and sensitive, were identified (See Appendix D).

\subsubsection{Need for cognition}

Need for cognition is defined as an individual's tendency to engage in and enjoy thinking. Individuals with a high need for cognition have a desire to make sense of and understand the world by organizing relevant situations in meaningful ways (Cacioppo \& Petty, 1982). Need for cognition measures an individual's general tendency as either a cognitive miser or a cognizer when presented with situations involving effortful problem solving (Cacioppo, Petty, Feinstein, \& Jarvis, 1996). Cacioppo and Petty (1982) developed a 34 item scale to measure participants need for cognition (NFC) which was consequently shortened to 18 items within Cacioppo et al. (1984). The reliability of the shortened scale was not significantly diminished. The 34-item scale was administered to 527 students and the reliability of the 34item scale against the derived 18-item scale was compared, with each scale providing a Cronbach's alpha coefficient of .91 and .90 respectively. The shortened scale contains items such as "I would prefer complex to simple problems" and "The notion of thinking abstractly is appealing to me". Several studies have since utilized the revised 18-item NFC scale to good effect (Drolet et al., 2008; Haugtvedt et al., 1992; Zhang, 1996), thus the abbreviated scale used within the current study was derived from these 18 items (See Appendix E).

\subsubsection{Perceived risk and perceived worry}

Sjöberg (1998) highlights a key distinction between perceived risk and perceived worry and suggests that risk perception research should consider both of these constructs. Research investigating the privacy paradox has not recognized this distinction when considering perceived risk as a potential determinant, often utilizing general risk perception questions 
which are neither cognitively nor affectively focused. Norberg et al. (2007) for example, measured risk perception using a one-item scale asking, "how risky was it to provide information to the marketer?".

The terms worry and anxiety are interwoven, and whilst some differences between the two can be shown, these are often small (Zebb \& Beck, 1998). The present study is not concerned with these differences and takes a more generalized approach. The worry questionnaire used in the present study is adapted from the technology anxiety survey within Meuter, Bitner, Ostrom, and Brown (2005), which had a Cronbach's alpha of .93, and was itself adapted from the five-point Likert scale of Raub (1981). The original questions were used as a guide to formulate three new questions which exhibit stronger face validity for measuring worry towards disclosing personal information online, for example the following "I feel apprehensive about disclosing information online" (See Appendix E). Worry refers to the persistent awareness of possible future danger which does not subside (Mathews, 1990), the construct worry within the present study is more focused and is defined as the persistent awareness of possible danger related to the disclosure of personal information online.

Malhotra, Kim, and Agarwal (2004) define risk perception as an individual's level of expectation that disclosing personal information to a company is associated with a high probability for loss. Malhotra et al. (2004) used a seven-point Likert scale with four items to measure risk perception. The scale had a Cronbach's alpha of .92 and contained items such as "Providing online firms with personal information involves many unexpected problems". The definition of risk perception given by Malhotra et al. (2004), and the four-item scale will be used within the present study, alongside only minor adaptations (See Appendix E).

It should be noted that perceived risk and perceived worry do not measure the participants perceptions of risk and worry towards responding to the company questionnaire within the experiment. Instead, the two constructs measure the traits of the individual, what are their enduring perceptions of risk or worry regarding disclosure behaviour.

\subsubsection{Dependent variables}

To garner a greater understanding of the phenomenon under investigation, three dependent variables were employed to measure actual disclosure. The first dependant variable and most frequently used within the literature is absolute disclosure (Phelps et al., 2000; Wang, Zhang, Liu, \& Jin, 2015). Absolute disclosure measures whether a question has been answered or not, this construct does not consider the qualitative value of the response. Norberg et al. 
(2007) uses absolute disclosure as their dependent variable, the benefits of this method include its simplicity to employ and its objectivity without needing to rely upon potential experimenter bias when evaluating responses. Absolute disclosure will be operationalized as the number of questions attempted, thus if 30 questions are asked then a participant who attempts to respond to all the questions will have an absolute disclosure of 30 , however if a participant did not attempt two questions they would have an absolute disclosure of 28 . In the case that absolute disclosure of a specified sensitivity level is required only those questions will be looked at.

Nonetheless, absolute disclosure may not provide a thorough understanding of the phenomenon, thus the quality of information provided will also be measured. Quality of information will be initially operationalized as a categorical variable with four values; true, false, incomplete, or not attempted. Near the end of the questionnaire participants will have the option to evaluate whether the answers they provided earlier in the company questionnaire were true, false, incomplete, or not attempted.

The value true refers to responses that are both correct and complete. False refers to responses that are complete lies, representing a participant's protective strategy to protect their personal information. Incomplete refers to responses that withhold some important information (e.g. excluding an income source, credit card information, or providing an unused email when prompted for a primary email address), representing a more mild protective strategy akin to blurring as proposed by Joinson et al. (2008). Not attempted refers to a participant deciding not to respond to the question at all, therefore representing a participant's clear employment of a protective strategy. For each participant, the total of each of these four values will be calculated.

To clarify, when measuring absolute disclosure, the only consideration is whether the question was answered in some capacity. Even if the participant indicated that their response was false or incomplete, it is still counted as a response. Only the number of "not attempted" responses was considered, with this number being subtracted from the total number of questions to calculate absolute disclosure.

The term quality of information will be used throughout the paper to refer to measurements of disclosure other than absolute disclosure, thus whether responses were false or incomplete. However, also included in quality of information is the created variable combined protective strategies. Combined protective strategies is a variable combining the total number of false 
and incomplete responses alongside the number of not attempted responses, thus combined protective strategies measures the total number of protective strategies employed by the participant.

Finally, response latency, which measures the length of time a respondent takes to provide a response to a question, will provide the third outcome variable. Participant responses will be timed from the moment the question appears to the moment they click to move onto the next question, thus even not attempted questions will have a response latency. For each participant, a sum total of the time it takes for each question to be answered will be calculated, the average will then represent the overall response latency. Similarly, to that above, when the difference between information sensitivity is under investigation the response latency will be split between high and low levels of sensitivity (See the paragraph on question selection below for an in-depth operationalisation of levels of sensitivity). Ultimately, response latency records the process of reading and understanding the question, gathering the information, formulating a response, deciding whether that response should be sent (risk analysis), and lastly writing the response and submitting it.

\subsubsection{Control variables}

Several variables were measured to serve as controls within this experiment. Participants age must be measured as studies have demonstrated a difference between both privacy perceptions and reported levels of disclosure between adolescents and adults (Christofides et al., 2012; Richard \& Ralphs, 2018). Previous research has also demonstrated a gender difference in disclosure levels where in some cases women were more likely to disclose personal information (Dindia \& Allen, 1992). Participants' motivation to complete the questionnaire was also measured to determine whether they were adequately invested in the questionnaire to provide responses, moreover motivation plays an important role in how individuals respond to and process information (Cacioppo \& Petty, 1982; Drolet et al., 2008). Measuring participants trust toward the company was also important to control for variance in participants disclosure, despite demonstrating a null impact on actual behaviour in previous research (Norberg et al., 2007). Participants' self-rated difficulty remembering the number served as both a manipulation check and control variable.

Two additional constructs were measured to serve as controls, offense sensitivity and sensory sensitivity. Offense sensitivity is defined as the frequency to which someone takes offense alongside the tolerance they have for offensive stimuli (Sigmon \& Snyder, 2006). The 
construct thus reflects an individual's susceptibility to becoming offended in a general sense. Sigmon and Snyder (2006) developed a 16-item Offense-Taking Scale comprising of two subscales, sensitivity and severity, with a Cronbach's alpha .87. Sigmon and Snyder (2006) suggested that the subscales may work well individually, thus the sensitivity subscale was adapted for use within the present study as the current research is more interested in an individual's susceptibility to take offense. Moreover, the questions for the severity subscale, such as "I usually do not stay angry very long" and "I recall every time individuals have wronged me in the past" did not match the context of the current research. The sensitivity scale was adapted to a seven-point Likert scale with six items, for example the question "It does not take much to make me mad" was changed to "It does not take much to make me uncomfortable" (See Appendix E).

Whereas offense sensitivity captures an individual's susceptibility to offensive stimuli, sensory sensitivity captures an individuals' susceptibility to become overwhelmed in the presence of general stimuli, for example loud noises, strong smells, or people's moods (Aron $\&$ Aron, 1997). Aron and Aron (1997) developed a 27-item questionnaire which measured sensory sensitivity and demonstrated a Cronbach's alpha of .87. The current study adapted the questionnaire, building a six-item scale using a seven-point Likert scale with questions such as "I find it unpleasant to have a lot going on at once" and "I'm easily overwhelmed by things like bright lights, strong smells, course fabrics, or sirens close by" (See Appendix E). A list of the independent and dependant variables alongside their respective definitions and measures is provided on the following page in Table 1. 
Table 1: List of variables, definitions, and measures

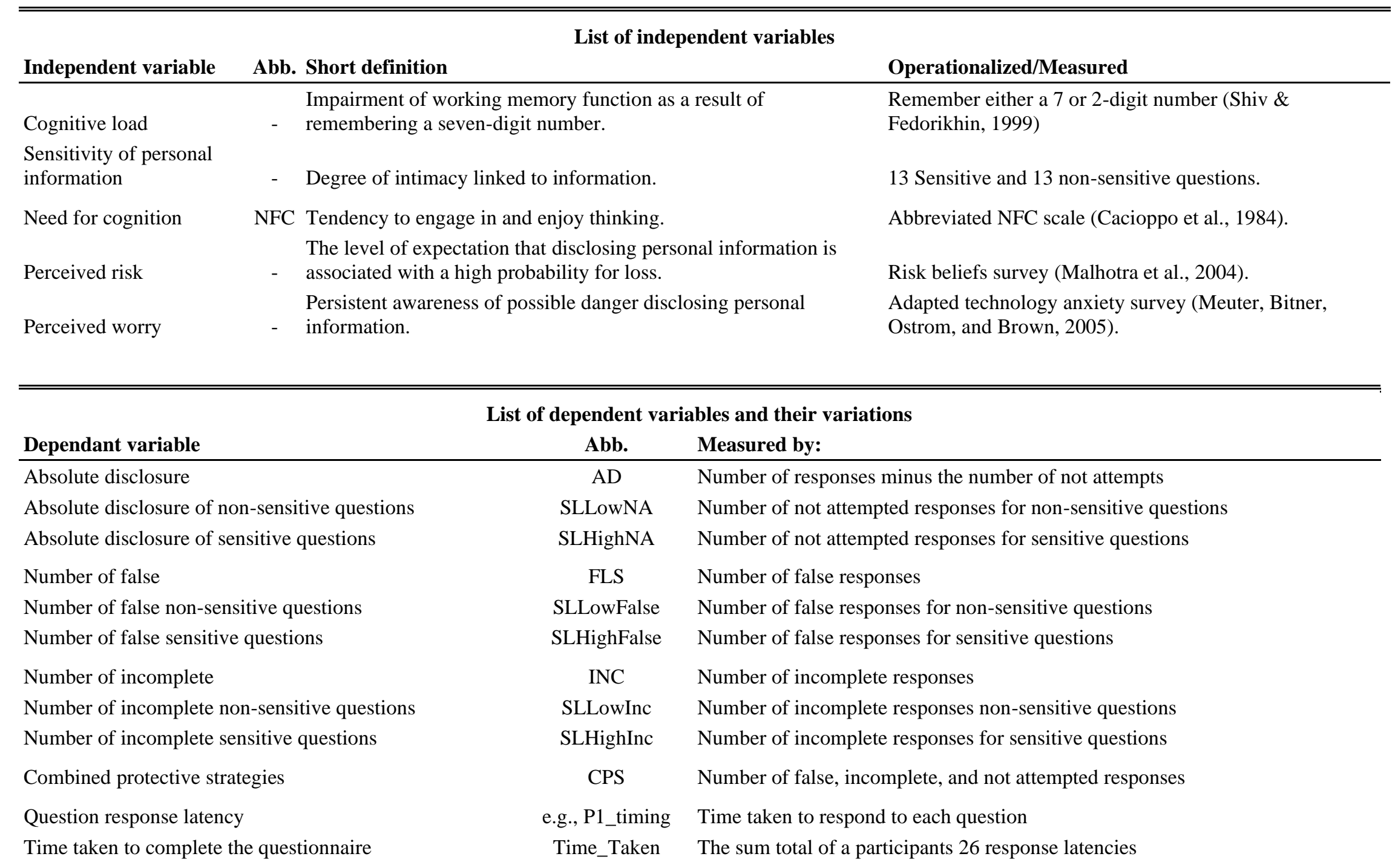




\subsection{Pre-tests: Scenario development and question selection}

Two pre-tests were administered with the goal of assessing the sensitivity of the company provided questions and validating the use of the general scenario.

\subsubsection{Initial scenario development}

The pre-test participants were asked to rate how trustworthy and risky they felt each situation to be. For the present study it was important to evaluate the trustworthiness and riskiness of providing personal information, to ensure the company was not overly trusted, and to guarantee a variability of absolute disclosure levels. Trust could not be so low that participants in both conditions refused to answer every question, nor too high that they had no problem answering them all.

Three scenarios were designed for evaluation in the first pre-test. The first two scenarios were adapted from Norberg et al. (2007) reflecting a bank and pharmaceutical scenario (See Appendix I for the original scenarios). These scenarios were chosen as they have been effectively used in a previous study and allow two-subsets of the most sensitive questions, financial and health-related to be asked organically (Horne \& Horne, 1998). The third scenario was developed as a general scenario wherein a company or industry was not specified.

Company anonymity is important to consider to ensure participants are not swayed by preconceived notions of particular industries or service offerings (Aaker \& Keller, 1990). Previous research has been unable to ask a breadth of personal questions by the limitations of the scenarios they have chosen. For example, the bank scenario above facilitates the collection of financial information, but other sensitive questions such as health-related measures would invoke severe suspicion (Norberg et al., 2007). Privacy perceptions also vary across individuals, with some people being very reluctant to share certain aspects of personal information whilst others may share those details with ease (Norberg et al., 2007; Nowak \& Phelps, 1992; Phelps et al., 2000; White, 2004). Because of this, it was important that a breadth of questions was asked to accommodate for this variance, thus a general scenario was developed. A potential limitation of the general scenario to be tested in the first pre-test was whether participants would hold similar disclosure and trust views towards this unspecified company. As participants are free to envision any company within this scenario, the variability of these factors could be too large to derive a reliable result, although this was not observed in the pre-test. 


\subsubsection{Pre-test one}

The first pre-test was administered to 32 individuals within the researchers' circle of acquaintances, 17 were female and 25 were aged between 18 and 34 years of age. Participants were asked to rate the sensitivity of 41 questions (See Appendix H). Secondly, participants were shown the three scenarios: general company, bank, and pharmaceutical company. Participants were then asked to indicate how likely they would be to share their five least/most sensitive questions with each of the scenarios, whilst also indicating how much trust they would have disclosing information in the scenario. The first pre-test demonstrated that individuals perceived a difference in sensitivity across the questions, with questions such as "What is your name?" and "What is your occupation?" had a mean sensitivity rating of 1.56 and 1.81, whilst questions such as "How many sexual partners have you had? and "What is your parents income?" had a mean sensitivity rating of 4.72, based on a 7-point Likert scale, with one indicating not at all sensitive and seven incredibly sensitive. Differences between each scenario also revealed the general scenario as the least trusted compared to the bank scenario and pharmaceutical scenario. Additionally, the standard deviations for individuals' willingness to share their five least/most sensitive answers with each of the scenarios revealed the general scenario as having the smallest standard deviations, compared with the pharmaceutical scenario, and the banking scenario, indicating that people are more likely to answer similarly to the general scenario (See Appendix G).

\subsubsection{Pre-test two}

The second pre-test was undertaken to evaluate the validity of the questions' sensitivity levels using a larger, random sample. The pre-test was distributed via a popular New Zealand-based Facebook group with a membership of over 130,000, 185 individuals responded, 119 were female and 166 were aged between 18 and 34 years of age (See Appendix G). The results largely reflected the sensitivity rankings of the first pre-test, although several questions such as "Who did you vote for last election?" and "What are two websites you use most often?" saw a decrease in sensitivity rankings of .85 and .63 respectively. However, questions pertaining to the internet may have seen a decrease in perceived sensitivity due to the sample of participants: individuals active on Facebook (Christofides et al., 2012). 
The second pre-test also exchanged the banking and pharmaceutical scenarios for two new scenarios. A dating application scenario was added, and the pharmaceutical scenario was changed to appear less socially desirable to lower trust. The dating scenario was developed as a potential alternative to the general scenario wherein the dating scenario could be more specific whilst also asking a breadth of sensitive questions which are associated with online dating (Hitsch, Hortaçsu, \& Ariely, 2010). The dating scenario had the lowest mean trust score ( $M=$ 2.28, $S D=0.98)$ compared to the general $(M=2.62, S D=1.03)$ and Pharmaceutical $(M=3.09$, $S D=1.2)$ scenarios. The general scenario had the largest difference between willingness to share their most and least sensitive answers whilst also having the lowest standard deviations for the two measures (willingness to share their five least/most sensitive answers), indicating again that people are likely to respond most similarly within this general scenario (See Appendix G). Therefore, the general scenario was deemed most appropriate for the current study.

\subsubsection{Question selection}

Each of the questions have been drawn from extant literature and the chosen general scenario also allows a breadth of questions to be asked due to the lack of specificity towards a single industry. This leaves the final criteria, selecting a range of information categories and questions of varying sensitivity levels, to be considered (Mothersbaugh et al., 2012). Seven information categories were identified from the previous literature: personal identity questions, generic personal questions, lifestyle questions, financial questions, political/religious questions, healthrelated questions, and contact detail questions, thus providing a range of information categories (See Appendix F). Additionally, the pre-tests revealed variation in sensitivity levels across the questions such that two categories of question sensitivity: non-sensitive and sensitive, could be identified.

Questions for the experiment were selected equally across the two categories of question sensitivity and cover each of the seven information categories. Care was also taken to ensure the standard deviation of each question selected was not too large to help ensure that participants were unlikely to have drastic variations in their perceptions of sensitivity. Ultimately twenty-six questions were chosen across the two categories of question sensitivity, thirteen from each (Appendix D). 


\subsection{Main experiment}

\subsubsection{Study design}

The main experiment employed a between-subjects design with participants randomly assigned to either a cognitive load or control condition. In addition, to investigate the impact of personal information sensitivity on participant's disclosure activity a repeated-measures design was used, whereby participants were exposed to questions of both high and low sensitivity within the same questionnaire.

Alongside manipulating participants cognitive load and the sensitivity of personal information, participants need for cognition (NFC), perceived risk, and perceived worry were also measured as independent variables. The three dependent variables measured included absolute disclosure, quality of disclosure, and response latency.

A laboratory experiment was deemed most appropriate for the present study to maintain an equal level of cognitive load across participants and to minimize extraneous variables such as distractions or participate intoxication (Alreck \& Robert, 2004; Zikmund, Ward, Lowe, Winzar, $\&$ Babin, 2011). Additionally, using controlled computer labs helped ensure the cognitive load task was carried out properly by participants without them 'cheating', such as writing down the number they were asked to remember instead of rehearsing it in their mind.

\subsubsection{Sample and sample frame}

The sample frame for the experiment was participants between the ages of 18 and 40. This range encompasses two generational groups; Generation Y and Z. Generation Y includes individuals born between 1980 and 1995, and Generation Z includes individuals born after 1995 (Richard \& Ralphs, 2018). These two generations are both digital natives and have been brought up surrounded by computer-based technology. Carrier et al. (2009) reveals a significant difference between levels of multitasking for these two groups compared to older generations such as Gen X (Born between 1960 and 1980) and Baby Boomers (Born between 1950 and 1960)(Richard \& Ralphs, 2018). Therefore, individuals from Generation $\mathrm{Y}$ and $\mathrm{Z}$ are more likely to be impacted by any detrimental impacts that distractions may have on personal information disclosure. Younger generations also report the difficulty of multitasking as being lower (Carrier et al., 2009). Thus, sampling a broader sample, such as 18 to 65 -year olds could negate any effect if participants have significantly different experiences with the task, for example older participants 
may find the memory task harder than younger participants. Additionally, there is evidence to suggest that adolescents and adults hold different perceptions of privacy (Livingstone, 2008; Richard \& Ralphs, 2018). Therefore, to broaden the sample would necessitate doubling the number of participants required, as two groups would need to be established separating Generation Y and Z from Generation X and Baby Boomers. Due to the time and monetary limitations of the present research, it was not possible to reach this required number of participants, specifically those from Generation $\mathrm{X}$ and Baby Boomers, thus the current sample frame sought to capture the behaviour of the generations most likely to multitask: Generation Y and Z (Carrier et al., 2009).

The study required a minimum total of sixty participants split between the two groups to attend a session in a computer lab. To gather these participants, posts were made on the University blackboard pages, relevant local social media sites such as Facebook, and fliers were distributed across the University campus and other social forums (See Appendix C).

Each participant was given a voucher from a local café to receive one free regular coffee for participating in the study. Participants were also given the option to enter a draw to win a $\$ 100$ groceries voucher. They were given this option at the end of the computer lab session before leaving by writing their email address on a piece of paper provided and putting it into a secure box from which the winner was drawn. The gifts were provided as an incentive for people to give up their time to participate, as they needed to physically attend a computer lab session. Providing gifts as an incentive has been shown to increase response rates in both telephone and face-to-face surveys without incurring a subsequent impairment in the quality of data obtained (Singer, Van Hoewyk, Gebler, \& McGonagle, 1999). Nonetheless, care was taken to ensure that participants did not associate the gifts with the fictitious company providing the questionnaire, further details will be provided below.

\subsection{Procedure}

The posts and fliers used to gather participants contained a link to a webpage where participants were given an information sheet providing them with a general guide of what to expect and their rights as a participant (See Appendix A). From this webpage potential participants were able to follow a link to Doodle, a website which provides online scheduling software, and from here 
potential participants were asked to sign up for a lab session by picking a time and room from a variety of different options.

During the session participants entered the study room and were seated at a computer desk with a physical copy of the information sheet and participation consent forms to be completed before beginning the experiment (For the information sheet see Appendix A; for the participant consent form see Appendix B). Participants were seated at individual computers and spaced so they could not see each other's screens. Ensuring participants cannot communicate with each other is important as people are more likely to admit to participating in sensitive behaviour if they believe others have also admitted to participating in the behaviour (Acquisti et al., 2012). Participants were instructed to leave their personal devices at the front of the room to ensure they were not distracted throughout the experiment (Ward et al., 2017). Once participants had read the information sheet and signed the consent forms, they began the experiment which was loaded onto the University provided computer. The procedure contained four phases: introduction of the study and scenario, the company questionnaire and manipulation, the non-company affiliated survey, and lastly, debrief and post company questionnaire evaluation.

\subsubsection{Phase one: Introduction of the study and scenario}

The importance of the first stage was to provide participants with enough information about the study, without disclosing the true nature of the factors being measured. This involved providing minimal information and framing the study as a simple experiment to investigate the impact of stress on behaviour. The term stress was used as some participants may be unfamiliar with the concept of cognitive load, whereas stress is conceptually similar and more understandable by the general public. Acquisti et al. (2012) demonstrated that cueing people to think about the intrusiveness of questions before an experiment negated the impact of order effects. This suggests that cueing participants enables them to form enduring attitudes towards sensitive behaviours, guiding people to respond differently than they may have in the moment. Therefore, it was important to minimize participant's expectation of being asked sensitive questions throughout the experiment.

Withholding the true intent behind a study provides two key benefits: firstly it allows the acquisition of certain information that would not be attainable under circumstances of full disclosure, and secondly it can provide more reliable and unbiased results, particularly in 
psychology experiments (Tai, 2012). Bortolotti and Mameli (2006) state that withholding information from participants is morally permissible when the significance of the research outweighs the potential harm towards the participants, whilst factoring the future harm of not conducting the research. Moreover, Bortolotti and Mameli (2006) argues that participant autonomy is not violated if participants are debriefed of any misinformation and given the opportunity to withdraw from the experiment along with the data they provided. The present study debriefed participants and allowed them the opportunity to withdraw, furthermore the harm induced by the study was negligible as individuals are asked to complete company questionnaires often, and in this case were able to skip any question or withdraw from the study at any point. Lastly, the study is addressing a societal issue, that of individuals providing excessive personal information online and to brands, thus it is in societies best interest if the factors behind this phenomenon are illuminated.

The present research required a cognitive load manipulation, therefore a similar confederateinspired scenario to that used within Norberg et al. (2007) could not be used. Instead participants were asked to "consider a company that they are already using..." was conducting market research and building customer profiles. This was deemed necessary by the ethics committee to eliminate potential deception that participants would believe the company was real. Nonetheless, the vignette was clearly described and frames the request for personal information within the context of a company's marketing research. Participants were also not aware that their disclosed information would be deleted upon completion of the experiment session, thus they still believed they were disclosing information that may be read by someone else. Therefore, despite not reflecting a true company requesting personal information, an approximate facsimile of a scenario wherein information is disclosed to a brand is achieved.

The ethics committee also decreed that participant responses to the company questionnaire must be deleted and at no point accessible to anyone, even the researchers, upon the participants completion of the experiment. To accommodate this protection of privacy, code was developed for use within the Qualtrics survey. This allowed responses to be temporarily stored throughout the experiment so the responses could be shown to the participant at the end of the survey for evaluation. Once the participant finished the experiment their responses were automatically permanently deleted. 
Care was taken to ensure that participants would not associate the incentives provided with the company questionnaire. It was important to do this as several studies have highlighted the risks of providing incentives acting as an additional benefit, leading to greater motivation for disclosure than intended (Kokolakis, 2017; Lee, Park, \& Kim, 2013; Norberg et al., 2007). Norberg et al. (2007) was able to overcome this by only offering monetary incentives in study 1 rather than study 2 , but the present study could not completely separate the incentive from the company questionnaire, instead participants were explicitly told that the vouchers were not connected with the fictitious company just prior to reading the company scenario. The goal being to draw participants into the study, but not increase their motivation to disclose information to the 'unaffiliated', fictitious company.

\subsubsection{Phase two: Company questionnaire and manipulation}

Phase two involved the participants undertaking the cognitive load manipulation and completing the company questionnaire (See Appendix E).

The first page served as a landing page with a short description of the company's goals and their intentions for collecting personal data. Additionally, by making a link between the company and the participant, highlighting that their actions will have consequences, increases their motivation to participate, although not necessarily disclose more information (White, 2004). To do this the present study stated that the new service was for a "company you are already using", and that a customer profile would be built from the information participants provided. Ganassali (2008) demonstrated that motivated respondents are not wearied by the length of a questionnaire, this is important as the present study measured disclosure levels and did not want an unanswered question to be falsely attributed to low motivation. Norberg et al. (2007) also highlight the need to demarcate the company from the study as students may hold an overabundance of trust in their educational institution, giving them greater confidence that their personal information will not be mistreated. Thus, a scenario outlining a company is used not only to reflect marketing practice but to also mitigate the overabundance of trust towards academic institutions.

After reading the scenario participants were asked to remember either a two- or seven-digit number. The cognitive load task is the same as that used by Shiv and Fedorikhin (1999) to split participants into either a cognitive load (remember the seven digit number) or control condition (remember the two digit number). Participants were randomly assigned to one of the two 
conditions. Similarly to Shiv and Fedorikhin (1999) participants were told that they would need to recall the number after completing the allotted task. The procedure within Craig et al. (2012) made participants remember their number for an extended period of time whilst they evaluated five product advertisements, thus asking participants to hold the number in memory for the duration of the company questionnaire within the present study is justifiable. As per previous research, to help ensure the cognitive load task was carried out by each participant they were also told not to write the number down (Craig et al., 2012). Previous studies have not disclosed whether they provided a specific length of time for participants to remember the number (e.g. Shiv \& Fedorikhin, 1999, 2002; Shu \& Carlson, 2014), thus to ensure consistency between participants, in the present study they each had twenty seconds to look at the number before they began the questionnaire in earnest.

Questions were presented one at a time and participants were able to type their response in the answer box provided or skip to the next question. Providing only one question at a time allowed the latency of each response to be measured. Questions were allocated into seven blocks with each block of questions falling under a distinct categorization. The block with questions pertaining to generic personal details such as 'what is your first name?' and 'what is your nationality?' was presented to participants first, this was done as these questions are often expected and would ease the participant into the questionnaire (Zikmund et al., 2011). Another block asking for contact details such as "what is your mobile phone number?" and "what is your email address?" was presented last, the provision of contact information is typically asked for last within company surveys, to improve the generalizability of the study the same approach was taken here. The other five blocks were presented to participants randomly to negate order effects (Zikmund et al., 2011). Avoiding order effects is important in the present study as some questions are more sensitive than others and early exposure to them may raise a participants' awareness of potential disclosure risks, creating a state of vigilance before that of other participants, or alternatively it could decrease the perceived sensitivity of following questions (Acquisti et al., 2012). Due to individuals having variations in their level of sensitivity towards different questions, it is not possible to create a questionnaire that would induce the same experience of sensitivity awareness across each participant. Therefore, randomizing the presentation order of the other five blocks was deemed the most effective way to overcome this barrier. 
Once participants finished the company questionnaire, they were asked to recall their number. Participants were asked to write down their best guess, even if they knew it did not match the number originally shown to them.

\subsubsection{Phase three: Non-company affiliated survey}

Phase three involved participants answering five surveys and three post-manipulation checks. Participants were informed that the following questions were not associated with the company questionnaire and would not be shared with the fictitious company, they were also told they no longer needed to remember their number. Participants were first presented with the shortened need for cognition (NFC) survey (Cacioppo et al., 1984) with all six items presented on the same page. The same process was used for the perceived risk survey (Malhotra et al., 2004), perceived worry survey (Meuter et al., 2005), offense sensitivity scale (Sigmon \& Snyder, 2006) and sensory sensitivity scale (Aron \& Aron, 1997). Finally, participants were asked to review their experience during the cognitive load task. This served as a manipulation check and provided a control variable. The present study used a similar manipulation check to that used within Goode et al. (2010) and Shiv and Fedorikhin (2002) to examine whether the cognitive load manipulation was successful by asking "how difficult was it to hold the number in your mind and complete the questionnaire?". Assessing participant's motivation to complete the questionnaire is also important to determine whether participants were adequately invested in the questionnaire enough to provide responses and not only focus on the memory task. Measuring participants' trust toward the company was also important to control for variance in participants' disclosure of personal information.

\subsubsection{Phase four: Debrief and post-company questionnaire evaluation}

Phase four included the debriefing and the post company questionnaire evaluation. Participants were informed that the information they provided would not be shared or seen by anyone other than the research team, and that the information would not be given to a company or used to contact or identify them in any way (See Appendix E). Additionally, the individual answers to the company questionnaire themselves were deleted upon participants completing the experiment. Participants were told that their individual answers did not matter but instead whether they were answered truthfully, or not at all. People generally have more trust in scientific or academic institutions compared to companies or the government (Haynes, Barclay, 
\& Pidgeon, 2008; Lantieri \& Chiagouris, 2009; Thomas, 1998), therefore by providing full disclosure regarding the nature of the study it was assumed participants would be more willing to accurately disclose whether the information they provided in the company questionnaire was true, false, or incomplete. Participants were presented with each of the questions from the company questionnaire and their answers again to provide this comprehensive evaluation. Participants then answered three demographics questions asking them for their age, gender, and education level.

Finally, whilst still on the computer, participants were asked not to discuss the study with anyone and thanked for their participation. As they left the computer lab, they were given their cafe voucher and the option to enter the draw to win a $\$ 100$ groceries voucher by writing their email address on a piece of paper provided and putting it into a secure box. 


\section{Results}

\subsection{Descriptive statistics}

SPSS version 25 was used to conduct the data analysis. In total sixty-four participants completed the experiment and were split evenly between the cognitive load and control conditions. The participants were members of Generation Y and Generation Z being between 18 and 40 years of age with the majority representing Generation $\mathrm{Z}$ aged between 18 and 20 (51.6\%). There were slightly fewer male respondents (45.3\%) than female (51.6\%) and two respondents refrained from selecting a gender. Participants' education levels were diverse; however, the majority of respondents' highest qualification was that of University 200 level or below (87.3\%).

Table 2: Descriptive statistics

\begin{tabular}{lrr}
\hline \hline Manipulation & Frequency & Percent \\
\hline Control & 32 & 50 \\
Cognitive Load & 32 & 50 \\
\hline Total & 64 & 100
\end{tabular}

\begin{tabular}{lrr}
\hline \hline Gender & Frequency & Percent \\
\hline Female & 33 & 51.6 \\
Male & 29 & 45.3 \\
Other & 1 & 1.6 \\
Missing & 1 & 1.6 \\
\hline Total & 64 & 100
\end{tabular}

\begin{tabular}{lrr}
\hline \hline Age & Frequency & Percent \\
Under 18 & 0 & 0.00 \\
$18-20$ & 33 & 51.6 \\
$21-24$ & 21 & 32.8 \\
$25-29$ & 3 & 4.7 \\
$30-35$ & 5 & 7.8 \\
$36-40$ & 1 & 1.6 \\
Missing & 1 & 1.6 \\
\hline Total & 64 & 100
\end{tabular}

\begin{tabular}{lrr}
\hline \hline Highest Qualification & Frequency & Percent \\
Some College & 10 & 15.6 \\
Finished College & 11 & 17.2 \\
Uni 100 level & 19 & 29.7 \\
Uni 200 level & 15 & 23.4 \\
Uni 300 Level & 7 & 10.9 \\
PhD & 1 & 1.6 \\
Missing & 1 & 1.6 \\
\hline Total & 64 & 100
\end{tabular}

\subsection{Construct validity}

Scales were drawn and adapted from the extant literature, therefore the constructs had an established theoretical basis justifying the use of confirmatory factor analysis (Hurley et al., 1997). Confirmatory factor analysis (CFA) for the perceived risk and perceived worry constructs revealed good internal reliability with Cronbach's Alpha scores greater than .800 , additionally factor loadings for each item were also above .800 indicating strong associations with their corresponding underlying variable. 
A CFA was conducted for the need for cognition (NFC) construct which revealed that the items were split evenly, loading across two factors (see Appendix J). The items were split to form NFC1 and NFC2, and upon re-evaluation the items comprising each new factor resembled measurements for two distinct constructs. The items constructing NFC1 tend towards a weak NFC measuring an individual's appreciation for cognition without necessarily applying it. NFC2 however, has items that more accurately measure an individuals' need for applied cognition matching the initial conceptualization of NFC as an individual's tendency to engage in and enjoy thinking.

A CFA was conducted for the offense sensitivity construct which revealed that the items were loading across two factors (See Appendix J). Four items loaded strongly on the first factor although one of these shared a similar loading across the second factor and thus was discarded. This left the second factor with only two items, this was deemed to have low face validity and was consequently dropped from further analysis, leaving the first factor with three items comprising the construct of offense sensitivity.

Finally, a CFA was conducted for the sensory sensitivity construct which revealed across two iterations that two items had communalities below .500 and thus they were removed (See Appendix K). The final sensory sensitivity construct therefore comprises 4 items with factor loadings above .700 and good internal validity with Cronbach's Alpha score greater of .788. To view a full list of the final confirmatory factor analyses, see Appendix K.

\subsection{Manipulation check}

A successful manipulation of cognitive load was demonstrated. Participants indicated that it was harder to hold the number in their mind and complete the questionnaire whilst in the seven-digit, cognitive load condition $(M=1.41, S D=.665)$ as compared to the two-digit, control condition, $(M=2.94, S D=1.605), t(41.344)=-4.985, p<0.001$. A 7-point Likert scale was used to measure the difficulty for participants to hold the number in their mind with one representing "extremely easy" and seven "extremely difficult". In addition there was no significant difference in participants' motivation levels, $t(62)=-.284, p=0.777$, or trust levels, $t(62)=-1.091, p<$ 0.279 , between the two groups. The 7-point Likert scales for the motivation and trust scales were respectively anchored at one as "extremely demotivated" and "extreme distrust" and seven as "extremely motivated" and "extreme trust". 


\subsection{Comparing the cognitive load and control condition}

To test the hypothesis that cognitive load would result in greater absolute disclosure an independent t-test was employed. A significant difference was found; individuals within the control group $(M=25.44, S D=1.014)$ disclosed significantly less information than the cognitive load group $(M=25.91, S D=0.296), t(36.25)=2.51, p=0.017$.

However, despite the results supporting H1a, no support was found to demonstrate an effect of cognitive load on the quality of information disclosed, H1b. Firstly, an independent t-test comparing the number of false responses found that the control group $(M=.94, S D=1.759) \mathrm{did}$ not significantly differ from the cognitive load group $(M=1.16, S D=1.986), t(62)=.467, p=$ 0.435. Secondly, an independent t-test comparing the number of incomplete responses found that the control group $(M=.1 .25, S D=1.814)$ did not significantly differ from the cognitive load group $(M=0.97, S D=1.555), t(62)=.666, p=0.256$. Finally, an independent t-test comparing the combined protective strategies (number of false, incomplete responses and not attempted responses) found that the control group $(M=2.75, S D=2.527)$ did not significantly differ from the cognitive load group $(\mathrm{M}=2.22, S D=2.485), t(62)=.848, p=0.400$.

Finally, partial support was found for H1c. Response latency was demonstrated to be significantly longer for participants under cognitive load than those within the control condition, however, this was only the case for two of the twenty-six questions (See Appendix L for a full list). An independent t-test results comparing the latency of responses to "What is your surname?" found that the control group $(M=4.593, S D=1.461)$ responded significantly quicker than the cognitive load group $(M=5.692, S D=2.419), t(50.965)=2.199, p=0.016$. Also, the latency of responses to "Do you experience mental illness? And if so, how would you describe it?" found that the control group $(M=9.955, S D=8.883)$ responded significantly quicker than the cognitive load group $(M=17.256, S D=16.529), t(47.526)=2.201, p=0.004$.

An additional two questions exhibited a trend towards significance, given the small sample size and prior hypothesis it was deemed necessary to consider them. The latency of responses to “How often do you use social media?" showed that the control group $(M=7.644, S D=3.432)$ responded quicker than the cognitive load group $(\mathrm{M}=10.117, S D=6.400), t(47.467)=1.926, p$ $=0.060$ and the latency of responses to "What is your parent(s) yearly income?" showed that the 
control group $(M=14.751, S D=.8 .984)$ responded quicker than the cognitive load group $(\mathrm{M}=$ 23.413, $S D=25.644), t(38.497)=1.803, p=0.079$.

\subsection{Cognitive load and sensitivity of personal information}

A paired samples t-test was conducted to compare the number of not attempted responses between sensitive and non-sensitive questions for participants within the control condition. There was a significant difference in the number of not attempted responses between the low sensitivity $(M=0.00, S D=0.000)$ and high sensitivity $(M=0.56, S D=1.014)$ conditions; $t(31)=-3.138, p=$ 0.004, supporting H2a. In contrast, the number of not attempted responses between sensitive and non-sensitive questions for participants within the cognitive load condition was not significantly different, $t(31)=-1.791, p=0.083$, supporting $\mathrm{H} 2 \mathrm{~b}$.

A series of paired samples t-tests were conducted to compare the quality of information disclosure of both sensitive and non-sensitive questions between the cognitive load and control condition (See Table 3). There were significantly more incomplete responses provided to sensitive questions $(M=0.94, S D=1.435)$ than non-sensitive questions $(M=0.31, S D=0.640)$ within the control condition $t(31)=-2.743, p=0.010$, providing support for $\mathrm{H} 2 \mathrm{c}(\mathrm{i})$. The same pattern was demonstrated within the cognitive load condition $t(31)=-2.533, p=0.017$, although this does not provide support for $\mathrm{H} 2 \mathrm{~d}(\mathrm{i})$ which predicted a non-significant difference. However, a non-significant difference was demonstrated between the number of false responses provided to non-sensitive and sensitive questions within the cognitive load condition $t(31)=-0.722, p=$ 0.476, whilst the control condition was nearing towards significance $t(31)=-1.982, p=0.056$, with participants providing more false responses to sensitive questions $(M=0.66, S D=1.285)$ than non-sensitive questions $(M=0.28, S D=0.683)$. Thus, providing partial support for both $\mathrm{H} 2 \mathrm{c}(\mathrm{f})$ and $\mathrm{H} 2 \mathrm{~d}(\mathrm{f})$.

\subsection{Multiple regression analyses}

A multiple regression analysis (MRA) was performed to better understand the relationship between absolute disclosure and the following predictor variables and controls: perceived risk, perceived worry, NFC1, NFC2, offense sensitivity, sensory sensitivity, age, gender, and education. In combination, these factors accounted for a non-significant $19.1 \%$ of the variability in absolute 
disclosure $R^{2}=0.191, F(9,53)=1.388, p=0.217$. The results of the multiple regression analysis are reported in Table 4.

Table 3: Cognitive load and sensitivity of personal information

\begin{tabular}{|c|c|c|c|c|c|}
\hline \multicolumn{6}{|c|}{ Paired Samples Statistics } \\
\hline $\begin{array}{l}\text { Manipulation }(1=7 \text { - } \\
\text { digit, } 0=2 \text {-digit })\end{array}$ & & & Mean & $\mathrm{N}$ & Std. Deviation \\
\hline \multirow[t]{8}{*}{ 2-Digit } & Control 1 & Non-sensitive True & 12.41 & 32 & 0.911 \\
\hline & & Sensitive True & 10.84 & 32 & 2.096 \\
\hline & Control 2 & Non-sensitive False & 0.28 & 32 & 0.683 \\
\hline & & Sensitive False & 0.66 & 32 & 1.285 \\
\hline & Control 3 & Non-sensitive Inc & 0.31 & 32 & 0.644 \\
\hline & & Sensitive Inc & 0.94 & 32 & 1.435 \\
\hline & Control 4 & Non-sensitive NA & 0.00 & 32 & 0.000 \\
\hline & & Sensitive NA & 0.56 & 32 & 1.014 \\
\hline \multirow[t]{8}{*}{ 7-Digit } & Load 1 & Non-sensitive True & 12.22 & 32 & 1.184 \\
\hline & & Sensitive True & 11.56 & 32 & 1.585 \\
\hline & Load 2 & Non-sensitive False & 0.53 & 32 & 1.047 \\
\hline & & Sensitive False & 0.63 & 32 & 1.070 \\
\hline & Load 3 & Non-sensitive Inc & 0.25 & 32 & 0.508 \\
\hline & & Sensitive Inc & 0.72 & 32 & 1.224 \\
\hline & Load 4 & Non-sensitive NA & 0.00 & 32 & 0.000 \\
\hline & & Sensitive NA & 0.09 & 32 & 0.296 \\
\hline
\end{tabular}

\begin{tabular}{|c|c|c|c|c|c|c|}
\hline \multicolumn{7}{|c|}{ Paired Samples Test } \\
\hline $\begin{array}{l}\text { Manipulation }(1=7- \\
\text { digit, } 0=2 \text {-digit })\end{array}$ & & & Mean & $\begin{array}{l}\text { Std. } \\
\text { Dev }\end{array}$ & $\mathrm{t} d f$ & $\begin{array}{r}\text { Sig. }(2- \\
\text { tailed) }\end{array}$ \\
\hline \multirow[t]{4}{*}{ 2-Digit } & Control 1 & Non-sensitive True - Sensitive True & 1.56 & 2.015 & 4.38631 & $<0.000$ \\
\hline & Control 2 & Non-sensitive Fls - Sensitive Fls & -0.38 & 1.070 & -1.98231 & 0.056 \\
\hline & Control 3 & Non-sensitive Inc - Sensitive Inc & -0.63 & 1.289 & -2.74331 & 0.010 \\
\hline & Control 4 & Non-sensitive NA - Sensitive NA & -0.56 & 1.014 & -3.13831 & 0.004 \\
\hline \multirow[t]{4}{*}{ 7-Digit } & Load 1 & Non-sensitive True - Sensitive True & 0.66 & 1.285 & 2.88831 & 0.007 \\
\hline & Load 2 & Non-sensitive Fls - Sensitive Fls & -0.09 & 0.734 & -0.72231 & 0.476 \\
\hline & Load 3 & Non-sensitive Inc - Sensitive Inc & -0.47 & 1.047 & -2.53331 & 0.017 \\
\hline & Load 4 & Non-sensitive NA - Sensitive NA & -0.09 & 0.296 & -1.79131 & 0.083 \\
\hline
\end{tabular}

To test H3a-f the data set was split into two groups, the control condition, and cognitive load condition. For each the MRA were repeated. The multiple regression for the control condition showed that the model accounted for a non-significant $34 \%$ of the variability in absolute disclosure $R^{2}=0.34, F(9,22)=1.261, p=0.311$. Despite the predictor variables serving as an unreliable 
predictor of the dependent variable when regressed together, perceived risk on its own demonstrated significant predictive power, supporting $\mathrm{H} 3 \mathrm{c}(\beta=-0.783, p=0.020)$. The multiple regression for the cognitive load condition showed that in combination, the independent variables accounted for a non-significant $32.9 \%$ of the variability in absolute disclosure $R^{2}=0.329, F(9,21)$ $=1.143, p=0.378$. However, no single factor had significant predictive power for absolute disclosure within the cognitive load condition. Thus, H3c was supported alongside H3b, d, and e, which predicted non-significant relationships, although $\mathrm{H} 3 \mathrm{a}$ and $\mathrm{H} 3 \mathrm{f}$ where not supported as NFC and perceived worry did not significantly influence absolute disclosure when expected. The results of the multiple regression analysis for the split data sets are also reported in Table 4.

A series of multiple regression analyses were conducted to better understand the relationship between the quality of information disclosed and the predictor. The multiple regression analyses with the number of false responses as the dependent variable was analysed first, followed by the number of incomplete responses, and combined protective strategies.

A multiple regression analysis was performed to test if the predictor variables significantly predicted participant's levels of false disclosure. The result of the regression was not significant $\left(R^{2}=0.183, F(9,53)=1.322, p=0.248\right)$. Neither were the models significant when the data-set was split between the control condition $\left(R^{2}=0.447, F(9,22)=1.977, p=0.093\right)$ and the cognitive load condition $\left(R^{2}=0.321, F(9,21)=1.101, p=0.403\right)$. Thus H4(f)a, c, and $\mathrm{f}$ were not supported, failing to demonstrate a significant influence on the number of false responses, H4(f)b, d, and e were supported demonstrating a non-significant result. The results of these three regression analyses are reported in Table 5.

A multiple regression analysis was performed to test if the predictor variables significantly predicted participants' levels of incomplete disclosure. The results of the regression indicated that the model explained $32 \%$ of the variance $(F(9,53)=2.727, p=0.011)$. It was found that in combination perceived worry $(\beta=0.426, p=0.020)$, offense sensitivity $(\beta=0.454, p=.001)$, age $(\beta=-0.304, p=0.07)$ and education $(\beta=0.269, p=0.094)$ significantly predicted levels of incomplete disclosure.

The data set was split into two groups, the control condition, and cognitive load condition. The multiple regression analyses were repeated for each. Within the control condition, the results indicated that the model significantly explained $51.4 \%$ of the variance of incomplete disclosure 
$(F(9,22)=2.581, p=0.034)$. Offense sensitivity $(\beta=0.782, p<0.001)$ significantly predicted levels of incomplete disclosure while NFC1 ( $\beta=0.341, p=0.08)$ was not significant. Interestingly, perceived worry was the least predictive in the control condition $(\beta<0.001, p=0.999)$ despite being a significant predictor when analysing the combined data set.

Within the cognitive load condition the results indicated that the model explained a non-significant $30.4 \%$ of the variance of incomplete disclosure $\left(R^{2}=0.304, F(9,21)=1.020, p=0.456\right)$. Despite the predictor variables serving as an unreliable predictor of the dependent variable when regressed together, perceived worry on its own was trending towards significance. Given the small sample size and prior hypothesis it was deemed necessary to consider this result ( $\beta=0.627, p=0.059$ ). As such, $\mathrm{H} 4 \mathrm{f}(\mathrm{i})$ was partially supported, demonstrating an overall impact on incomplete responses and nearing significance within the cognitive load condition. H4(i)a and c were not supported as perceived risk and NFC demonstrated no impact on incomplete responses within the control condition, however H4(i)b and d were supported as perceived risk and NFC demonstrated a nonsignificant impact on incomplete responses within the cognitive load condition. Additionally, H4(i)e was supported as perceived worry demonstrated a non-significant impact on incomplete responses within the control condition. The results of these three regression analyses are reported in Table 6. 
Table 4: Regression model with absolute disclosure as dependent variable

\begin{tabular}{lrrrrrr}
\hline \hline & Regression model with absolute disclosure as dependent variable & & & \\
Variable & B & S.E. & $\boldsymbol{\beta}$ & t-value & $\boldsymbol{p}$ & VIF \\
\hline (Constant) & 26.395 & 1.035 & & 25.512 & $<0.001$ & \\
Age & 0.293 & 0.142 & 0.369 & 2.070 & 0.043 & 2.086 \\
Gender & -0.030 & 0.214 & -0.021 & -0.140 & 0.889 & 1.398 \\
Education & -0.161 & 0.101 & -0.274 & -1.596 & 0.116 & 1.932 \\
Perceived risk & -0.235 & 0.120 & -0.356 & -1.967 & 0.054 & 2.144 \\
Perceived worry & -0.034 & 0.105 & -0.061 & -0.319 & 0.751 & 2.429 \\
NFC1 & 0.218 & 0.113 & 0.292 & 1.924 & 0.060 & 1.512 \\
NFC2 & -0.142 & 0.120 & -0.184 & -1.185 & 0.241 & 1.574 \\
Offense sensitivity & -0.062 & 0.105 & -0.085 & -0.595 & 0.554 & 1.349 \\
Sensory sensitivity & 0.037 & 0.080 & 0.066 & 0.460 & 0.647 & 1.328 \\
$\mathrm{n}=63 ; R 2=0.19 ; F(9,53)=1.388, p=0.217$ & & & & & & \\
\hline \hline
\end{tabular}

$\mathrm{n}=63 ; R 2=0.19 ; F(9,53)=1.388, p=0.217$

\begin{tabular}{lrrrrrr}
\hline \hline \multicolumn{1}{c}{ Regression model with absolute disclosure as dependent variable: Control condition } \\
Variable & B & S.E. & $\boldsymbol{\beta}$ & t-value & $\boldsymbol{P}$ & VIF \\
\hline (Constant) & 26.834 & 2.199 & & 12.201 & $<0.001$ & \\
Age & 0.457 & 0.259 & 0.447 & 1.766 & 0.091 & 2.135 \\
Gender & 0.156 & 0.373 & 0.084 & 0.419 & 0.679 & 1.344 \\
Education & -0.342 & 0.187 & -0.465 & -1.829 & 0.081 & 2.156 \\
Perceived risk & -0.623 & 0.250 & -0.783 & -2.497 & 0.020 & 3.283 \\
Perceived worry & 0.280 & 0.293 & 0.314 & 0.958 & 0.348 & 3.591 \\
NFC1 & 0.271 & 0.195 & 0.301 & 1.393 & 0.178 & 1.553 \\
NFC2 & -0.274 & 0.271 & -0.259 & -1.011 & 0.323 & 2.196 \\
Offense sensitivity & -0.110 & 0.198 & -0.119 & -0.555 & 0.584 & 1.531 \\
Sensory sensitivity & 0.036 & 0.166 & 0.046 & 0.217 & 0.831 & 1.525 \\
$\mathrm{n}=32 ; R 2=0.34 ; F(9,22)=1.261, p=0.311$ & & & & & & \\
\hline \hline
\end{tabular}

Regression model with absolute disclosure as dependent variable: Cognitive load condition

\begin{tabular}{lrrrrrr} 
Variable & $\boldsymbol{B}$ & S.E. & $\boldsymbol{\beta}$ & t-value & $\boldsymbol{p}$ & VIF \\
\hline (Constant) & 25.605 & 0.572 & & 44.779 & $<0.001$ & \\
Age & -0.004 & 0.088 & -0.014 & -0.047 & 0.963 & 2.687 \\
Gender & 0.226 & 0.155 & 0.357 & 1.455 & 0.161 & 1.886 \\
Education & 0.028 & 0.060 & 0.121 & 0.468 & 0.644 & 2.091 \\
Perceived risk & -0.066 & 0.072 & -0.243 & -0.924 & 0.366 & 2.158 \\
Perceived worry & -0.025 & 0.055 & -0.142 & -0.461 & 0.650 & 2.987 \\
NFC1 & 0.064 & 0.075 & 0.205 & 0.844 & 0.408 & 1.845 \\
NFC2 & -0.017 & 0.064 & -0.060 & -0.260 & 0.798 & 1.689 \\
Offense sensitivity & 0.110 & 0.074 & 0.378 & 1.473 & 0.156 & 2.059 \\
Sensory sensitivity & -0.042 & 0.046 & -0.210 & -0.918 & 0.369 & 1.642
\end{tabular}


Table 5: Regression with number of false responses as dependent variable

\begin{tabular}{lrrrrrr}
\hline \hline & Regression model with number of false responses as dependent variable & & \\
Variable & B & S.E. & $\boldsymbol{B}$ & t-value & $\boldsymbol{p}$ & VIF \\
\hline (Constant) & 4.999 & 2.488 & & 2.009 & 0.050 & \\
Age & 0.238 & 0.340 & 0.125 & 0.698 & 0.488 & 2.086 \\
Gender & -0.597 & 0.514 & -0.170 & -1.162 & 0.251 & 1.398 \\
Education & -0.070 & 0.243 & -0.050 & -0.289 & 0.774 & 1.932 \\
Perceived risk & 0.132 & 0.288 & 0.084 & 0.460 & 0.648 & 2.144 \\
Perceived worry & 0.100 & 0.253 & 0.077 & 0.396 & 0.694 & 2.429 \\
NFC1 & -0.289 & 0.273 & -0.161 & -1.057 & 0.295 & 1.512 \\
NFC2 & -0.085 & 0.288 & -0.046 & -0.295 & 0.769 & 1.574 \\
Offense sensitivity & -0.650 & 0.252 & -0.372 & -2.582 & 0.013 & 1.349 \\
Sensory sensitivity & -0.181 & 0.193 & -0.134 & -0.936 & 0.354 & 1.328 \\
$n=63 ; R 2=0.183 ; F(9,53)=1.322, p=0.248$ & & & & & & \\
\hline \hline
\end{tabular}

Regression model with number of false responses as dependent variable: Control condition

\begin{tabular}{lrrrrrr} 
Variable & B & S.E. & $\boldsymbol{\beta}$ & t-value & $\boldsymbol{p}$ & VIF \\
\hline (Constant) & 1.492 & 3.492 & & 0.427 & 0.673 & \\
Age & 0.499 & 0.411 & 0.281 & 1.215 & 0.237 & 2.135 \\
Gender & -1.550 & 0.593 & -0.481 & -2.616 & 0.016 & 1.344 \\
Education & -0.477 & 0.297 & -0.374 & -1.608 & 0.122 & 2.156 \\
Perceived risk & 0.385 & 0.396 & 0.279 & 0.971 & 0.342 & 3.283 \\
Perceived worry & -0.075 & 0.465 & -0.049 & -0.162 & 0.873 & 3.591 \\
NFC1 & -0.136 & 0.309 & -0.087 & -0.441 & 0.664 & 1.553 \\
NFC2 & 0.461 & 0.430 & 0.252 & 1.073 & 0.295 & 2.196 \\
Offense sensitivity & -0.266 & 0.315 & -0.166 & -0.844 & 0.407 & 1.531 \\
Sensory sensitivity & -0.040 & 0.264 & -0.030 & -0.153 & 0.880 & 1.525 \\
$n=32 ; R 2=0.447 ; F(9,22)=1.977, p=0.093$ & & & & & & \\
\hline \hline
\end{tabular}

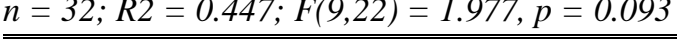

\begin{tabular}{lrrrrrr}
\hline \multicolumn{7}{c}{ Regression model with number of false responses as dependent variable: Cognitive load } \\
Variable & B & S.E. & $\boldsymbol{\beta}$ & t-value & $\boldsymbol{p}$ & VIF \\
\hline (Constant) & 4.611 & 3.842 & & 1.2 & 0.243 & \\
Age & 0.093 & 0.592 & 0.046 & 0.158 & 0.876 & 2.687 \\
Gender & 0.666 & 1.043 & 0.158 & 0.638 & 0.530 & 1.886 \\
Education & 0.288 & 0.400 & 0.187 & 0.718 & 0.480 & 2.091 \\
Perceived risk & -0.024 & 0.481 & -0.013 & -0.050 & 0.961 & 2.158 \\
Perceived worry & -0.035 & 0.370 & -0.029 & -0.093 & 0.927 & 2.987 \\
NFC1 & -0.310 & 0.507 & -0.150 & -0.612 & 0.547 & 1.845 \\
NFC2 & -0.136 & 0.433 & -0.073 & -0.314 & 0.757 & 1.689 \\
Offense sensitivity & -0.847 & 0.500 & -0.437 & -1.694 & 0.105 & 2.059 \\
Sensory sensitivity & -0.103 & 0.310 & -0.077 & -0.332 & 0.743 & 1.642
\end{tabular}


Table 6: Regression model with number of incomplete responses as dependent variable

\begin{tabular}{lrrrrrr}
\hline \hline & Regression model with number of incomplete responses as dependent variable & & \\
Variable & B & S.E. & $\boldsymbol{\beta}$ & t-value & $\boldsymbol{p}$ & VIF \\
\hline (Constant) & -4.857 & 2.052 & & -2.367 & 0.022 & \\
Age & -0.520 & 0.281 & -0.304 & -1.853 & 0.070 & 2.086 \\
Gender & 0.102 & 0.424 & 0.032 & 0.241 & 0.810 & 1.398 \\
Education & 0.342 & 0.200 & 0.269 & 1.707 & 0.094 & 1.932 \\
Perceived risk & -0.063 & 0.237 & -0.044 & -0.264 & 0.793 & 2.144 \\
Perceived worry & 0.502 & 0.209 & 0.426 & 2.409 & 0.020 & 2.429 \\
NFC1 & 0.273 & 0.225 & 0.169 & 1.211 & 0.231 & 1.512 \\
NFC2 & 0.209 & 0.237 & 0.125 & 0.880 & 0.383 & 1.574 \\
Offense sensitivity & 0.715 & 0.208 & 0.454 & 3.444 & 0.001 & 1.349 \\
Sensory sensitivity & -0.130 & 0.159 & -0.107 & -0.818 & 0.417 & 1.328 \\
$n=63 ; R 2=0.316 ; F(9,53)=2.727, p=0.011$ & & & & & & \\
\hline \hline
\end{tabular}

$n=63 ; R 2=0.316 ; F(9,53)=2.727, p=0.011$

Regression model with number of incomplete responses as dependent variable: Control condition

\begin{tabular}{|c|c|c|c|c|c|c|}
\hline Variable & B & S.E. & $\beta$ & t-value & $p$ & VIF \\
\hline (Constant) & -11.141 & 3.378 & & -3.298 & 0.003 & \\
\hline Age & -0.159 & 0.397 & -0.087 & -0.401 & 0.693 & 2.135 \\
\hline Gender & 0.404 & 0.573 & 0.121 & 0.705 & 0.488 & 1.344 \\
\hline Education & 0.234 & 0.287 & 0.178 & 0.816 & 0.423 & 2.156 \\
\hline Perceived risk & 0.243 & 0.383 & 0.171 & 0.633 & 0.533 & 3.283 \\
\hline Perceived worry & -0.001 & 0.449 & $<0.001$ & -0.001 & 0.999 & 3.591 \\
\hline NFC1 & 0.550 & 0.299 & 0.341 & 1.838 & 0.080 & 1.553 \\
\hline NFC2 & 0.627 & 0.416 & 0.332 & 1.508 & 0.146 & 2.196 \\
\hline Offense sensitivity & 1.295 & 0.305 & 0.782 & 4.253 & $<0.001$ & 1.531 \\
\hline Sensory sensitivity & 0.063 & 0.256 & 0.045 & 0.245 & 0.809 & 1.525 \\
\hline
\end{tabular}

Regression model with number of incomplete responses as dependent variable: Cognitive load

\begin{tabular}{lrrrrrr} 
Variable & $\mathbf{B}$ & $\mathbf{S . E}$ & $\boldsymbol{\beta}$ & t-value & $\boldsymbol{p}$ & VIF \\
\hline Age & -0.603 & 0.469 & -0.384 & -1.286 & 0.212 & 2.687 \\
Gender & -0.593 & 0.826 & -0.180 & -0.718 & 0.481 & 1.886 \\
Education & 0.377 & 0.317 & 0.313 & 1.187 & 0.248 & 2.091 \\
Perceived risk & -0.158 & 0.381 & -0.111 & -0.415 & 0.682 & 2.158 \\
Perceived worry & 0.584 & 0.293 & 0.627 & 1.993 & 0.059 & 2.987 \\
NFC1 & 0.038 & 0.401 & 0.023 & 0.094 & 0.926 & 1.845 \\
NFC2 & 0.150 & 0.343 & 0.104 & 0.438 & 0.666 & 1.689 \\
Offense sensitivity & 0.251 & 0.396 & 0.165 & 0.633 & 0.533 & 2.059 \\
Sensory sensitivity & -0.175 & 0.246 & -0.166 & -0.711 & 0.485 & 1.642
\end{tabular}

$n=31 ; R 2=0.304 ; F(9,21)=1.102, p=0.456$ 
Table 7: Regression model with combined protective strategies as dependant variable

\begin{tabular}{lrrrrrr}
\hline \hline & Regression model with combined protective strategies as dependant variable \\
Variable & B & S.E. & $\boldsymbol{\beta}$ & t-value & $\boldsymbol{p}$ & VIF \\
\hline (Constant) & -0.253 & 3.267 & & -0.077 & 0.939 & \\
Age & -0.575 & 0.447 & -0.227 & -1.287 & 0.204 & 2.086 \\
Gender & -0.465 & 0.675 & -0.099 & -0.689 & 0.494 & 1.398 \\
Education & 0.433 & 0.319 & 0.231 & 1.358 & 0.180 & 1.932 \\
Perceived risk & 0.305 & 0.378 & 0.144 & 0.807 & 0.423 & 2.144 \\
Perceived worry & 0.636 & 0.332 & 0.365 & 1.916 & 0.061 & 2.429 \\
NFC1 & -0.234 & 0.358 & -0.098 & -0.653 & 0.516 & 1.512 \\
NFC2 & 0.266 & 0.377 & 0.108 & 0.704 & 0.485 & 1.574 \\
Offense sensitivity & 0.127 & 0.331 & 0.055 & 0.385 & 0.701 & 1.349 \\
Sensory sensitivity & -0.348 & 0.254 & -0.193 & -1.372 & 0.176 & 1.328 \\
$n=63 ; R 2=0.209 ; F(9,53)=1.558, p=0.152$ & & & & & & \\
\hline \hline
\end{tabular}

\begin{tabular}{lrrrrrr}
\hline \multicolumn{1}{c}{ Regression model with combined protective strategies as dependant variable: Control condition } \\
Variable & B & S.E. & $\boldsymbol{\beta}$ & t-value & $\boldsymbol{p}$ & VIF \\
\hline (Constant) & -10.483 & 4.763 & & -2.201 & 0.039 & \\
Age & -0.117 & 0.560 & -0.046 & -0.209 & 0.837 & 2.135 \\
Gender & -1.302 & 0.808 & -0.281 & -1.611 & 0.121 & 1.344 \\
Education & 0.099 & 0.405 & 0.054 & 0.244 & 0.809 & 2.156 \\
Perceived risk & 1.251 & 0.541 & 0.631 & 2.314 & 0.030 & 3.283 \\
Perceived worry & -0.356 & 0.634 & -0.160 & -0.562 & 0.580 & 3.591 \\
NFC1 & 0.142 & 0.422 & 0.063 & 0.337 & 0.739 & 1.553 \\
NFC2 & 1.363 & 0.587 & 0.518 & 2.323 & 0.030 & 2.196 \\
Offense sensitivity & 1.140 & 0.429 & 0.494 & 2.653 & 0.015 & 1.531 \\
Sensory sensitivity & -0.014 & 0.360 & -0.007 & -0.038 & 0.970 & 1.525 \\
$n=32 ; R 2=0.502 ; F(9,22)=2.463, p=0.041$ & & & & & & \\
\hline \hline
\end{tabular}

$\underline{\underline{n-32 ; R 2}=0.502, F(9,22)=2.463, p=0.041}$

Regression model with combined protective strategies as dependant variable: Cognitive load

\begin{tabular}{lrrrrrr} 
Variable & $\mathbf{B}$ & S.E. & $\boldsymbol{\beta}$ & t-value & $\boldsymbol{p}$ & VIF \\
\hline (Constant) & 4.375 & 4.772 & & 0.917 & 0.37 & \\
Age & -0.506 & 0.736 & -0.203 & -0.688 & 0.499 & 2.687 \\
Gender & -0.153 & 1.296 & -0.029 & -0.118 & 0.907 & 1.886 \\
Education & 0.636 & 0.497 & 0.333 & 1.279 & 0.215 & 2.091 \\
Perceived risk & -0.116 & 0.597 & -0.051 & -0.194 & 0.848 & 2.158 \\
Perceived worry & 0.575 & 0.460 & 0.389 & 1.251 & 0.225 & 2.987 \\
NFC1 & -0.336 & 0.629 & -0.131 & -0.534 & 0.599 & 1.845 \\
NFC2 & 0.031 & 0.537 & 0.013 & 0.058 & 0.955 & 1.689 \\
Offense sensitivity & -0.706 & 0.621 & -0.293 & -1.137 & 0.269 & 2.059 \\
Sensory sensitivity & -0.235 & 0.386 & -0.141 & -0.611 & 0.548 & 1.642
\end{tabular}

$n=31 ; R 2=0.32 ; F(9,21)=1.1, p=0.404$

A multiple regression analysis was performed to test if the predictor variables significantly predicted participants' total response quality (combined number of false, incomplete, and non- 
attempted responses). The result of the MRA were not significant $R^{2}=0.209, F(9,53)=1.558, p$ $=0.152$. Within the control condition the results indicated that the model significantly explained $50.2 \%$ of variance $(F(9,22)=2.463, p=0.041)$. It was found that perceived risk $(\beta=0.631, p=$ $0.03)$, NFC2 $(\beta=0.518, p=0.030)$, and sensory sensitivity $(\beta=0.429, p=0.015)$ significantly predicted combined levels of false, incomplete and non-attempted responses, supporting H4(cps)a, and c. Within the cognitive control condition the results indicated that the model explained a nonsignificant $32 \%$ of variance $F(9,21)=1.100, p=0.404$. Thus $H 4($ cps)f was not supported as perceived worry did not predict combined protective strategies within the cognitive load condition, however, H4(cps)b, d, and e were supported demonstrating a non-significant impact on combined protective strategies. The results of these three regression analyses are reported in Table 7.

Finally, a series of three multiple regression analyses were conducted to better understand the relationship between the time taken to complete the company questionnaire (time taken) and the predictor variables. An MRA was performed to test if the individual variables significantly predicted participants' time taken. The results of the regression indicated that the model significantly explained $29.2 \%$ of the variance $F(9,53)=2.429, p=0.022$. It was found that NFC1 $(\beta=-0.361, p=0.0140)$, and NFC2 $(\beta=0.552, p<0.001)$, significantly predicted participants' total company questionnaire response time. Within the control condition the results indicated that the model explained a non-significant $32.9 \%$ of variance $(F(9,22)=1.196, p=0.346)$. Despite the overall model serving as a non-significant predictor of the time taken, $\mathrm{NFC} 2(\beta=0.657, p=0.019)$ and sensory sensitivity $(\beta=0.535, p=0.021)$ on their own were significant predictors, supporting H5a. Within the cognitive load condition the model neared significance to explain $49 \%$ of the variance in time taken $(F(9,21)=2.238, p=0.062)$. Nonetheless, despite the overall model only nearing significance, NFC1 $(\beta=-0.623, p=0.008)$ and NFC2 $(\beta=0.674, p=0.003)$ on their own were significant predictors of time taken. Thus, $\mathrm{H} 5 \mathrm{~b}, \mathrm{c}$, and $\mathrm{f}$ were not supported, failing to demonstrate the expected impact on time taken, however, H5d and e were supported demonstrating a non-significant impact on time taken. The results of these three regression analyses are reported in Table 8.

A complete summary of the hypotheses and their level of support is given in Table 9. 
Table 8: Regression model with time taken as dependant variable

\begin{tabular}{|c|c|c|c|c|c|c|}
\hline \multicolumn{7}{|c|}{ Regression model with time taken as dependant variable } \\
\hline Variable & B & S.E. & $\boldsymbol{\beta}$ & t-value & $p$ & VIF \\
\hline (Constant) & -7.326 & 137.257 & & -0.053 & 0.958 & \\
\hline Age & 4.346 & 18.778 & 0.039 & 0.231 & 0.818 & 2.086 \\
\hline Gender & 35.529 & 28.367 & 0.171 & 1.252 & 0.216 & 1.398 \\
\hline Education & 4.629 & 13.397 & 0.056 & 0.346 & 0.731 & 1.932 \\
\hline Perceived risk & 19.849 & 15.868 & 0.212 & 1.251 & 0.216 & 2.144 \\
\hline Perceived worry & -22.879 & 13.954 & -0.295 & -1.640 & 0.107 & 2.429 \\
\hline NFC1 & -38.275 & 15.057 & -0.361 & -2.542 & 0.014 & 1.512 \\
\hline $\mathrm{NFC} 2$ & 60.340 & 15.862 & 0.552 & 3.804 & $<0.001$ & 1.574 \\
\hline Offense sensitivity & 9.274 & 13.887 & 0.090 & 0.668 & 0.507 & 1.349 \\
\hline Sensory sensitivity & 19.780 & 10.665 & 0.247 & 1.855 & 0.069 & 1.328 \\
\hline$n=63 ; R 2=.292 ;$ & & & & & & \\
\hline
\end{tabular}

$n=63 ; R 2=.292 ; F(9,53)=2.429, p=.022$

\section{Regression model with time taken as dependant variable}

\begin{tabular}{lrrrrrr} 
Variable & B & S.E. & $\boldsymbol{\beta}$ & t-value & $\boldsymbol{p}$ & VIF \\
\hline (Constant) & -51.204 & 194.58 & & -0.263 & 0.795 & \\
Age & -2.839 & 22.895 & -0.032 & -0.124 & 0.902 & 2.135 \\
Gender & 28.150 & 33.019 & 0.173 & 0.853 & 0.403 & 1.344 \\
Education & -6.172 & 16.540 & -0.096 & -0.373 & 0.713 & 2.156 \\
Perceived risk & 25.879 & 22.086 & 0.371 & 1.172 & 0.254 & 3.283 \\
Perceived worry & -36.462 & 25.885 & -0.466 & -1.409 & 0.173 & 3.591 \\
NFC1 & -17.177 & 17.226 & -0.217 & -0.997 & 0.330 & 1.553 \\
NFC2 & 60.847 & 23.960 & 0.657 & 2.540 & 0.019 & 2.196 \\
Offense sensitivity & -0.857 & 17.545 & -0.011 & -0.049 & 0.961 & 1.531 \\
Sensory sensitivity & 36.491 & 14.726 & 0.535 & 2.478 & 0.021 & 1.525 \\
$n=32 ; R 2=.329 ; F(9,22)=1.196, p=.346$ & & & & & & \\
\hline \hline
\end{tabular}

$\underline{\underline{n=32, R 2}=.329, F(9,22)=1.196, p=.346}$

Regression model with time taken as dependant variable

\begin{tabular}{lrrrrrr} 
Variable & B & S.E. & $\boldsymbol{\beta}$ & t-value & $\boldsymbol{p}$ & VIF \\
\hline (Constant) & -31.232 & 218.207 & & -0.143 & 0.888 & \\
Age & -2.308 & 33.644 & -0.018 & -0.069 & 0.946 & 2.687 \\
Gender & 90.811 & 59.249 & 0.328 & 1.533 & 0.140 & 1.886 \\
Education & 17.155 & 22.744 & 0.170 & 0.754 & 0.459 & 2.091 \\
Perceived risk & 0.388 & 27.318 & 0.003 & 0.014 & 0.989 & 2.158 \\
Perceived worry & 0.220 & 21.017 & 0.003 & 0.010 & 0.992 & 2.987 \\
NFC1 & -84.679 & 28.772 & -0.623 & -2.943 & 0.008 & 1.845 \\
NFC2 & 81.783 & 24.573 & 0.674 & 3.328 & 0.003 & 1.689 \\
Offense sensitivity & 39.716 & 28.387 & 0.313 & 1.399 & 0.176 & 2.059 \\
Sensory sensitivity & 10.301 & 17.632 & 0.117 & 0.584 & 0.565 & 1.642
\end{tabular}




\section{Table 9: Hypotheses summary}

\begin{tabular}{l} 
Hypothesis \\
\hline H1a: Participants in the cognitive load group will answer significantly more questions than
\end{tabular} participants in the control group.

H1b: Participants in the cognitive load group will provide significantly less false, incomplete, and combined protective strategy responses than participants in the control group.

H1c: Participants in the cognitive load group will take significantly longer to respond to questions than participants in the control group.

H2a: Participants in the control group will answer significantly fewer sensitive questions than non-sensitive questions.

H2b: Participants in the cognitive load group will not significantly differ in their disclosure between sensitive and non-sensitive questions.

H2c: Participants in the control group will provide significantly more false, and incomplete responses to sensitive questions than non-sensitive questions:

$\mathrm{H} 2 \mathrm{c}(\mathrm{f})$ Number of false responses

H2c(i) Number of incomplete responses

H2d: Participants in the cognitive load group will not significantly differ in the number of false, and incomplete responses provided between sensitive and non-sensitive questions.

$\mathrm{H} 2 \mathrm{~d}(\mathrm{f})$ Number of false responses

H2d(i) Number of incomplete responses

H3a: In the control group participants need for cognition will have a significant negative relationship with absolute disclosure

H3b: In the cognitive load group participants need for cognition will not have a significant relationship with absolute disclosure

H3c: In the control group participants perceived risk will have a significant negative relationship with absolute disclosure.

H3d: In the cognitive load group participants perceived risk will not have a significant relationship with absolute disclosure.

H3e: In the control group participants perceived worry will not have a significant relationship with absolute disclosure.

H3f: In the cognitive load group participants perceived worry will have a significant negative relationship with absolute disclosure.

H4a: In the control group participants need for cognition will have a significant positive relationship with the number of false, incomplete, and t combined protective strategy responses provided.

$\mathrm{H} 4 \mathrm{a}(\mathrm{f})$ Number of false responses

$\mathrm{H} 4 \mathrm{a}$ (i) Number of incomplete responses

$\mathrm{H} 4 \mathrm{a}$ (cps) Number of combined protective strategy responses

H4b: In the cognitive load group participants need for cognition will not have a significant relationship with the number of false, incomplete, and combined protective strategy responses provided.

$\mathrm{H} 4 \mathrm{~b}$ (f) Number of false responses

$\mathrm{H} 4 \mathrm{~b}$ (i) Number of incomplete responses
Support

Supported

Not supported

Partial support

Supported

Supported

Partial support

Supported

Supported

Not supported

Not supported

Supported

Supported

Supported

Supported

Not supported

Not Supported

Not Supported

Supported

Supported

Supported 
H4c: In the control group participants perceived risk will have a significant positive relationship with the number of false, incomplete, and combined protective strategy responses provided.

$\mathrm{H} 4 \mathrm{c}(\mathrm{f})$ Number of false responses

Not Supported

$\mathrm{H} 4 \mathrm{c}(\mathrm{i})$ Number of incomplete responses

Not Supported

$\mathrm{H} 4 \mathrm{c}$ (cps) Number of combined protective strategy responses

Supported

H4d: In the cognitive load group participants perceived risk will not have a significant relationship with the number of false, incomplete, and combined protective strategy responses provided.

H4d(f) Number of false responses

Supported

H4d(i) Number of incomplete responses

Supported

H4d(cps) Number of combined protective strategy responses

Supported

H4e: In the control group participants perceived worry will not have a significant relationship with the number of false, incomplete, and combined protective strategy responses provided.

$\mathrm{H} 4 \mathrm{e}(\mathrm{f})$ Number of false responses

$\mathrm{H} 4 \mathrm{e}(\mathrm{i})$ Number of incomplete responses

Supported

$\mathrm{H} 4 \mathrm{e}$ (cps) Number of combined protective strategy responses

Supported

Supported

H4f: In the cognitive load group participants perceived worry will have a significant positive relationship with the number of false, incomplete, and combined protective strategy responses provided.

H4f(f) Number of false responses

Not Supported

H4f(i) Number of incomplete responses

H4f(cps) Number of combined protective strategy responses

Partial Support

Not Supported

H5a: In the control group participants need for cognition will have a significant positive relationship with the time taken to complete the questionnaire.

Supported

H5b: In the cognitive load group participants need for cognition will not have a significant relationship with the time taken to complete the questionnaire.

H5c: In the control group participants perceived risk will have a significant positive relationship with the time taken to complete the questionnaire.

H5d: In the cognitive load group participants perceived risk will not have a significant relationship with the time taken to complete the questionnaire.

H5e: In the control group participants perceived worry will not have a significant relationship with the time taken to complete the questionnaire.

H5f: In the cognitive load group participants perceived worry will have a significant positive relationship with the time taken to complete the questionnaire.

Supported

Not Supported

Supported

Supported

Not Supported 


\section{Discussion}

The primary objective of the study, to better understand the impact of cognitive load on consumers' propensity to disclose personal information was satisfied. The results demonstrated that individuals under cognitive load were more likely to disclose personal information than individuals in the control condition. In other words, participants who were not required to remember a seven-digit number were more likely to avoid responding to a sensitive question entirely. This result supports the collection of literature which found cognitive load inhibits self-regulation, in other words high cognitive load impairs an individuals' ability to monitor their behaviour and align this with their goals (Argo \& White, 2012; Drolet \& Frances Luce, 2004; Shiv \& Fedorikhin, 1999; Shu \& Carlson, 2014). The finding also fits the persuasion knowledge model, as participants under cognitive load demonstrated a diminished ability to employ the defensive strategy of non-disclosure to protect their personal privacy. This matches the findings of Evans and Hoy (2016), which showed how cognitive load impairs an adult's ability to access persuasion knowledge whilst playing an advergame. Alongside the primary objective, most secondary objectives were also satisfied, reinforcing aspects of the conceptual framework, and revealing notable nuances underpinning the phenomena.

Secondary objective number one; to better understand how cognitive load impacts the disclosure of sensitive and non-sensitive information, was satisfied. As expected, the impact of cognitive load on participants' absolute disclosure interacted with the sensitivity level of the personal information being requested. The difference in absolute disclosure levels between individuals within the cognitive load and control condition was only found for responses to sensitive questions. In fact, none of the participants in either condition abstained from responding to a non-sensitive question. Several previous papers have each discussed the impact of information sensitivity on self-disclosure patterns, thus this replication was anticipated (Horne \& Horne, 1998; Mothersbaugh et al., 2012; Phelps et al., 2000; White, 2004). Moreover, this difference only occurred whilst participants were in control of their cognitive faculties, participants in the cognitive load condition responded to sensitive and non-sensitive questions in equal measure.

Interestingly, cognitive load did not influence the quality of information that participants disclosed. There was no difference between the numbers of false responses participants gave to questions whilst within the cognitive load or control conditions. The same null result was 
found for the number of incomplete responses. This result does not support the conceptual framework which proposes that the quality of information disclosed will be greater under cognitive load due to less privacy protection strategies being employed. Although, the hypothesis did suggest that the effect would be partly mitigated as individuals experience a general impairment of writing skill and recollection when they are distracted (Rosen, Carrier, \& Cheever, 2013). Unfortunately, the study could not distinguish whether participants' false or incomplete responses were due to a deliberate choice to withhold the truth, or whether they occurred from an inability of the participant to tell the truth, for example the inability to properly recall their address in the moment. Nonetheless, the third secondary objective which sought to evaluate the effectiveness of using the quality of information construct was not satisfactorily achieved. The results did not demonstrate a significant difference between the quality of information provided between the cognitive load and control conditions, however the influence of predictor variables: need for cognition, perceived risk, and perceived worry, regressed upon quality of information, was demonstrated to be moderated by the presence of cognitive load.

Secondary objective number two which aimed to better understand which factors influence a consumer's propensity to disclose personal information, and to observe whether these factors are moderated by the presence of cognitive load, was comprehensively explored. Whilst several hypotheses were not supported, the general trend of hypothesized results was demonstrated. The results attributable to this objective will now be discussed.

The hypothesis that greater need for cognition (NFC) would result in less absolute disclosure was not supported. The NFC construct was split into two distinct constructs: NFC1 and NFC2. The items constructing NFC1 represent a weak NFC measuring an individuals' appreciation for cognition without necessarily applying it. NFC2 however, has items that more accurately measure an individuals' need for applied cognition. NFC1 was a poor predictor of both absolute disclosure and quality of disclosure, however NFC2 demonstrated a positive relationship with combined numbers of false, incomplete, and not attempted responses within the control condition. The relationship was not exhibited for those within the cognitive load condition, as expected. This demonstrates that greater NFC only increases an individuals' privacy protection strategies when they were not under cognitive load.

It was expected that an individual under cognitive load with a greater NFC would not be able to enlist privacy protection strategies. Despite the resource model of working memory 
accommodating task switching (Fukuda, Awh, \& Vogel, 2010), this process likely requires some spare resources to do so. Moreover task-switching may have been underutilized within the current experiment. Participants may have been more motivated to finish the questionnaire or remember their number and thus prefer not to risk freeing up cognitive space to contemplate the potential risks of their responses further. As such the results match the current conceptualization that working memory is limited in capacity (Cowan, 2001). Moreover, the results support Drolet et al. (2008) which found load impaired high NFC individuals' ability to choose based on their self-goals rather than a compromise option. Additionally, the result that NFC2 positively predicts participants' combined privacy protection strategies is supported by Haugtvedt et al. (1992), which demonstrated that participants high in NFC were more likely to follow the central route to attitude formation.

Perceived risk demonstrated strong predictive power for absolute disclosure levels within the control condition. Participants with higher levels of perceived risk were less likely to divulge personal information than participants with lower levels of perceived risk. This relationship was only significant for participants within the control condition, an individuals' level of absolute disclosure whilst under cognitive load was not impacted by their perceived risk, suggesting that cognitive load reduces an individuals' ability to perceive risk.

Similarly, perceived risk only demonstrated predictive power for the quality of information provided when participants were not exposed to high cognitive load. Participants in the control condition with high levels of perceived risk were more likely to respond with a combined number of false, incomplete, and not attempted responses. This differential result between perceived risk and its impact on participants in either the cognitive load or control condition matches the relationship outlined in the hypotheses. Perceived risk is more cognitive in nature (Sjöberg, 1998), as such it was expected to have a greater impact on disclosure when participants had greater control of their cognitive faculties. Similarly to NFC2 above, it is likely that participants under cognitive load were not influenced at all by their levels of perceived risk as they had limited cognitive capacity to consider the risks and, additionally, were not motivated to switch tasks to reallocate their cognitive resources.

Contrary to expectations, perceived worry did not predict levels of absolute disclosure in either the control or cognitive load conditions. However, perceived worry demonstrated strong predictive power for the number of incomplete responses provided, participants with greater perceived worry were more likely to respond incorrectly. Furthermore, perceived 
worry showed a contrary relationship to that of perceived risk. Where perceived risk showed predictive power for absolute and quality of disclosure within the control condition, perceived worry neared significant predictive power for incomplete responses for participants within the cognitive load condition, whilst no predictive power was demonstrated within the control condition.

This result suggests perceived worry is serving a heuristic purpose. Heuristics guide decision making when participants have limited motivation or resources available to enlist more deliberative processing (Tversky \& Kahneman, 1974). Perceived worry may be triggering the affect heuristic which refers to an inverse relationship between perceived risk and the potential benefit or cost, wherein if the activity is perceived as positive then the risks are viewed as low and the benefits high, and vice versa (Alhakami \& Slovic, 1994). Thus, the results suggest that individuals under cognitive load will be influenced by the affect heuristic, whilst individuals in a non-load situation will instead have the cognitive resources available to base their privacy protection strategies upon their more deliberative perceptions of risk.

The second secondary objective was satisfied as the above results demonstrated that perceived risk and NFC influenced aspects of quality of information only whilst participants were in control of their cognitive faculties, moreover perceived worry only influenced aspects of quality of information whilst participants were cognitively impaired. Although each of the outlined relationships were not demonstrated across all the quality of information variables: false, incomplete, and combined protective strategies, the expected pattern of results emerged.

Secondary objective number four which sought to evaluate the effectiveness of using response latency to explore nuances in disclosure patterns was partially satisfied. It was hypothesized that cognitive load would result in longer response latency, this was supported in two instances. Participants in the cognitive load condition took longer to respond to the questions "what is your surname?" and "do you experience mental illness? And if so, how would you describe it?" than those within the control condition. The other 24 questions did not differ in their latencies.

The question "what is your surname?" was presented second, thus participants were likely still formulating their rehearsal strategy, this suggests that once participants have established a rehearsal strategy for remembering the seven-digit number they could provide their responses without taking longer than the control group. This aligns with the proposition of 
Naveh-Benjamin and Jonides (1984) that maintenance rehearsal is a two-stage activity wherein the first stage requires more cognitive effort to process and execute the rehearsal strategy, whilst stage two is more automatic. The longer response time for cognitively loaded participants responding to the question "do you experience mental illness? And if so, how would you describe it?" could be explained as the question is much longer than each of the others, whilst also being double-barrelled, therefore despite participants having an established rehearsal strategy, the length and complexity of the question may have interrupted this process (Service, 1998).

The final hypotheses investigated the impact of NFC, perceived risk, and perceived worry on participants' time taken to respond to the company questionnaire. Neither perceived risk nor perceived worry were shown to predict time taken, however both NFC constructs were strong predictors. Participants with greater NFC2 were more likely to take longer completing the company questionnaire, thus supporting hypothesis H3c. However, NFC1 demonstrated the opposite effect wherein greater NFC1 scores were predictive of less time taken by participants to complete the questionnaire. These relationships were reflected for participants of the cognitive load condition, whilst only NFC2 revealed predictive power within the control condition. NFC2 represents the NFC construct which directs the hypotheses. The positive relationship between NFC2 and the time taken to respond to the company questionnaire therefore supports the conception of Cacioppo and Petty (1982), wherein the 'high need for cognition' individuals show a greater tendency towards the central route of attitude formation, which necessitates more deliberation. The contrasting results of NFC1 were not hypothesized as this construct measures an individuals' appreciation for cognition without necessarily applying it, this construct was not originally intended for measurement within this study. Discussion of this result would be both superfluous and speculative, in the context of this paper it merely represents further nuances of human psychology. The fourth secondary objective was partially satisfied as the results were able to shed some understanding upon the phenomena, although this is scattered and requires further research.

\subsection{Implications}

\subsubsection{Privacy paradox and research}

The results of the present study add greater nuance to the privacy paradox research.

Participants were more likely to disclose personal information when they were in a state of cognitive load. This insight is vital, especially as consumers become increasingly distracted by technology. Furthermore, people are using technology in multitasking situations, a 
common example is using a smartphone or laptop whilst watching television. In this case the consumer is prone to diminished cognitive resources as it is split across two tasks rather than focussed on one. Thus, if the consumer is targeted by a request for personal information in this moment of cognitive impairment, they are likely to disclose more personal information. Whilst the current paper by no means proposes cognitive load as the primary component driving the privacy paradox, it is likely to be a contributing factor in many situations. Consequently, it is expected that cognitive load may exacerbate the impact of other factors such as the routinization of personal information disclosure (Norberg et al., 2007), and negative repercussions of information asymmetries (Kokolakis, 2017), which have been proposed drivers of the discrepancy between actual and intended disclosure patterns. If we presume that the high levels of information disclosure exhibited by participants in the present study in the non-load condition was driven by routinization of disclosure behaviours, then the current findings demonstrate how cognitive load can promote even greater levels of disclosure, thus suggesting that cognitive load serves to exacerbate the privacy paradox discrepancy between disclosure intentions and behaviour.

Cognitive load may also represent a previously unconsidered confound within privacy paradox research. Norberg et al. (2007) used a classroom setting to undertake their experiment, therefore the participants may have been distracted by their classmates, schoolwork, or even their phone or other devices/items on their person. Spiekermann et al. (2001) demonstrated the discrepancy between self-reported privacy concerns and their actual disclosure behaviour by getting participants to navigate an unfamiliar E-commerce website wherein they were asked personal questions. These papers did not consider whether the situations imposed different levels of cognitive impairment upon the participants, nor did they question whether this may have impacted participants' disclosure behaviour. Of particular importance to note in contemporary research, wherein smartphones and other smart devices have become entrenched in our daily lives, may be whether participants had any smart devices accessible during the research process. Ward et al. (2017) has demonstrated that being in the vicinity of ones' own smartphone impairs the cognitive abilities of an individual. Consequently, researchers and marketers must be cognizant of cognitive load, and the factors that may impose it, when investigating discrepancies in consumer's privacy disclosure behaviours. 


\subsubsection{Policymakers and marketing practitioners}

The results provide implications for policymakers and marketing practitioners. The study demonstrates that individuals responding to a company's request for personal information are more likely to divulge information if they are in a state of cognitive load. Thus, companies that require more personal information from consumers, particularly sensitive information, will be able to acquire the information if they are able to request it from consumers when they are in a temporary state of cognitive impairment. For example, a company asking customers to complete a personal information form whilst they are at the checkout in a physical store and surrounded by distracting stimuli.

An obvious moral dilemma arises here. Is it ethical to request personal information from consumers when they are in an impaired cognitive state? It is considered unethical to target vulnerable populations such as individuals with cognitive disabilities and children (Brenkert, 1998). Gentry, Kennedy, Paul, and Hill (1995) even suggest that marketers should abide to a stand down period when targeting temporarily vulnerable populations such as those grieving from the loss of a loved one. As such the call for moral prudence should be maintained. However, cognitive load is a natural, unavoidable condition that can be imposed quickly, the severity of which can range from minimal to severe, and it can then be withdrawn immediately (Maranges et al., 2017). Lacking omnipresence, marketers are therefore unable to completely avoid targeting customers in their moments of cognitive impairment, however marketers do have a modicum of control over their targeting behaviours.

To avoid a comprehensive discussion of moral philosophy, the present paper will only explore this moral dilemma through the lens of agent-centred deontology. This approach evaluates the morality of requesting personal information from an individual under cognitive load, upon the actions and intentions of the marketer (Alexander \& Moore, 2016). If the marketer intended to use the consumers moment of cognitive impairment to induce greater disclosure, then the act would be considered immoral. However, if it was only by chance that the consumer was cognitively impaired in the moment, and the marketer had no purposeful intention of utilizing this, then the act would not be immoral, despite the same outcome occurring. For example, the marketer that designs a convoluted website which is designed to request personal information from consumers whilst they are distracted would be immorally benefiting from the consumers' state of cognitive impairment, whereas the marketer whom through sheer incompetence designed a website which mirrored the other, but otherwise had no intention of imposing cognitive load on their users, would not be an immoral actor. 
Nonetheless, and to assuage the consequentialist reader, policy must be developed to protect consumers against both: companies using malicious techniques to gain unwarranted personal information from consumers, and companies unintentionally benefiting from the temporary cognitive impairment of consumers. Through technology such as geolocation or virtual breathalysers it will become much easier for companies to identify when an individual has impaired cognitive functioning, consequently allowing companies the ability to choose that moment to request personal information from users.

The current research should guide policy to prevent predatory practices. A starting point is the use of risk perception reminders, asking consumers to only disclose information that they want to disclose. This is similar to suggestions that individuals should be told of the persuasive nature of covert advertisements prior to exposure (van Reijmersdal, Lammers, Rozendaal, \& Buijzen, 2015). Proactive software could also be developed for smartphones, identifying when an individual is in a potential situation of temporary cognitive impairment, and subsequently provide privacy protection reminders, or even having the ability to override an individual's responses to company requests for personal information with those inputted at an earlier moment, when the user was in control of their cognitive faculties. Additionally, children and adults alike should be taught about the dangers of disclosing personal information online, and the myriad of techniques that companies may use to retrieve their information. Through an accumulation of knowledge and experience around safe internet use and privacy protection strategies, individuals should be better equipped to recognize and protect themselves against excessive personal information disclosure (Evans \& Park, 2015).

Companies which subscribe to moral marketing practice should utilize risk perception reminders and protective software regardless of whether the above policies are implemented. Taking a proactive approach by revealing how consumers' personal information is collected, stored, and used, will demonstrate transparency, fostering trust amongst consumers. Morey, Forbath, and Schoop (2015) argue that fostering transparency and trust will be vital for data firms moving forward, positing that a less trustworthy company will be hard-pressed to willingly gain sensitive information from customers. Therefore, for companies to establish comprehensive transparency, they will need to evaluate whether their consumers may be asked to disclose personal information in situations where they may have temporarily impaired cognition, and if so, develop tools to help mitigate this danger. 


\subsubsection{Perceived risk and perceived worry under cognitive load}

The current research provides support that perceived risk and perceived worry are distinct constructs and should both be utilized when undertaking research regarding privacy disclosure behaviours. Both constructs demonstrated usefulness in distinct yet complementary ways. Perceived risk influenced participants' disclosure when they were in greater control of their cognitive faculties, whilst perceived worry influenced disclosure when participants were under cognitive load. This differential result suggests perceived risk is an attitude that is accessed and activated through deliberative processing whereas perceived worry is visceral and serves a heuristic purpose, guiding decision making when participants have limited cognitive control (Tversky \& Kahneman, 1974). Because perceived risk did not impact disclosure whilst participants were under cognitive load, nor perceived worry impact disclosure whilst participants were cognitively adept, it would be folly to utilize a combined construct of risk perception incorporating items from both. The perceived risk construct in the current research uses questions which are more objective, not referring to the responder directly, whilst the perceived worry items are more subjective. This distinction between the two constructs steers clear of the ambiguity present from a more general approach. Thus, the current research helps elucidate why previous studies using risk perception as a construct were unable to establish a relationship with actual disclosure. Norberg et al. (2007) for example, measured risk perception using a single item, asking "how risky was it to provide information to the marketer?", the question is neither clearly subjective nor objective. The present research signifies the importance of utilizing both perceived risk and perceived worry as distinct constructs when investigating phenomena with cognitive load as an independent variable. Moreover, it highlights the importance of using a risk perception survey with nonsubjective questions if future researchers aspire to explore the relationship between risk perception and personal information disclosure.

\subsubsection{Absolute disclosure, quality of disclosure, and response latency}

'Absolute disclosure' provided the clearest expression of the phenomenon, however recording the quality of disclosure revealed the diversity of participants' responses. Whilst the present research found mixed support for the hypotheses concerning quality of disclosure, this does not diminish its potential importance as a dependant variable when investigating personal information disclosure. Rather, the confounding results suggest a realm of nuance hidden within the current research which requires further investigation. Nonetheless, the current study demands a reconsideration of the quality of information construct, particularly 
whether the current categorisation of false, incomplete, and not attempted responses is adequate.

Response latency provided limited insights within the current study. There were two pertinent problems with response latency that were evident in the data collected. Firstly, response latency included responses that were not attempted, incomplete, and false. Whilst individuals are expected to take longer perceiving the risk of disclosure to enlist these privacy protection strategies, once the individual reaches this decision, they are able to move onto the next question without investing the time to complete their response fully or at all. Secondly, the data revealed outliers with extreme response times across each of the questions.

Reconfiguring the data by excluding not attempted responses, using standardized $\mathrm{z}$ values, or excluding outliers, also failed to provide any clarity from response latency.

\subsubsection{Broader implications considering the trends of society}

The most poignant implications of the current research hinges on the adoption of several emerging technologies. Current technology is limited in its capacity to comprehensively scan our personal environments and autonomously derive from that a qualitative situational analysis which could subsequently inform software if an individual is likely to be inhibited by cognitive load. Using location-based-mobile-marketing, companies can track consumer locations, for example pinpointing which city you are in, or even whether you are at the supermarket. Companies can use this information for marketing purposes such as targeting a customers' phone with an advertisement for chocolate as they near the supermarket (Bauer \& Strauss, 2016). However, this technology could also be used to assess whether a consumer may temporarily have competing cognitive demands. Locations such as a supermarket, a football stadium, or a nightclub, could signal to a company that a consumer is likely to be distracted and consequently vulnerable to disclosing excess personal information. Locationbased-mobile-marketing would only serve an assisting role due to its inability to know a customers' exact location, their activity, or if they are distracted.

Beacons, on the other hand, provide more accurate location data and are an emerging technology that use low-energy Bluetooth beacons scattered throughout an indoor environment which, complements location-based-mobile-marketing (van de Sanden, Willems, \& Brengman, 2019). Additionally, Uber has recently filed a patent for technology which would be capable of detecting whether users of its app were in an abnormal state, such as being drunk (Mahdawi, 2018). The patent outlines using data such as the users walking 
speed, unusual typos, swaying of the phone, and the angle of the phone, to determine whether users are in an abnormal state. This technology combined with location-based technology, could conceivably be used to identify whether an individual is experiencing varying states of cognitive load.

Smart speakers are also rising in popularity and provide another medium for companies to identify and analyse a consumer's environment and evaluate their cognitive state. Smart speakers are always listening, waiting for a wake word such as "ok Google" or "Alexa" which then sets the device to record and respond to user requests (Nathan et al., 2019). Although these devices do not record or analyse conversations unless a wake word has been spoken, this software could be adjusted to allow the device to assess, through the frequency of conversation or presence of background noise, whether the environment is likely to induce cognitive load.

The adoption of smart glasses poses a threat to consumers' personal privacy. Smart glasses utilize a front-facing camera, recording everything in the user's line-of-sight, whilst also having access to audio in a manner similar to smart speakers (Rauschnabel \& Ro, 2016). Moreover, smart glasses are expected to supplant the smartphone in general use and functionality. Therefore, features such as Bluetooth, geo-location, and wireless networking will also be available (Rauschnabel \& Ro, 2016). This combination of features could theoretically provide a company with the comprehensive data required to assess an individual's environment and determine whether they would be in a state of cognitive load. Policy limiting this potentiality should be developed and upheld. Nonetheless, widespread adoption of smart glasses technology would likely increase individuals multitasking behaviour. Currently we are limited by the need to hold our smartphones whilst we interact with them. A primary advantage of smart glasses is their hands-free nature, potentially allowing you to navigate its software, search the internet, and compose messages with only an array of eye movements and voice recognition technology (Kangas et al., 2016; Syberfeldt, Danielsson, \& Gustavsson, 2017). Thus, individuals could find themselves in a state of near constant cognitive impairment, leaving them exceptionally vulnerable to companies requesting personal information. It is imperative that guidelines are established to protect consumers from malevolent business practices that may arise from these emerging technologies. 


\subsection{Limitations}

\subsubsection{Sample frame}

The sample frame limits the generalizability of the results. The participants were comprised of Generation Y and Z, aged between 18 and 40 years, with the majority representing Generation $\mathrm{Z}$ aged between 18 and 20. This sample was selected due to reported generational differences in multitasking skills (Carrier et al., 2009), and evidence to suggest differences in perceptions of privacy (Livingstone, 2008; Richard \& Ralphs, 2018). Whilst it is likely that the underlying neurological effect of cognitive load impacting an individuals' adherence to goal-related behaviour is similarly experienced across population segments, it is uncertain whether the qualitative conditions present in the current study would generate a replication of the results if undertaken by other generational cohorts. Future research with greater access to resources would benefit from expanding the sample frame to include groups of 30 to 60 participants representing Generation Z, Y, X, and Baby boomers, allowing comparisons to be drawn amongst them.

\subsubsection{Fictitious setting}

The study was not able to present the company survey as real, therefore it is unclear whether participants reported disclosure patterns which would match those from a real scenario. People generally have greater trust in academic institutions compared to companies (Haynes et al., 2008; Lantieri \& Chiagouris, 2009; Thomas, 1998), thus it is likely that participants may have disclosed less personal information if they believed their responses would be reviewed by a company. Nonetheless, the study reflects individuals' patterns of absolute disclosure as they were still unaware of exactly how the information would be used or who would have access to it. Consequently, the potential level of trust within the present study suggests that the impact of cognitive load may be more pronounced in a low trust situation, which would strongly necessitate the harmony of an individual's goals with their actions.

\subsubsection{Self-reported data}

The dependent variables relied upon self-reported data. Participants were shown their responses to each question and asked to indicate whether they responded to each one truthfully, falsely, incompletely, or to indicate whether they did not attempt the question. Unfortunately, the study could not determine whether participants selected the correct response for each question or whether they understood the difference between the four options. Social desirability bias poses a significant threat to the validity of the research. Social desirability bias refers to the tendency of individuals to present themselves in a 
favourable light, often in accordance to societal norms (King \& Bruner, 2000). Additionally, King and Bruner (2000) suggests that socially sensitive topics are most at risk to augmentation by social desirability bias. Because the present study asks a range of sensitive questions participants may have felt influenced to respond in a manner that shone on them most favourably. Participants may have also used the self-report opportunity as a second chance to alter their response from that given earlier. Van de Mortel (2008) suggests administering a social desirability scale whenever self-reporting is necessary, allowing social desirability to be controlled for when analysing the results. Future research utilizing a similar method should follow this advice.

\subsubsection{Demarcating refusal to disclose and inability to recall}

The study was also limited in its ability to demarcate between nonresponses, as either refusals to disclose information, or participants inability to recall the correct response. This limitation also marred the assessment of false and incomplete responses, hindering the ability to conclude that cognitive load inhibits an individual's capacity to align their goals with behaviour.

If participants are not responding to questions because they do not know the information requested, then this does not reflect a privacy protection strategy, but rather incomplete knowledge or interference with retrieval. Shoemaker, Eichholz, and Skewes (2002) provided guidelines to distinguish between "don't know" and "refuse" responses. "Don't know" responses refer to participants inability to formulate or recall a correct response. Shoemaker et al. (2002) suggested that the frequency of "don't know" responses increases with the degree of cognitive effort involved in responding to the question. "Refusals" on the other hand are posited to increase in frequency when the questions sensitivity is greater. The results from the current research however do not clearly align with these guidelines. For example, the number of incomplete responses to sensitive questions in the cognitive load condition compared to responses to non-sensitive questions was much higher than would be expected if the cognitive effort involved was driving the frequency of don't know/incomplete responses.

Future research must develop a means to make the distinction between "don't know" and "refusals" transparent so a more complete picture of cognitive load's impact on personal information disclosure can be painted. Doing so will increase the utility of the construct "quality of information". 


\subsection{Future research}

The current experiment had a relatively small sample size, it is likely this limited the power of the results. Future experiments should aim to double the number of participants and attempt to replicate the results, further examining the relationships that were trending towards significance. Preferably, an adapted replication of the current study would follow a withinsubjects design, utilizing elements of the Norberg et al. (2007) procedure wherein participants at one stage are asked to evaluate the degree to which they would be comfortable disclosing various personal questions to a company, and then, at a later date, given a company questionnaire which asks participants to provide responses to those same questions. Taking a University class of 120 students, the students could complete the initial disclosure intention survey at the start of the trimester, midway through the trimester the class could complete a company questionnaire with students randomly assigned to either the cognitive load or control condition, and finally at the end of the trimester the students complete another company questionnaire wherein they are assigned to the other condition. Key advantages of a within-subject design includes a substantial boost in statistical power, and as participants are allocated to each condition, the internal validity of the study is not dependent upon random assignment (Charness, Gneezy, \& Kuhn, 2012). This experiment would allow a direct comparison to be observed between participants disclosure behaviour whilst under cognitive load compared to when they are in control of their cognitive faculties. Moreover, actual disclosure could also be compared with disclosure intentions, allowing the discrepancy between intentions and actual disclosure whilst under cognitive load or no load to be measured.

Secondly, incorporating a qualitative element to the experiment would allow a better phenomenological understanding of peoples' cognitive processing, surrounding an act of personal information disclosure. Following the participants completion of the company questionnaire it would be beneficial to ask participants to describe their experience. Doing so would provide greater insight into questions such as what goals, if any, participants hold whilst responding to the questionnaire, whether participants recognize the danger of disclosing personal information whilst responding, and it would help elucidate why participants may or may not, for specific questions, withhold information, provide false responses, or leave responses incomplete.

The study should also be replicated across other situations such as a non-controlled environment where participants are surrounded by others and may use their own devices. 
When people are in a social environment they undertake impression management wherein they attempt to control the impressions that others may have of them (Leary \& Kowalski, 1990). Thus, if an individual is disclosing sensitive personal information in the presence of others this may increase the salience of their privacy protection goals. It would be interesting to investigate whether the saliency of privacy protection goals influences the impact of cognitive load upon disclosure such that the disinhibition of accessing privacy goals is negated when they are made salient.

Finally, as mentioned in the limitations section above, future research should expand the sample frame to include Baby boomers and Generations X, alongside Generations Y and Z, so any generational differences can be observed regarding the impact of cognitive load.

\subsection{Conclusion}

The current study investigated the impact of cognitive load on the propensity to disclose personal information. The findings suggest that cognitive load influences levels of disclosure such that individuals under load are more likely to disclose personal information. Results also found the impact of information sensitivity, perceived risk, perceived worry, and need for cognition on absolute disclosure, quality of disclosure, and response latency. Notably, a differential pattern was revealed wherein need for cognition and perceived risk were demonstrated to impact disclosure behaviours whilst participants were in control of their cognitive faculties, whereas perceived worry impacted disclosure behaviour whilst participants were under cognitive load. In closing, the study successfully explored the impact of cognitive load on personal information disclosure and subsequently adds greater nuance to the privacy paradox literature by identifying cognitive load as an exacerbating variable, increasing the discrepancy between privacy intentions and disclosure behaviour. To address the potential harm caused by cognitive load on individuals' privacy behaviours, implications for marketing practitioners and policymakers were provided, alongside avenues for future research. 


\section{References}

Aaker, D. A., \& Keller, K. L. (1990). Consumer evaluations of brand extensions. Journal of Marketing, 54(1), 27-41. doi:10.1177/002224299005400102

Acquisti, A. (2004). Privacy in electronic commerce and the economics of immediate gratification. Paper presented at the Proceedings of the 5th ACM conference on Electronic commerce.

Acquisti, A., Gritzalis, S., Lambrinoudakis, C., \& di Vimercati, S. (2007). Digital privacy: Theory, technologies, and practices. Boca Raton, FL: Auerbach Publications.

Acquisti, A., John, L. K., \& Loewenstein, G. (2012). The impact of relative standards on the propensity to disclose. Journal of Marketing Research, 49(2), 160-174.

Adler, R. F., \& Benbunan-Fich, R. (2012). Juggling on a high wire: Multitasking effects on performance. International Journal of Human-Computer Studies, 70(2), 156-168. doi:https://doi.org/10.1016/j.ijhcs.2011.10.003

Alexander, L., \& Moore, M. (2016). Deontological ethics. In E. N. Zalta (Ed.), The Stanford Encyclopedia of Philosophy (Winter 2016 ed.): Metaphysics Research Lab, Stanford University.

Alhakami, A. S., \& Slovic, P. (1994). A psychological study of the inverse relationship between perceived risk and perceived benefit. Risk Analysis, 14(6), 1085-1096. doi:10.1111/j.1539-6924.1994.tb00080.x

Alreck, P., \& Robert, S. (2004). The survey research handbook (3rd ed.). New York, NY: McGraw-Hill.

Appel, M., Krisch, N., Stein, J.-P., \& Weber, S. (2019). Smartphone zombies! Pedestrians' distracted walking as a function of their fear of missing out. Journal of Environmental Psychology, 63, 130-133. doi:https://doi.org/10.1016/j.jenvp.2019.04.003 
Argo, J. J., \& White, K. (2012). When do consumers eat more? The role of appearance selfesteem and food packaging cues. Journal of Marketing, 76(2), 67-80. Retrieved from http://www.jstor.org.helicon.vuw.ac.nz/stable/41406849

Aron, E. N., \& Aron, A. (1997). Sensory-processing sensitivity and its relation to introversion and emotionality. Journal of Personality and Social Psychology, 73(2), 345.

Asch, S. E. (1955). Opinions and social pressure. Scientific American, 193(5), 31-35. Retrieved from http://www.jstor.org/stable/24943779

Baddeley, A. (1992). Working memory. Science, 255(5044), 556-559. doi:10.1126/science.1736359\%J Science

Baddeley, A. (2000). The episodic buffer: a new component of working memory? Trends in Cognitive Sciences, 4(11), 417-423. doi:https://doi.org/10.1016/S1364$\underline{6613(00) 01538-2}$

Baddeley, A. (2001). Is working memory still working? American Psychologist, 56(11), 851864.

Baddeley, A., Thomson, N., \& Buchanan, M. (1975). Word length and the structure of shortterm memory. Journal of Verbal Learning and Verbal Behavior, 14(6), 575-589. doi:https://doi.org/10.1016/S0022-5371(75)80045-4

Baddeley, M. (2010). Herding, social influence and economic decision-making: sociopsychological and neuroscientific analyses. Philosophical Transactions of the Royal Society of London. , 365(1538), 281-290. doi:10.1098/rstb.2009.0169

Bahrick, H. P., Bahrick, P. O., \& Wittlinger, R. P. (1975). Fifty years of memory for names and faces: A cross-sectional approach. Journal of Experimental Psychology: General, 104(1), 54. 
Bandura, A. (1991). Social cognitive theory of self-regulation. Organizational Behavior and Human Decision Processes, 50(2), 248-287. doi:https://doi.org/10.1016/0749$\underline{5978(91) 90022-\mathrm{L}}$

Barrouillet, P., Bernardin, S., Portrat, S., Vergauwe, E., \& Camos, V. (2007). Time and cognitive load in working memory. Journal of Experimental Psychology: Learning, Memory, and Cognition, 33(3), 570-585. doi:10.1037/0278-7393.33.3.570

Bauer, C., \& Strauss, C. (2016). Location-based advertising on mobile devices. Journal of Management Review Quarterly

66(3), 159-194. doi:10.1007/s11301-015-0118-z

Baumeister, R. F., Bratslavsky, E., Muraven, M., \& Tice, D. M. (1998). Ego depletion: Is the active self a limited resource? Journal of Personality and Social Psychology, 74(5), 1252-1265. doi:10.1037/0022-3514.74.5.1252

Beresford, A. R., Kübler, D., \& Preibusch, S. (2012). Unwillingness to pay for privacy: A field experiment. Economics Letters, 117(1), 25-27. doi:https://doi.org/10.1016/j.econlet.2012.04.077

Bonner, C., \& Newell, B. R. (2010). In conflict with ourselves? An investigation of heuristic and analytic processes in decision making. Memory \& Cognition, 38(2), 186-196. doi:10.3758/mc.38.2.186

Bortolotti, L., \& Mameli, M. (2006). Deception in Psychology: Moral costs and benefits of unsought self-knowledge. Accountability in Research, 13(3), 259-275. doi:10.1080/08989620600848561

Brenkert, G. G. (1998). Marketing and the vulnerable. The Ruffin Series of the Society for Business Ethics, 1, 7-20. 
Brenner, L., Sood, S., \& Rottenstreich, Y. (2007). Feeling and thinking in memory-based versus stimulus-based choices. Journal of Consumer Research, 33(4), 461-469. doi:10.1086/510219

Brewer, W. F., \& Nakamura, G. V. (2000). Bartlett's concept of the schema and its impact on theories of knowledge representation in contemporary cognitive psychology (325). Retrieved from Center for the Study of Reading Technical Report:

Brown, B. (2001). Studying the internet experience. HP laboratories technical report HPL, 49.

Brown, J. (1958). Some tests of the decay theory of immediate memory. Quarterly Journal of Experimental Psychology, 10(1), 12-21. doi:10.1080/17470215808416249

Brunken, R., Plass, J. L., \& Leutner, D. (2003). Direct measurement of cognitive load in multimedia learning. Educational Psychologist, 38(1), 53-61. doi:10.1207/S15326985EP3801_7

Cacioppo, J., Petty, R., \& Feng Kao, C. (1984). The efficient assessment of NFC. Journal of Personality Assessment, 48, 306-307. doi:10.1207/s15327752jpa4803_13

Cacioppo, J., \& Petty, R. E. (1982). The need for cognition. Journal of Personality and Social Psychology, 42(1), 116-131. doi:10.1037/0022-3514.42.1.116

Cacioppo, J., Petty, R. E., Feinstein, J. A., \& Jarvis, W. B. G. (1996). Dispositional differences in cognitive motivation: The life and times of individuals varying in need for cognition. Psychological Bulletin, 119(2), 197.

Carrascal, J. P., Riederer, C., Erramilli, V., Cherubini, M., \& de Oliveira, R. (2013). Your browsing behavior for a big mac: Economics of personal information online. Paper presented at the Proceedings of the 22nd international conference on World Wide Web. 
Carrier, L. M., Cheever, N. A., Rosen, L. D., Benitez, S., \& Chang, J. (2009). Multitasking across generations: Multitasking choices and difficulty ratings in three generations of Americans. Computers in Human Behavior, 25(2), 483-489.

Cases, A.-S. (2002). Perceived risk and risk-reduction strategies in Internet shopping. The International Review of Retail, Distribution and Consumer Research, 12(4), 375-394. doi:10.1080/09593960210151162

Charness, G., Gneezy, U., \& Kuhn, M. A. (2012). Experimental methods: Between-subject and within-subject design. Journal of Economic Behavior \& Organization, 81(1), 1-8. doi:https://doi.org/10.1016/j.jebo.2011.08.009

Christofides, E., Muise, A., \& Desmarais, S. (2012). Hey Mom, what's on your Facebook? Comparing Facebook disclosure and privacy in adolescents and adults. Social Psychological and Personality Science, 3(1), 48-54. doi:10.1177/1948550611408619

Colle, H. A., \& Welsh, A. (1976). Acoustic masking in primary memory. Journal of Verbal Learning and Verbal Behavior, 15(1), 17-31. doi:https://doi.org/10.1016/S0022-

\section{$\underline{5371(76) 90003-7}$}

Cornelissen, G., Dewitte, S., Warlop, L., \& Yzerbyt, V. (2007). Whatever people say I am, that's what I am: Social labeling as a social marketing tool. International Journal of Research in Marketing, 24(4), 278-288.

Cowan, N. (1988). Evolving conceptions of memory storage, selective attention, and their mutual constraints within the human information-processing system. Psychological Bulletin, 104(2), 163.

Cowan, N. (2001). The magical number 4 in short-term memory: A reconsideration of mental storage capacity. Behavioral and Brain Sciences, 24(1), 87-114.

doi:10.1017/S0140525X01003922 
Craig, A. W., Loureiro, Y. K., Wood, S., \& Vendemia, J. M. C. (2012). Suspicious minds: Exploring neural processes during exposure to deceptive advertising. Journal of Marketing Research, 49(3), 361-372. doi:10.1509/jmr.09.0007

D'Souza, G., \& Phelps Joseph, E. (2009). The privacy paradox: The case of secondary disclosure. In Review of Marketing Science (Vol. 7).

de Jong, T. (2010). Cognitive load theory, educational research, and instructional design: some food for thought. Instructional Science, 38(2), 105-134. doi:10.1007/s11251009-9110-0

Debatin, B., Lovejoy, J. P., Horn, A.-K., \& Hughes, B. N. (2009). Facebook and online privacy: Attitudes, behaviors, and unintended consequences. Journal of ComputerMediated Communication, 15(1), 83-108. doi:10.1111/j.1083-6101.2009.01494.x

Dindia, K., \& Allen, M. (1992). Sex differences in self-disclosure: A meta-analysis. Psychological Bulletin, 112(1), 106-124. doi:10.1037/0033-2909.112.1.106

Dinev, T., \& Hart, P. (2006). An extended privacy calculus model for E-Commerce transactions. Information Systems Research, 17(1), 61-80. doi:10.1287/isre.1060.0080

Drolet, A., \& Frances Luce, M. (2004). The rationalizing effects of cognitive load on emotion-based trade-off avoidance. Journal of Consumer Research, 31(1), 63-77.

Drolet, A., Simonson, I., \& Luce, M. F. (2008). When does choice reveal preference? Moderators of heuristic versus goal-based choice. Journal of Consumer Research, 36(1), 137-147. doi:10.1086/596305

Dunning, D., Heath, C., \& Suls, J. M. (2004). Flawed self-assessment: Implications for health, education, and the workplace. Psychological Science in the Public Interest, 5(3), 69-106. doi:10.1111/j.1529-1006.2004.00018.x 
Einhorn, H. J., \& Hogarth, R. M. (1981). Behavioral decision theory: Processes of judgement and choice. Annual Review of Psychology, 32(1), 53-88. doi:10.1146/annurev.ps.32.020181.000413

Elsley, J. V., \& Parmentier, F. B. R. (2009). Short article: Is verbal-spatial binding in working memory impaired by a concurrent memory load? Quarterly Journal of Experimental Psychology, 62(9), 1696-1705. doi:10.1080/17470210902811231

Epstein, S. (1994). Integration of the cognitive and the psychodynamic unconscious. American Psychologist, 49(8), 709-724. doi:10.1037/0003-066X.49.8.709

Evans, N. J., \& Hoy, M. G. (2016). Parents' presumed persuasion knowledge of children's advergames: The influence of advertising disclosure modality and cognitive Load. Journal of Current Issues \& Research in Advertising, 37(2), 146-164. doi:10.1080/10641734.2016.1171181

Evans, N. J., \& Park, D. (2015). Rethinking the persuasion knowledge model: Schematic antecedents and associative outcomes of persuasion knowledge activation for covert advertising. Journal of Current Issues \& Research in Advertising, 36(2), 157-176. doi:10.1080/10641734.2015.1023873

Finucane, M. L., Alhakami, A., Slovic, P., \& Johnson, S. M. (2000). The affect heuristic in judgments of risks and benefits. Journal of Behavioral Decision Making, 13(1), 1-17. doi:10.1002/(sici)1099-0771(200001/03)13:1<1::Aid-bdm333>3.0.Co;2-s

Foehr, U. G. (2006). Media multitasking among American youth: Prevalence, predictors and pairings. Henry J. Kaiser Family Foundation.

Friestad, M., \& Wright, P. (1994). The persuasion knowledge model: How people cope with persuasion attempts. Journal of Consumer Research, 21(1), 1-31. doi:10.1086/209380 
Fukuda, K., Awh, E., \& Vogel, E. K. (2010). Discrete capacity limits in visual working memory. Current Opinion in Neurobiology, 20(2), 177-182. doi:https://doi.org/10.1016/j.conb.2010.03.005

Ganassali, S. (2008). The influence of the design of web survey questionnaires on the quality of responses. Paper presented at the Survey research methods.

Gentry, J. W., Kennedy, P. F., Paul, K., \& Hill, R. P. (1995). The vulnerability of those grieving the death of a loved one: Implications for public policy. Journal of Public Policy \& Marketing, 14(1), 128-142. doi:10.1177/074391569501400112

Gobet, F., Lane, P. C. R., Croker, S., Cheng, P. C. H., Jones, G., Oliver, I., \& Pine, J. M. (2001). Chunking mechanisms in human learning. Trends in Cognitive Sciences, 5(6), 236-243. doi:https://doi.org/10.1016/S1364-6613(00)01662-4

Goode, M. R., Dahl, D. W., \& Moreau, C. P. (2010). The effect of experiential analogies on consumer perceptions and attitudes. Journal of Marketing Research, 47(2), 274-286. doi:10.1509/jmkr.47.2.274

Harless, D. W., \& Camerer, C. F. (1994). The predictive utility of generalized expected utility theories. Econometrica, 62(6), 1251-1289. doi:10.2307/2951749

Haugtvedt, C. P., Petty, R. E., \& Cacioppo, J. T. (1992). Need for cognition and advertising: Understanding the role of personality variables in consumer behavior. Journal of Consumer Psychology, 1(3), 239-260. doi:10.1016/s1057-7408(08)80038-1

Haynes, K., Barclay, J., \& Pidgeon, N. (2008). The issue of trust and its influence on risk communication during a volcanic crisis. Bulletin of Volcanology, 70(5), 605-621.

Hitsch, G. J., Hortaçsu, A., \& Ariely, D. (2010). What makes you click?-Mate preferences in online dating. Quantitative Marketing and Economics, 8(4), 393-427.

Hogben, G. (2007). Security issues and recommendations for online social networks. Paper presented at the ENISA position paper. 
Horne, D. R., \& Horne, D. A. (1998). Domains of privacy: Toward an understanding of underlying factors. Paper presented at the Direct Marketing Educators' Conference, San Francisco, CA.

Hurley, A. E., Scandura, T. A., Schriesheim, C. A., Brannick, M. T., Seers, A., Vandenberg, R. J., \& Williams, L. J. (1997). Exploratory and confirmatory factor analysis: guidelines, issues, and alternatives. Journal of Organizational Behavior, 18(6), 667683. doi:10.1002/(sici)1099-1379(199711)18:6<667::Aid-job874>3.0.Co;2-t

Jefferies, E., Lambon Ralph, M. A., \& Baddeley, A. D. (2004). Automatic and controlled processing in sentence recall: The role of long-term and working memory. Journal of Memory and Language, 51(4), 623-643. doi:https://doi.org/10.1016/j.jml.2004.07.005

Jeong, S.-H., \& Fishbein, M. (2007). Predictors of multitasking with media: Media factors and audience factors. Media Psychology, 10(3), 364-384.

doi:10.1080/15213260701532948

Jiang, Z., Heng, C. S., \& Choi, B. (2013). Privacy concerns and privacy-protective behavior in synchronous online social interactions. Information Systems Research, 24(3), 579595. doi:10.1287/isre.1120.0441

Joinson, A. N., Paine, C., Buchanan, T., \& Reips, U.-D. (2008). Measuring self-disclosure online: Blurring and non-response to sensitive items in web-based surveys. Computers in Human Behavior, 24(5), 2158-2171. doi:https://doi.org/10.1016/j.chb.2007.10.005

Kahneman, D., Slovic, S. P., Slovic, P., \& Tversky, A. (1982). Judgment under uncertainty: Heuristics and biases. Cambridge, UK: Cambridge University Press.

Kane, M. J., Engle, R. W., \& Review. (2002). The role of prefrontal cortex in workingmemory capacity, executive attention, and general fluid intelligence: An individual- 
differences perspective. Psychonomic Bulletin \& Review, 9(4), 637-671. doi:10.3758/bf03196323

Kangas, J., Špakov, O., Isokoski, P., Akkil, D., Rantala, J., \& Raisamo, R. (2016). Feedback for smooth pursuit gaze tracking based control. Geneva, Switzerland: Association for Computing Machinery.

King, M. F., \& Bruner, G. C. (2000). Social desirability bias: A neglected aspect of validity testing. Psychology and Marketing, 17(2), 79-103. doi:10.1002/(sici)15206793(200002)17:2<79::Aid-mar2>3.0.Co;2-0

Kokolakis, S. (2017). Privacy attitudes and privacy behaviour: A review of current research on the privacy paradox phenomenon. Computers and Security, 64, 122-134.

Lantieri, T., \& Chiagouris, L. (2009). Brand trust in an age without trust: expert opinions. Journal of Consumer Marketing, 26(2), 78-86.

Lavie, N., Hirst, A., De Fockert, J. W., \& Viding, E. (2004). Load theory of selective attention and cognitive control. Journal of Experimental Psychology: General, 133(3), 339.

Leary, M. R., \& Kowalski, R. M. (1990). Impression management: A literature review and two-component model. Psychological Bulletin, 107(1), 34-47. doi:10.1037/00332909.107.1.34

Lee, H., Park, H., \& Kim, J. (2013). Why do people share their context information on Social Network Services? A qualitative study and an experimental study on users' behavior of balancing perceived benefit and risk. International Journal of Human-Computer Studies, 71(9), 862-877. doi:https://doi.org/10.1016/j.ijhcs.2013.01.005

Livingstone, S. (2008). Taking risky opportunities in youthful content creation: teenagers' use of social networking sites for intimacy, privacy and self-expression. New Media \& Society, 10(3), 393-411. doi:10.1177/1461444808089415 
Loewenstein, G. F., Weber, E. U., Hsee, C. K., \& Welch, N. (2001). Risk as feelings. Psychological Bulletin, 127(2), 267.

Ma, W. J., Husain, M., \& Bays, P. M. (2014). Changing concepts of working memory. Nature Neuroscience, 17(3), 347-356. doi:10.1038/nn.3655

Mahdawi, A. (2018). Uber developing technology that would tell if you're drunk. Retrieved from https://www.theguardian.com/technology/2018/jun/11/uber-drunk-technologynew-ai-feature-patent

Malhotra, N. K. (1982). Information load and consumer decision making. Journal of Consumer Research, 8(4), 419-430.

Malhotra, N. K. (1984). Information and sensory overload. Information and sensory overload in psychology and marketing. Psychology and Marketing, 1(3-4), 9-21.

Malhotra, N. K., Kim, S. S., \& Agarwal, J. (2004). Internet users' information privacy concerns (IUIPC): Tthe construct, the scale, and a causal model. Information Systems Research, 15(4), 336-355. doi:10.1287/isre.1040.0032

Maranges, H. M., Schmeichel, B. J., \& Baumeister, R. F. (2017). Comparing cognitive load and self-regulatory depletion: Effects on emotions and cognitions. Learning and Instruction, 51, 74-84. doi:https://doi.org/10.1016/j.learninstruc.2016.10.010

Martin, K. (2016). Data aggregators, consumer data, and responsibility online: Who is tracking consumers online and should they stop? The Information Society, 32(1), 5163. doi:10.1080/01972243.2015.1107166

Mathews, A. (1990). Why worry? The cognitive function of anxiety. Behaviour Research and Therapy, 28(6), 455-468. doi:https://doi.org/10.1016/0005-7967(90)90132-3

Mathews, A., Derlega, V. J., \& Morrow, J. (2006). What Is highly personal information and how is it related to self-disclosure decision-making? The perspective of college 
students. Communication Research Reports, 23(2), 85-92.

doi:10.1080/08824090600668915

McCoy, B. R. (2016). Digital distractions in the classroom phase II: Student classroom use of digital devices for non-class related purposes. Journal of Media Education, 7(1), 5-32.

Menon, G., \& Raghubir, P. (2003). Ease-of-retrieval as an automatic input in judgments: A mere-accessibility framework? Journal of Consumer Research, 30(2), 230-243. doi:10.1086/376804

Meuter, M. L., Bitner, M. J., Ostrom, A. L., \& Brown, S. W. (2005). Choosing among alternative service delivery modes: An investigation of customer trial of self-service technologies. Journal of Marketing, 69(2), 61-83. doi:10.1509/jmkg.69.2.61.60759

Meyers-Levy, J., \& Malaviya, P. (1999). Consumers' processing of persuasive advertisements: An integrative framework of persuasion theories. Journal of Marketing, 63(4_suppl1), 45-60.doi:10.1177/00222429990634s106

Miller, G. A. (1956). The magical number seven, plus or minus two: some limits on our capacity for processing information. Psychological Review, 63(2), 81-97. doi:10.1037/h0043158

Moon, Y. (2000). Intimate exchanges: Using computers to elicit self-disclosure from consumers. Journal of Consumer Research, 26(4), 323-339. doi:10.1086/209566 \%J Journal of Consumer Research

Moos, D. C., \& Pitton, D. (2014). Student teacher challenges: using the cognitive load theory as an explanatory lens. Teaching Education, 25(2), 127-141. doi:10.1080/10476210.2012.754869

Morey, T., Forbath, T., \& Schoop, A. (2015). Customer data: Designing for transparency and trust. Harvard Business Review, 93(5), 96-105. 
Mothersbaugh, D. L., Foxx, W. K., Beatty, S. E., \& Wang, S. (2012). Disclosure antecedents in an online service context: The role of sensitivity of information. Journal of service research, 15(1), 76-98.

Muraven, M., Tice, D. M., \& Baumeister, R. F. (1998). Self-control as a limited resource: Regulatory depletion patterns. Journal of Personality and Social Psychology, 74(3), 774-789. doi:10.1037/0022-3514.74.3.774

Nathan, M., Joe, D., Allen, T., Primal, W., Serge, E., \& David, W. (2019). Privacy attitudes of smart speaker users. Proceedings on Privacy Enhancing Technologies, 2019(4), 250-271. doi:https://doi.org/10.2478/popets-2019-0068

Naveh-Benjamin, M., \& Jonides, J. (1984). Maintenance rehearsal: A two-component analysis. Journal of Experimental Psychology: Learning, Memory, and Cognition, 10(3), 369-385. doi:10.1037/0278-7393.10.3.369

Nelson, M. R. (2002). Recall of brand placements in computer/video games. Journal of Advertising Research, 42(2), 80-92. doi:10.2501/jar-42-2-80-92

Norberg, P. A., Horne, D. R., \& Horne, D. A. (2007). The privacy paradox: Personal information disclosure intentions versus behaviors. The Journal of Consumer Affairs, $41(1), 100-126$.

Nowak, G. J., \& Phelps, J. E. (1992). Understanding privacy concerns: An assessment of consumers' information-related knowledge and beliefs. Journal of Direct Marketing, 6(4), 28-39. doi:https://doi.org/10.1002/dir.4000060407

Oberauer, K., Farrell, S., Jarrold, C., \& Lewandowsky, S. (2016). What limits working memory capacity? Psychological Bulletin, 142(7), 758-799. doi:10.1037/bul0000046

Oberauer, K., \& Kliegl, R. (2006). A formal model of capacity limits in working memory. Journal of Memory and Language, 55(4), 601-626. doi:https://doi.org/10.1016/j.jml.2006.08.009 
Peterson, L., \& Peterson, M. J. (1959). Short-term retention of individual verbal items. Journal of Experimental Psychology, 58(3), 193-198. doi:10.1037/h0049234

Petty, R. E., \& Cacioppo, J. T. (1986). The elaboration likelihood model of persuasion. In Communication and Persuasion: Central and Peripheral Routes to Attitude Change (pp. 1-24). New York, NY: Springer New York.

Petty, R. E., Cacioppo, J. T., \& Goldman, R. (1981). Personal involvement as a determinant of argument-based persuasion. Journal of Personality and Social Psychology, 41(5), 847-855. doi:10.1037/0022-3514.41.5.847

Petty, R. E., Cacioppo, J. T., \& Schumann, D. (1983). Central and peripheral routes to advertising effectiveness: The moderating role of involvement. Journal of Consumer Research, 10(2), 135-146. doi:10.1086/208954

Phelps, J., Nowak, G., \& Ferrell, E. (2000). Privacy concerns and consumer willingness to provide personal information. Journal of Public Policy and Marketing

19(1), 27-41.

Pocheptsova, A., Amir, O., Dhar, R., \& Baumeister, R. F. (2009). Deciding without resources: Resource depletion and choice in context. Journal of Marketing Research, 46(3), 344-355. doi:10.1509/jmkr.46.3.344

Radvansky, G. A., \& Ashcraft, M. H. (2014). Cognition (6th ed.). Upper Saddle River, NJ: Pearson Education.

Raub, A. C. (1981). Correlates of computer anxiety in college students. (Educational Psychology). University of Pennsylvania, University Microfilms International. (8208027)

Rauschnabel, P. A., \& Ro, Y. K. (2016). Augmented reality smart glasses: An investigation of technology acceptance drivers. International Journal of Technology Marketing, 11(2), 123-148. 
Richard, J., \& Ralphs, D. (2018). Only the brave: Perceived risk of social media. Paper presented at the Academy of Marketing Conference Proceedings 2018.

Rosen, L. D., Carrier, L., \& Cheever, N. A. (2013). Facebook and texting made me do it: Media-induced task-switching while studying. Computers in Human Behavior, 29(3), 948-958. doi:https://doi.org/10.1016/j.chb.2012.12.001

Sanbonmatsu, D. M., Strayer, D. L., Medeiros-Ward, N., \& Watson, J. M. (2013). Who multi-tasks and why? Multi-tasking ability, perceived multi-tasking ability, impulsivity, and sensation seeking. PLOS ONE, 8(1), e54402. doi:10.1371/journal.pone.0054402

Sayre, S., \& Horne, D. (2000). Trading secrets for savings: how concerned are consumers about club cards as a privacy threat? Advances in Consumer Research, 27.

Schwarz, N., Bless, H., Strack, F., Klumpp, G., Rittenauer-Schatka, H., \& Simons, A. (1991). Ease of retrieval as information: Another look at the availability heuristic. Journal of Personality and Social Psychology, 61(2), 195-202. doi:10.1037/0022-3514.61.2.195

Service, E. (1998). The effect of word length on immediate serial recall depends on phonological complexity, not articulatory duration. The Quarterly Journal of Experimental Psychology Section A, 51(2), 283-304. doi:10.1080/713755759

Sheehan, K. B., \& Hoy, M. G. (1999). Flaming, complaining, abstaining: How online users respond to privacy concerns. Journal of Advertising, 28(3), 37-51. doi:10.1080/00913367.1999.10673588

Shiv, B., \& Fedorikhin, A. (1999). Heart and mind in conflict: The interplay of affect and cognition in consumer decision making. Journal of Consumer Research, 26(3), 278292. doi:10.1086/209563 
Shiv, B., \& Fedorikhin, A. (2002). Spontaneous versus controlled influences of stimulusbased affect on choice behavior. Organizational Behavior and Human Decision Processes, 87(2), 342-370. doi:https://doi.org/10.1006/obhd.2001.2977

Shoemaker, P. J., Eichholz, M., \& Skewes, E. A. (2002). Item nonresponse: Distinguishing between don't know and refuse. International Journal of Public Opinion Research, 14(2), 193-201. doi:10.1093/ijpor/14.2.193 \%J International Journal of Public Opinion Research

Shu, S. B., \& Carlson, K. A. (2014). When three charms but four alarms: Identifying the optimal number of claims in persuasion settings. Journal of Marketing, 78(1), 127139. Retrieved from http://www.jstor.org.helicon.vuw.ac.nz/stable/43784350

Sigmon, D. R., \& Snyder, C. R. (2006). Offense-taking: Development and validation of a trait self-report measure. Cognitive Therapy and Research, 30(4), 445-456. doi:10.1007/s10608-006-9053-6

Singer, E., Van Hoewyk, J., Gebler, N., \& McGonagle, K. (1999). The effect of incentives on response rates in interviewer-mediated surveys. Journal of Official Statistics, 15(2), 217.

Sjöberg, L. (1998). Worry and risk perception. Risk Analysis, 18(1), 85-93. doi:10.1111/j.1539-6924.1998.tb00918.x

Slovic, P. (1987). Perception of risk. Science, 236(4799), 280-285. doi:10.1126/science.3563507 \%J Science

Slovic, P., \& Peters, E. (2006). Risk perception and affect. Current Directions in Psychological Science, 15(6), 322-325.

Son, J.-Y., \& Kim, S. S. (2008). Internet users' information privacy-protective responses: A taxonomy and a nomological model. MIS Quarterly, 32(3), 503-529. doi:10.2307/25148854 
Speier, C., Valacich, J. S., \& Vessey, I. (1999). The influence of task interruption on individual decision making: An information overload perspective. Decision Sciences, 30(2), 337-360. doi:10.1111/j.1540-5915.1999.tb01613.x

Spiekermann, S., Grossklags, J., \& Berendt, B. (2001). E-privacy in 2nd generation Ecommerce: privacy preferences versus actual behavior. Paper presented at the Proceedings of the 3rd ACM conference on Electronic Commerce.

Suchotzki, K., Verschuere, B., Van Bockstaele, B., Ben-Shakhar, G., \& Crombez, G. (2017). Lying takes time: A meta-analysis on reaction time measures of deception. Psychological Bulletin, 143(4), 428-453. doi:10.1037/bul0000087

Suter, R. S., \& Hertwig, R. (2011). Time and moral judgment. Cognition, 119(3), 454-458. doi:https://doi.org/10.1016/j.cognition.2011.01.018

Sweller, J. (2010). Element interactivity and intrinsic, extraneous, and germane cognitive load. Educational Psychology Review, 22(2), 123-138. doi:10.1007/s10648-010-91285

Syberfeldt, A., Danielsson, O., \& Gustavsson, P. (2017). Augmented reality smart glasses in the smart factory: Product evaluation guidelines and review of available products. IEEE Access, 5, 9118-9130. doi:10.1109/ACCESS.2017.2703952

Taddicken, M. (2014). The 'privacy paradox' in the social web: The impact of privacy concerns, individual characteristics, and the perceived social relevance on different forms of self-disclosure. Journal of Computer-Mediated Communication, 19(2), 248273. doi:10.1111/jcc4.12052

Tai, M. C.-T. (2012). Deception and informed consent in social, behavioral, and educational research (SBER). Tzu Chi Medical Journal, 24(4), 218-222. doi:https://doi.org/10.1016/j.tcmj.2012.05.003 
Thomas, C. W. (1998). Maintaining and restoring public trust in government agencies and their employees. Administration and Society, 30(2), 166-193.

Trzesniewski, K. H., Donnellan, M. B., \& Robins, R. W. (2003). Stability of self-esteem across the life span. Journal of Personality and Social Psychology, 84(1), 205-220. doi:10.1037/0022-3514.84.1.205

Tufekci, Z. (2008). Can you see me now? Audience and disclosure regulation in online social network sites. Bulletin of Science, Technology \& Society, 28(1), 20-36. doi:10.1177/0270467607311484

Tversky, A., \& Kahneman, D. (1974). Judgment under uncertainty: Heuristics and biases. Science, 185(4157), 1124-1131. doi:10.1126/science.185.4157.1124

Tyler, J. M., \& Burns, K. C. (2009). Triggering conservation of the self's regulatory resources. Basic and Applied Social Psychology, 31(3), 255-266. doi:10.1080/01973530903058490

Van de Mortel, T. F. (2008). Faking it: social desirability response bias in self-report research. The Australian Journal of Advanced Nursing, 25(4), 40.

van de Sanden, S., Willems, K., \& Brengman, M. (2019). In-store location-based marketing with beacons: from inflated expectations to smart use in retailing. Journal of Marketing Management, 35(15-16), 1514-1541. doi:10.1080/0267257X.2019.1689154

van Reijmersdal, E. A., Lammers, N., Rozendaal, E., \& Buijzen, M. (2015). Disclosing the persuasive nature of advergames: moderation effects of mood on brand responses via persuasion knowledge. International Journal of Advertising, 34(1), 70-84. doi:10.1080/02650487.2014.993795

Verschuere, B., Köbis, N. C., Bereby-Meyer, Y., Rand, D., \& Shalvi, S. (2018). Taxing the brain to uncover lying? Meta-analyzing the effect of imposing cognitive load on the 
reaction-time costs of lying. Journal of Applied Research in Memory and Cognition, 7(3), 462-469. doi:https://doi.org/10.1016/j.jarmac.2018.04.005

Vogel, E. K., \& Machizawa, M. G. (2004). Neural activity predicts individual differences in visual working memory capacity. Nature, 428(6984), 748-751. doi:10.1038/nature02447

Wang, N., Zhang, B., Liu, B., \& Jin, H. (2015). Investigating effects of control and Ads awareness on Android users' privacy behaviors and perceptions. Paper presented at the Proceedings of the 17th International Conference on Human-Computer Interaction with Mobile Devices and Services, Copenhagen, Denmark.

Ward, A. F., Duke, K., Gneezy, A., \& Bos, M. W. (2017). Brain drain: The mere presence of one's own smartphone reduces available cognitive capacity. Journal of the Association for Consumer Research, 2(2), 140-154. doi:10.1086/691462

Waugh, N. C., \& Norman, D. A. (1965). Primary memory. Psychological Review, 72(2), 89104. doi:10.1037/h0021797

Weinstein, N. D. (1989). Optimistic biases about personal risks. Science, 246, 1232+. Retrieved from https://link.galegroup.com/apps/doc/A8351381/HRCA?u=vuw\&sid=HRCA\&xid=2b1 $\underline{\text { abaf8 }}$

White, T. B. (2004). Consumer disclosure and disclosure avoidance: A motivational framework. Journal of Consumer Psychology, 14(1-2), 41-51.

Xie, E., Teo, H.-H., \& Wan, W. (2006). Volunteering personal information on the internet: Effects of reputation, privacy notices, and rewards on online consumer behavior. Marketing Letters, 17(1), 61-74. doi:10.1007/s11002-006-4147-1

Zebb, B. J., \& Beck, J. G. (1998). Worry versus anxiety: Is there really a difference? Behavior Modification, 22(1), 45-61. doi:10.1177/01454455980221003 
Zhang, Y. (1996). Responses to humorous advertising: The moderating effect of need for cognition. Journal of Advertising, 25(1), 15-32.

doi:10.1080/00913367.1996.10673493

Zikmund, W. G., Ward, S., Lowe, B., Winzar, H., \& Babin, B. J. (2011). Marketing

Research: Second Asia-Pacific Edition. Melbourne, Australia: Cengage Learning 


\section{Appendices}

\section{Appendix A: Information sheet for participants}

\section{The Impact of Stress \\ INFORMATION SHEET FOR PARTICIPANTS}

You are invited to take part in this research. Please read this information before deciding whether or not to take part. If you decide to participate, thank you. If you decide not to participate, thank you for considering this request.

Who am I?

My name is Paul Harrison and I am a Maters student in Marketing at Victoria University of Wellington. This research project is work towards my dissertation.

What is the aim of the project?

The aim of the project is to investigate the impact of cognitive load on behaviour, to determine whether people operate differently when their cognitive resources are diminished.

This research has been approved by the Victoria University of Wellington Human Ethics Committee [RM 0000027778].

How can you help?

If you agree to take part you will be asked to answer several questionnaires and follow directions on a computer provided in a computer lab. Sensitive questions may be asked. The research will take around 20-30 minutes.

You can stop the experiment at any time by getting up from your seat and leaving without giving a reason. You can withdraw from the study by contacting me at any time before October $30^{\text {th }}$. If you withdraw, the information you provided will be destroyed or returned to you. You will receive a $\$ 5$ coffee voucher from participating in this study and have the option to go into the draw to win a $\$ 100$ grocery.

What will happen to the information you give?

All responses collected will remain confidential with responses being de-identified. All of the material related to survey responses will only be viewed by the researcher and the supervisor. All printed information will be kept in a locked file with access restricted to the researcher. All electronic data will be kept in a password protected file only accessible by the researcher. Data collected in this experiment will be destroyed after five years.

What will the project produce?

The information from my research will be used in my Masters report. It is possible that summary results from this survey may appear in academic or professional journals and may also be presented at academic or professional conferences. The data may also be used for further research projects (e.g. $\mathrm{PhD}$ ).

If you accept this invitation, what are your rights as a research participant?

You do not have to accept this invitation if you don't want to. If you do decide to participate, you have the right to:
choose not to answer any question; stop the experiment at any time; withdraw from the study before October $30^{\text {th }}$

- $\quad$ ask any questions about the study at any time;

- be able to read the final report of this research by emailing the researcher to request a copy

If you have any questions or problems, who can you contact?

If you have any questions, either now or in the future, please feel free to contact either:

Student:

Name: Paul Harrison

University email address:

harrispaul2@myvuw.ac.nz
Human Ethics Committee information

If you have any concerns about the ethical conduct of the research you may contact the Victoria University HEC Convenor: Dr Judith Loveridge. Email hec@vuw.ac.nz or telephone +64-4-463 6028.

\section{Supervisor:}

Name: Dr. James Richard

Email: james.richard@vuw.ac.nz 


\section{Appendix B: Consent form to participate in study}

\section{Impact of Stress}

\section{CONSENT TO PARTICIPATE IN STUDY}

This consent form will be held for five years.

Researcher: Paul Harrison, School of Marketing and International Business, Victoria University of Wellington.

- I have read the Information Sheet and the project has been explained to me. My questions have been answered to my satisfaction. I understand that I can ask further questions at any time.

- I agree to take part in this study.

I understand that:

- I may withdraw from this study at any point during the experiment without providing a reason. I may also withdraw at any time before October $30^{\text {th }}$ and any information that $\mathrm{I}$ have provided will be returned to me or destroyed.

- $\quad$ The identifiable information I have provided will be destroyed on October $30^{\text {th }}$.

- $\quad$ Any information I provide may be included in a final report but the data will be aggregated therefore not traceable to a single participant. Data provided will be kept confidential to the researcher and the supervisor.

- $\quad$ I understand that the results will be used for a Masters dissertation and or academic publications/presented to conferences/future research projects (e.g. $\mathrm{PhD})$.

- My name will not be used in reports and utmost care will be taken not to disclose any information that would identify me.

- I would like to receive a copy of the final report and have added my email address Yes below.

Signature of participant:

Name of participant:

Date:

Contact details: 


\section{Appendix C: Gathering participants}

\section{On social Media:}

Hey everyone!

Do you like free stuff? How about receiving a $\$ 5$ Coffee voucher for 20 minutes of your time? And the chance to go into the draw to win a $\$ 100$ grocery voucher!

Well, if you are over 18 and have some spare time then you're in luck because I need your help!

I'm a Masters student investigating the impact of stress on behaviour.

I need people who are able to spare 20 minutes to participate in a short experiment in a computer lab at Victoria University. The experiment will involve a simple memory task and answering several questions on a computer. Upon completion you will receive your voucher and have the option to go into the draw to win even more!

Several time slots and locations will be available, if you are interested please follow the link below to sign up for a slot, or feel free to email me.

(Link to Doodle)

Paulharrison@outlook.co.nz

Ethics approval [RM 0000027778] has been obtained for this research from the Pipitea Human Ethics Committee.

\section{On Blackboard:}

Hey everyone!

Do you like free stuff? How about receiving a \$5 Coffee voucher for 20 minutes of your time? And the chance to go into the draw to win a $\$ 100$ grocery voucher!

Well, if you have some spare time then you're in luck because I need your help!

I'm a Masters student investigating the impact of stress on behaviour.

I need people who are able to spare 20 minutes to participate in a short experiment in a computer lab at Victoria University. The experiment will involve a simple memory task and answering several questions on a computer. Upon completion you will receive your voucher and have the option to go into the draw to win even more!

Several time slots and locations will be available, if you are interested please follow the link below to sign up for a slot, or feel free to email me.

(Link to Doodle)

Paulharrison@outlook.co.nz

Ethics approval [RM 0000027778] has been obtained for this research from the Pipitea Human Ethics Committee. 


\section{Appendix D: Company questions}

\section{Personal identity:}

What is your first name? (NS)

What is your surname? (NS)

What is your nationality? (NS)

\section{Generic:}

What is your occupation? (NS)

What is your highest qualification? (NS)

What is your relationship status? (NS)

\section{Lifestyle:}

What is your favourite TV show? (NS)

What was your last purchase you can remember? (NS)

How often do you make online purchases? (NS)

What are two websites you use most often? (NS)

How often do you use social media? (NS)

\section{Financial:}

What amount is your student loan? (S)

Are you in any debt? (Excluding student loan) (S)

$(\mathrm{S})=$ Sensitive question

$(\mathrm{NS})=$ Non-sensitive question
How many credit cards do you have? (S)

What is your yearly income? (S)

How much money do you save a month? (S)

What is your parent(s) yearly income? (S)

\section{Political/Religious}

What is your political inclination? (S)

Who did you vote for last election? (S)

\section{Health information}

How often do you smoke cigarettes? (NS)

How often do you consume alcohol? (NS)

Do you experience mental illness? And if so, how would you describe it? (S)

How many sexual partners have you had? (S)

\section{Contact details}

What is your email? (S)

What is your address? (S)

What is your mobile number? (S) 


\section{Appendix E: Complete questionnaire guide}

\section{The Impact of Stress}

This study is being undertaken as part of my Marketing Masters to investigate the impact of stress on behavior. Participation in the study is completely voluntary and you may leave the session any time. You will be asked to answer several questionnaires and follow directions on a computer provided in a computer lab. The research will take around 20-30 minutes.

Instructions on how to answer the survey are on the following page. Results from the study will be compiled into a written report. Ethics approval [RM 0000027778] has been obtained for this research from the Pipitea Human Ethics Committee.

This is a secure website and all responses collected will remain confidential with responses being de-identified. All of the material related to survey responses will only be viewed by the researcher and the supervisor. All printed information will be kept in a locked file with access restricted to the researcher. All electronic data will be kept in a password protected file only accessible by the researcher. Data collected in this experiment will be destroyed after five years. If you feel uncomfortable at any point during the study you are free to leave.

It is possible that summary results from this survey may appear in academic or professional journals and may also be presented at academic or professional conferences. The data may also be used for further research projects (e.g. $\mathrm{PhD})$.

You will receive a $\$ 5$ coffee voucher from participating in this study and have the option to go into the draw to win a $\$ 100$ grocery voucher.

If you have any concerns, questions or require any further information please feel free to contact:
Student Researcher
Research Supervisor
Paul Harrison
Dr. James Richard
Email: Harrispaul2@myvuw.ac.nz
Email: james.richard@vuw.ac.nz

Thank you for your interest and help in completing this research

Sincerely,

Paul Harrison

\section{Human Ethics Committee information}

If you have any concerns about the ethical conduct of the research you may contact the Victoria University HEC Convenor: Dr Judith Loveridge. Email hec@vuw.ac.nz or telephone +64-4-463 6028.

\section{----- New Page -----}

\section{Study Information}

Please read the following carefully.

Firstly, you will undertake two tasks that will simulate stress before being given a set of follow-up questions and a final debriefing. If you feel uncomfortable at any point throughout the study, you are free to skip a question or withdraw from the study.

\section{Component One:}

You will be given two tasks which are to be done simultaneously, a primary task where you will be asked to remember a string of numbers (to recall after completing the first component of the study), and another task which is responding to a company questionnaire. Put an equal amount of effort into both tasks. 
The company questionnaire is collecting information that a company may ask potential consumers for market research purposes.

\section{----- New Page -----}

Please read the notes for the company questionnaire carefully:

- On the next page you will be presented with a number and given 20 seconds to look at it, you will be asked to recall this number after completing the company questionnaire.

- Do not write the number down.

- Rehearse the number in your head as you complete the company questionnaire. When asked to recall your number write down your best guess, even if you know it doesn't match the original.

- Questions will be presented one at a time, and once you move on from a question you will not be able to return to it.

- The coffee and grocery voucher are NOT connected with this company.

\section{Company Questionnaire}

Consider a company that you are already using is implementing a new service. You enter their website and are given the following message:

We are developing a new service and are collecting information to better understand our potential users and develop a database to use for trials. The following questionnaire requests answers to a range of questions in order to build a customer profile.

Click the arrow to continue.

Remember this number: (Participants presented with 7-or 2-digit number)

\section{----- New Page -----}

\section{Questionnaire}

Questions will be presented one at a time and in sets.

The questions identified below are supported by the literature and to ensure variability of item sensitivity they will be validated with a pre-test.

The set in blue will be presented at the start of the questionnaire and the set in red will be presented at the end. The other five blocks will be presented to participants in a random order. Participants will be able to respond to or skip any question.

Upon completion participants will be asked to recall their number.

What is your first name?

What is your surname?

What is your nationality?

What is your occupation?

What is your highest qualification?

What is your relationship status?
What is your favorite TV show?

What was your last purchase you can remember? How often do you make online purchases? What are two websites you use most often? How often do you use social media?

What amount is your student loan? Are you in any debt? (Excluding student loan) 
How many credit cards do you have?

What is your yearly income?

How much money do you save a month?

What is your parent(s) yearly income?

What is your political inclination?

Who did you vote for last election?

How often do you smoke cigarettes?
How often do you consume alcohol?

Do you experience mental illness? And if so, how would you describe it?

How many sexual partners have you had?

What is your email?

What is your address?

What is your mobile number?

----- New Page -----

Please recall your number. Write down your best guess, even if you know it doesn't match the original.

----- New Page -----

Thank you for completing the questionnaire and the recall task. The following questions are not associated with the company questionnaire. Please answer them completely and honestly.

You no longer need to remember your number.

\section{----- New Page -----}

Indicate your degree of agreement or disagreement with each of the statements listed below.

( 1 = Strongly disagree, $2=$ disagree, $3=$ somewhat disagree, $4=$ neither agree nor disagree, $5=$ somewhat agree, $6=$ agree, $7=$ strongly agree) .

1. I would prefer complex to simple problems

2. Thinking is not my idea of fun*

3. I try to anticipate and avoid situations where there is likely chance that I will have to think in depth about something*

4. I really enjoy a task that involves coming up with solutions to problems

5. The notion of thinking abstractly is appealing to me

6. It's enough for me that something gets the job done, I don't care how or why it works*

\section{----- New Page -----}

Indicate your degree of agreement or disagreement with each of the statements listed below.

1. In general, it is risky to give information to online companies.

2. There is a high potential for loss associated with giving information to online firms.

3. There is too much uncertainty associated with giving information to online firms.

4. Providing online firms with information involves many unexpected problems.

\section{----- New Page -----}

Indicate your degree of agreement or disagreement with each of the statements listed below.

1. I feel apprehensive about disclosing information online.

2. I have avoided disclosing information online because it worries me.

3. I hesitate to give personal information online for fear of how the information may be used. 
Indicate your degree of agreement or disagreement with each of the statements listed below.

1. It takes something fairly severe to offend me

2. It does not take much to make me uncomfortable

3. People rarely offend me

4. I lose my patience easily

5. I'm relatively open

6. My friends often tell me I over-react to perceived slights

----- New Page -----

Indicate your degree of agreement or disagreement with each of the statements listed below.

1. I make it a high priority to arrange my life to avoid upsetting or overwhelming situations

2. I find it unpleasant to have a lot going on at once

3. Changes in my life shake me up

4. I get rattled when I have a lot to do in a short amount of time

5. I find myself needing to withdraw during busy days into bed or into a darkened room or any place where I can have some privacy and relief from stimulation

6. I'm easily overwhelmed by things like bright lights, strong smells, coarse fabrics, or sirens close by

$$
\text { ----- New Page ----- }
$$

The following questions will ask you to review your experience during the cognitive load task earlier.

1. How difficult was it to hold the number in your mind and complete the questionnaire? (Likert scale with $1=$ Extremely easy, $7=$ Extremely difficult)

2. How motivated were you to complete the questionnaire provided by the company? (Likert scale with $1=$ Extremely demotivated, $7=$ Extremely motivated)

3. How much do you trust the company providing the questionnaire? (Likert scale with $1=$ Extreme distrust, $7=$ Extremely trust)

$$
\text { ----- New Page ----- }
$$

To be clear, the company questionnaire presented earlier is not connected to a real company, it was fabricated for the study to represent a set of questions that a real company could ask consumers. The current study is looking at the impact of stress on information disclosure.

The information you provided here will not be shared or seen by anyone, other than the researcher and the supervisor. The personal information provided in the 'company questionnaire' will be deleted after your session ends. To clarify, your information will not be given to a company and no one will use the information provided to contact or identify you. The answers you provided in the questionnaire are not what matters, but instead whether you answered truthfully or not at all.

On the next page you will be shown your responses to the company questionnaire. We want you to evaluate whether the information you provided to us was true, false, incomplete, or not attempted.

We want you to be $100 \%$ honest in this evaluation, we do not mind whether you answered everything falsely in the questionnaire, we are interested in how you answered, not what you answered. 
Please evaluate whether the information you provided to us was true, false, incomplete, or not attempted.

True $=$ Answer is correct:

(Your name is Jon Snow-Smith and for the question "what is your last name" you write "Snow-Smith")

False $=$ Answer is a lie:

(Your name is Jon Snow-Smith and for the question "what is your last name" you write "Julius Caesar") Incomplete $=$ Answer is missing important information:

(Your name is Jon Snow-Smith and for the question "what is your last name" you write "Snow")

Not attempted $=$ The question was skipped completely or you refused to answer in a different way:

(Your name is Jon Snow-Smith and for the question "what is your last name" you write "fbrb jbe")

Participants will be presented with the questions and their answers again so they can indicate whether they were answered truthfully and in full.

\section{----- New Page -----}

What is your age?

- Under 18

- $18-20$

- 21-24

- 25-29

What is your gender?

- Female

- Male

Highest level of education?

- Some college/high school

- Finished college/high school

- Uni 100 level or equivalent

- Uni 200 level or equivalent

$$
\begin{aligned}
& 30-35 \\
& 36-40 \\
& 41-64 \\
& 65+
\end{aligned}
$$

- Other

- Uni 300 level or equivalent

- Master's degree or equivalent

- PhD

Please wait patiently until everyone else has completed the experiment.

Please do not discuss the study with anyone, especially other potential participants.

You will be given your coffee voucher on the way out, a debriefing sheet, and the option to go into the draw to win a grocery voucher, please spend a few minutes reading the debriefing sheet before leaving the area in case you have any questions.

Thank you very much for participating. 


\section{Appendix F: Question selection}

\begin{tabular}{|c|c|c|}
\hline & Question & Source \\
\hline \multirow{6}{*}{$\begin{array}{l}\text { Personal } \\
\text { identity }\end{array}$} & What is your first name & Generic \\
\hline & What is your surname & Generic \\
\hline & What is your middlename & Generic \\
\hline & What gender do you identify as? & Generic, Norberg, Horne and Horne (2007) \\
\hline & What is your date of birth? & $\begin{array}{l}\text { Generic, Phelps, Nowak and ferrel (2000), } \\
\text { Norberg, Horne and Horne (2007) }\end{array}$ \\
\hline & What is your nationality? & Generic \\
\hline \multirow{5}{*}{$\begin{array}{l}\text { Generic } \\
\text { personal }\end{array}$} & What is your occupation? & Generic, Phelps, Nowak and Ferrel (2000) \\
\hline & How many children do you have? & Generic, Mothersbaugh et al. (2012) \\
\hline & What is your relationship status & $\begin{array}{l}\text { Generic, Mothersbaugh et al. (2012), Phelps, } \\
\text { Nowak and Ferrel (2000) }\end{array}$ \\
\hline & What is your highest qualification? & Generic, Phelps, Nowak and Ferrel (2000) \\
\hline & What is your area of expertise/profession? & Generic \\
\hline \multirow[t]{8}{*}{ Lifestyle } & What are two of your favourite TV shows? & Mothersbaugh et al. (2012) \\
\hline & What are two of your favourite leisure activities? & $\begin{array}{l}\text { Mothersbaugh et al. (2012), Norberg, Horne } \\
\text { and Horne (2007) }\end{array}$ \\
\hline & How often do you make online purchases? & Mothersbaugh et al. (2012) \\
\hline & How often do you use social media? & Mothersbaugh et al. (2012) \\
\hline & What are two websites you use most often? & Phelps, Nowak and Ferrel (2000) \\
\hline & What were your last two purchases? & Phelps, Nowak and Ferrel (2000) \\
\hline & What two stores do you shop at most often? & Phelps, Nowak and Ferrel (2000) \\
\hline & How often do you consume alcohol? & $\begin{array}{l}\text { Norberg, Horne and Horne (2007), Hitsch, } \\
\text { Hortacsu, and Ariely, (2010) }\end{array}$ \\
\hline \multirow[t]{7}{*}{ Financial } & What is your yearly income & $\begin{array}{l}\text { Phelps, Nowak and ferrel (2000), Norberg, } \\
\text { Horne and Horne (2007) }\end{array}$ \\
\hline & Are you in any debt? (Excluding student loan) & Derived \\
\hline & What amount is your student loan? & Derived \\
\hline & How many credit cards do you have? & Phelps, Nowak and Ferrel (2000) \\
\hline & Your credit cards are from which bank(s)? & Derived \\
\hline & What is your parent(s) income? & Norberg, Horne and Horne (2007) \\
\hline & How much money do you save a month? & Norberg, Horne and Horne (2007) \\
\hline \multirow[t]{3}{*}{$\begin{array}{l}\text { Political/ } \\
\text { religious }\end{array}$} & What are your religious beliefs? & $\begin{array}{l}\text { Norberg, Horne and Horne (2007), Hitsch, } \\
\text { Hortacsu, and Ariely, (2010) }\end{array}$ \\
\hline & What is your political inclination? & Hitsch, Hortacsu, and Ariely, (2010) \\
\hline & Who did you vote for in the last election? & Derived, Hitsch, Hortacsu, and Ariely, (2010) \\
\hline \multirow{9}{*}{$\begin{array}{c}\text { Health } \\
\text { information }\end{array}$} & Have you bought condoms this year? & White (2004) \\
\hline & How frequently do you view porn? & White (2004) \\
\hline & How many sexual partners have you had? & Joinson, Paine, Buchanan and Reips, 2008, \\
\hline & What is your sexual orientation? & Derived \\
\hline & Who's your general practitioner for STD's? & Norberg, Horne and Horne (2007) \\
\hline & $\begin{array}{l}\text { Do you experience mental illness? And if so, how } \\
\text { would you describe it? }\end{array}$ & Norberg, Horne and Horne (2007) \\
\hline & $\begin{array}{l}\text { How often do you use illicit drugs for recreational } \\
\text { use? }\end{array}$ & Hitsch, Hortacsu, and Ariely, 2010 \\
\hline & How often do you smoke cigarettes? & Hitsch, Hortacsu, and Ariely, 2010 \\
\hline & $\begin{array}{l}\text { Do you experience a physical disability? And if so, } \\
\text { how would you describe it? }\end{array}$ & Derived, Hitsch, Hortacsu, and Ariely, (2010) \\
\hline \multirow[t]{4}{*}{$\begin{array}{l}\text { Contact } \\
\text { details }\end{array}$} & What is your mobile phone number? & $\begin{array}{l}\text { Generic, White (2004), Mothersbaugh et al. } \\
\text { (2012), Phelps, Nowak and Ferrel (2000) }\end{array}$ \\
\hline & What is your email address? & Generic, Norberg, Horne and Horne (2007) \\
\hline & What is your secondary email address? & Generic \\
\hline & What is your address? & $\begin{array}{l}\text { Generic, White (2004), Norberg, Horne and } \\
\text { Horne (2007) }\end{array}$ \\
\hline
\end{tabular}




\section{Appendix G: Pre-test 1 and 2 demographic and scenario data}

\section{Pre-test 1}

\section{Demographics}

\begin{tabular}{|l|r|r|}
\hline Age & Frequency & Percent \\
\hline $18-24$ & 19 & 59.4 \\
\hline $25-34$ & 6 & 18.8 \\
\hline $35-44$ & 2 & 6.3 \\
\hline $45-54$ & 3 & 9.4 \\
\hline $55-64$ & 1 & 3.1 \\
\hline Total & 31 & 96.9 \\
\hline Missing & 1 & 3.1 \\
\hline & 32 & 100 \\
\hline Gender & Frequency & Percent \\
\hline Female & 17 & 53.1 \\
\hline Male & 14 & 43.8 \\
\hline Total & 31 & 96.9 \\
\hline Missing & 1 & 3.1 \\
\hline & 32 & 100 \\
\hline
\end{tabular}

\section{Pre-test 2}

\section{Demographics}

\begin{tabular}{|l|r|r|}
\hline Age & Frequency & Percent \\
\hline Under 18 & 2 & 1.1 \\
\hline $18-24$ & 107 & 57.8 \\
\hline $25-34$ & 59 & 31.9 \\
\hline $35-44$ & 8 & 4.3 \\
\hline $45-54$ & 8 & 4.3 \\
\hline Total & 184 & 99.5 \\
\hline Missing & 1 & 0.5 \\
\hline & 185 & 100 \\
\hline Gender & Frequency & Percent \\
\hline Female & 119 & 64.3 \\
\hline Male & 60 & 32.4 \\
\hline Other & 6 & 3.2 \\
\hline Total & 185 & 100 \\
\hline
\end{tabular}

\section{Scenarios}

\begin{tabular}{|l|l|r|r|}
\hline Item & N & Mean & Std. Deviation \\
\hline General Share to the five most sensitive & 31 & 2.20 & 0.907 \\
\hline General Share to the five least sensitive & 30 & 4.23 & 0.898 \\
\hline General Trust & 31 & 2.42 & 1.205 \\
\hline Bank Share to the five most sensitive & 31 & 2.32 & 1.275 \\
\hline Bank Share to the five least sensitive & 30 & 4.00 & 1.050 \\
\hline Bank Trust & 31 & 2.90 & 1.274 \\
\hline Pharma Share to the five most sensitive & 31 & 3.48 & 1.151 \\
\hline Pharma Share to the five least sensitive & 30 & 4.07 & 1.230 \\
\hline Pharma trust & 30 & 3.60 & 1.192 \\
& & & \\
\hline
\end{tabular}

\section{Scenarios}

\begin{tabular}{|l|l|l|l|}
\hline Item & N & Mean & $\begin{array}{l}\text { Std. } \\
\text { Deviation }\end{array}$ \\
\hline $\begin{array}{l}\text { General share to } \\
\text { the five most } \\
\text { sensitive }\end{array}$ & 185 & 2.10 & 1.022 \\
\hline $\begin{array}{l}\text { General share to } \\
\text { the five least } \\
\text { sensitive }\end{array}$ & 185 & 3.90 & 1.027 \\
\hline General Trust & 185 & 2.62 & 1.031 \\
\hline $\begin{array}{l}\text { Pharma share to } \\
\text { the five most } \\
\text { sensitive }\end{array}$ & 184 & 2.74 & 1.230 \\
\hline $\begin{array}{l}\text { Pharma share to } \\
\text { the five least } \\
\text { sensitive }\end{array}$ & 183 & 3.88 & 1.166 \\
\hline Pharma trust & 184 & 3.09 & 1.200 \\
\hline $\begin{array}{l}\text { Dating share to the } \\
\text { five most sensitive }\end{array}$ & 184 & 2.17 & 1.210 \\
\hline $\begin{array}{l}\text { Dating share to the } \\
\text { five least sensitive }\end{array}$ & 184 & 3.48 & 1.241 \\
\hline Dating Trust & 184 & 2.28 & 0.978 \\
\hline
\end{tabular}




\section{Appendix H: Pre-test 1 and 2 questions}

\section{Pre-test 1 questions}

\begin{tabular}{|c|c|c|c|}
\hline Item & $\mathbf{N}$ & Mean & Std. Deviation \\
\hline What is your first name? & 32 & 1.56 & 1.134 \\
\hline What are two of your favourite TV shows? & 32 & 1.68 & 1.354 \\
\hline What is your occupation? & 32 & 1.81 & 1.029 \\
\hline What is your area of expertise/profession?? & 32 & 1.94 & 0.981 \\
\hline What is your middle name? & 32 & 1.97 & 1.204 \\
\hline What are two of your favourite leisure activities? & 32 & 1.97 & 1.256 \\
\hline What is your nationality? & 32 & 2.06 & 1.318 \\
\hline What is your surname? & 31 & 2.13 & 1.565 \\
\hline What gender do you identify as? & 32 & 2.19 & 1.424 \\
\hline How many children do you have? & 32 & 2.44 & 1.435 \\
\hline What two stores do you shop at most often? & 32 & 2.53 & 1.367 \\
\hline What is your highest qualification? & 32 & 2.56 & 1.268 \\
\hline How often do you smoke cigarettes? & 32 & 2.63 & 1.497 \\
\hline How often do you use social media? & 32 & 2.66 & 1.428 \\
\hline How often do you make online purchases? & 32 & 2.72 & 1.325 \\
\hline What is your date of birth? & 32 & 2.75 & 1.883 \\
\hline What are two websites you use most often? & 32 & 2.81 & 1.468 \\
\hline What is your relationship status? & 32 & 2.81 & 1.490 \\
\hline What are your religious beliefs? & 32 & 2.81 & 1.574 \\
\hline What is your secondary email? & 32 & 2.94 & 1.740 \\
\hline What were your last two purchases? & 32 & 3.00 & 1.565 \\
\hline How often do you consume alcohol? & 32 & 3.09 & 1.729 \\
\hline What is your email? & 32 & 3.12 & 1.680 \\
\hline What is your sexual orientation? & 32 & 3.19 & 1.891 \\
\hline Have you bought condoms this year? & 32 & 3.34 & 1.734 \\
\hline How many credit cards do you have? & 32 & 3.62 & 1.518 \\
\hline What amount is your student loan? & 32 & 3.78 & 1.640 \\
\hline What is your political inclination? & 32 & 3.78 & 1.518 \\
\hline What is your mobile number? & 32 & 4.12 & 1.946 \\
\hline Your credit cards are from which bank(s)? & 32 & 4.15 & 1.833 \\
\hline How often do you use illicit drugs for recreational use? & 32 & 4.28 & 1.904 \\
\hline Who's your general practitioner for STD & 32 & 4.28 & 1.904 \\
\hline How frequently do you view porn? & 32 & 4.37 & 1.930 \\
\hline Are you in any debt? (Excluding student loan) & 32 & 4.43 & 1.664 \\
\hline Who did you vote for last election? & 32 & 4.43 & 1.830 \\
\hline What is your yearly income? & 32 & 4.56 & 1.479 \\
\hline How much money do you save a month? & 32 & 4.56 & 1.584 \\
\hline Do you have a form of mental illness? And if so, how would you describe it? & 32 & 4.59 & 1.643 \\
\hline What is your address? & 32 & 4.62 & 1.879 \\
\hline What is your parent(s) income? & 32 & 4.71 & 1.745 \\
\hline How many sexual partners have you had? & 32 & 4.71 & 1.954 \\
\hline
\end{tabular}




\section{Pre-test 2 questions}

\begin{tabular}{|c|c|c|c|}
\hline Question & $\mathbf{N}$ & Mean & Std. Deviation \\
\hline What are two of your favourite TV shows? & 185 & 1.27 & 0.653 \\
\hline What is your first name? & 185 & 1.38 & 0.955 \\
\hline What are two of your favourite leisure activities? & 185 & 1.45 & 0.914 \\
\hline What gender do you identify as? & 184 & 1.62 & 1.243 \\
\hline What is your occupation? & 185 & 1.85 & 1.194 \\
\hline What is your nationality? & 185 & 1.86 & 1.305 \\
\hline What is your area of expertise/profession?? & 185 & 1.97 & 1.235 \\
\hline What two stores do you shop at most often? & 185 & 2.07 & 1.331 \\
\hline How many children do you have? & 185 & 2.08 & 1.529 \\
\hline How often do you use social media? & 185 & 2.09 & 1.315 \\
\hline What is your surname? & 184 & 2.10 & 1.480 \\
\hline What is your middle name? & 185 & 2.17 & 1.489 \\
\hline What are two websites you use most often? & 185 & 2.18 & 1.425 \\
\hline How often do you smoke cigarettes? & 184 & 2.22 & 1.639 \\
\hline What is your date of birth? & 185 & 2.34 & 1.597 \\
\hline How often do you make online purchases? & 185 & 2.37 & 1.477 \\
\hline What are your religious beliefs? & 185 & 2.39 & 1.588 \\
\hline How often do you consume alcohol? & 185 & 2.43 & 1.524 \\
\hline What is your sexual orientation? & 185 & 2.54 & 1.817 \\
\hline What is your highest qualification? & 185 & 2.60 & 1.605 \\
\hline What is your relationship status? & 185 & 2.68 & 1.553 \\
\hline What were your last two purchases? & 185 & 2.86 & 1.731 \\
\hline Do you have a physical disability? And if so, how would you describe it? & 184 & 2.89 & 1.910 \\
\hline What is your email? & 185 & 3.03 & 1.738 \\
\hline What is your political inclination? & 185 & 3.09 & 1.849 \\
\hline What is your secondary email? & 185 & 3.15 & 1.942 \\
\hline Have you bought condoms this year? & 185 & 3.17 & 1.883 \\
\hline How often do you use illicit drugs for recreational use? & 185 & 3.49 & 2.129 \\
\hline Who did you vote for last election? & 185 & 3.58 & 2.083 \\
\hline How many credit cards do you have? & 185 & 3.60 & 2.119 \\
\hline Your credit cards are from which bank(s)? & 185 & 3.64 & 2.258 \\
\hline Do you have a form of mental illness? And if so, how would you describe it? & 185 & 3.85 & 1.964 \\
\hline What amount is your student loan? & 185 & 3.89 & 2.002 \\
\hline What is your mobile number? & 185 & 3.98 & 1.923 \\
\hline How much money do you save a month? & 185 & 4.03 & 1.833 \\
\hline Who's your general practitioner for STDs? & 185 & 4.09 & 2.183 \\
\hline What is your yearly income? & 185 & 4.20 & 1.867 \\
\hline Are you in any debt? (Excluding student loan) & 185 & 4.25 & 1.998 \\
\hline How frequently do you view porn? & 185 & 4.54 & 2.045 \\
\hline How many sexual partners have you had? & 185 & 4.70 & 1.956 \\
\hline What is your address? & 185 & 4.85 & 1.849 \\
\hline What is your parent(s) income? & 185 & 4.97 & 1.859 \\
\hline
\end{tabular}




\section{Appendix I: Scenario selection}

The bank and pharmaceutical company scenarios were derived from Norberg et al. (2007) and are replicated in full below.

\section{Bank Scenario}

"A large bank, with an excellent reputation for ethical programs, is developing a "Student Supreme" credit card that will give a percentage of purchase prices back to the student in gift certificates to the college bookstore and other businesses located on campus. As part of their analysis of whether to go forward with this program, they are doing research into this student market. They have acquired a list of students and contacted you to take part in the research. You would be compensated \$20”.

\section{Pharmaceutical Company Scenario}

"A pharmaceutical company, which has had some recent high-profile failures, has invested significant resources in developing a drug intended for the over-the-counter market, which, when taking after drinking, limits the negative impacts associated with hangovers (i.e., fatigue, headache, nausea). As they design a marketing strategy for this product, they are collecting research to evaluate if and how it can be successfully introduced. In order to collect the data, they are asking students to sign up to take part in the study. Once accepted, students are asked to fill out a questionnaire (in exchange for \$20)”. 
Appendix J: Initial confirmatory factor analyses

\begin{tabular}{|c|c|c|c|c|c|c|c|c|c|}
\hline Construct & Item & Mean & SD. & Loading 1 & Loading 2 & Communalities & $\alpha$ & AVE & KMO \\
\hline \multirow{6}{*}{ NFC } & I would prefer complex to simple problems & 4.16 & 1.348 & 0.695 & 0.191 & 0.519 & \multirow{6}{*}{0.715} & \multirow{6}{*}{$\begin{array}{r}\text { Component } \\
\text { 1: } 43.626 \\
\text { Component } \\
\text { 2: } 17.495\end{array}$} & \multirow{6}{*}{0.759} \\
\hline & Thinking is not my idea of fun & 5.09 & 1.411 & 0.742 & 0.338 & 0.664 & & & \\
\hline & $\begin{array}{l}\text { I try to anticipate and avoid situations where there is likely chance } \\
\text { that I will have to think in depth about something }\end{array}$ & 5.33 & 1.310 & 0.755 & -0.134 & 0.588 & & & \\
\hline & $\begin{array}{l}\text { I really enjoy a task that involves coming up with solutions to } \\
\text { problems }\end{array}$ & 5.42 & 1.096 & 0.487 & 0.569 & 0.561 & & & \\
\hline & The notion of thinking abstractly is appealing to me & 5.09 & 1.422 & 0.441 & 0.688 & 0.667 & & & \\
\hline & $\begin{array}{l}\text { It's enough for me that something gets the job done, I don't care } \\
\text { how or why it works }\end{array}$ & 4.61 & 1.549 & -0.136 & 0.805 & 0.667 & & & \\
\hline Construct & Item & Mean & SD. & Loading 1 & Loading 2 & Communalities & $\alpha$ & AVE & KMO \\
\hline \multirow{6}{*}{$\begin{array}{l}\text { General } \\
\text { Sensitivity }\end{array}$} & It takes something fairly severe to offend me & 3.03 & 1.414 & 0.807 & 0.221 & 0.700 & \multirow{6}{*}{0.593} & \multirow{6}{*}{$\begin{array}{r}\text { Component } \\
1: 36.072 \\
\text { Component } \\
2: 21.468\end{array}$} & \multirow{6}{*}{0.604} \\
\hline & It does not take much to make me uncomfortable & 3.72 & 1.517 & 0.584 & -0.281 & 0.420 & & & \\
\hline & People rarely offend me & 2.89 & 1.286 & 0.525 & 0.599 & 0.635 & & & \\
\hline & I lose my patience easily & 3.84 & 1.72 & 0.259 & 0.744 & 0.620 & & & \\
\hline & I'm relatively open & 2.58 & 1.51 & 0.686 & 0.114 & 0.483 & & & \\
\hline & My friends often tell me I over-react to perceived slights & 2.84 & 1.439 & -0.254 & 0.728 & 0.594 & & & \\
\hline Construct & Item & Mean & SD. & Loading 1 & Communalities & $\alpha$ & AVE & KMO & \\
\hline \multirow{4}{*}{$\begin{array}{l}\text { Perceived } \\
\text { Risk }\end{array}$} & In general, it is risky to give information to online companies. & 5.27 & 1.087 & 0.819 & 0.670 & \multirow{4}{*}{0.866} & \multirow{4}{*}{72.065} & \multirow{4}{*}{0.828} & \\
\hline & $\begin{array}{l}\text { There is a high potential for loss associated with giving information } \\
\text { to online firms. }\end{array}$ & 4.63 & 1.475 & 0.852 & 0.726 & & & & \\
\hline & $\begin{array}{l}\text { There is too much uncertainty associated with giving information to } \\
\text { online firms. }\end{array}$ & 4.97 & 1.553 & 0.863 & 0.745 & & & & \\
\hline & $\begin{array}{l}\text { Providing online firms with information involves many unexpected } \\
\text { problems. }\end{array}$ & 4.48 & 1.425 & 0.861 & 0.742 & & & & \\
\hline Construct & Item & Mean & SD. & Loading 1 & Communalities & $\alpha$ & AVE & KMO & \\
\hline \multirow{2}{*}{$\begin{array}{l}\text { Perceived } \\
\text { Worry }\end{array}$} & I feel apprehensive about disclosing information online. & 5.03 & 1.458 & 0.868 & 0.753 & \multirow{2}{*}{0.865} & \multirow{2}{*}{78.887} & \multirow{2}{*}{0.727} & \\
\hline & I have avoided disclosing information online because it worries me. & 4.75 & 1.700 & 0.910 & 0.828 & & & & \\
\hline
\end{tabular}


I hesitate to give personal information online for fear of how the information may be used.

0.886

0.785

\begin{tabular}{|c|c|c|c|c|c|c|c|c|}
\hline Construct & Item & Mean & SD. & Loading 1 & Communalities & $\alpha$ & AVE & KMO \\
\hline \multirow{6}{*}{$\begin{array}{l}\text { Sensory } \\
\text { Sensitivity } \\
\text { (Iteration 1) }\end{array}$} & $\begin{array}{l}\text { I make it a high priority to arrange my life to avoid upsetting or } \\
\text { overwhelming situations }\end{array}$ & 4.63 & 1.569 & 0.358 & 0.128 & $\alpha$ & \multirow{6}{*}{48.862} & \multirow{6}{*}{0.734} \\
\hline & I find it unpleasant to have a lot going on at once & 4.64 & 1.567 & 0.709 & 0.503 & & & \\
\hline & Changes in my life shake me up & 4.47 & 1.573 & 0.830 & 0.688 & & & \\
\hline & I get rattled when I have a lot to do in a short amount of time & 5.17 & 1.475 & 0.690 & 0.476 & & & \\
\hline & $\begin{array}{l}\text { I find myself needing to withdraw during busy days into bed or into } \\
\text { a darkened room or any place where I can have some privacy and } \\
\text { relief from stimulation }\end{array}$ & 4.25 & 2.008 & 0.770 & 0.593 & & & \\
\hline & $\begin{array}{l}\text { I'm easily overwhelmed by things like bright lights, strong smells, } \\
\text { coarse fabrics, or sirens close by }\end{array}$ & 3.09 & 1.925 & 0.737 & 0.544 & & & \\
\hline Construct & Item & Mean & SD. & Loading 1 & $\overline{\text { Communalities }}$ & $\alpha$ & AVE & KMO \\
\hline \multirow{5}{*}{$\begin{array}{l}\text { Sensory } \\
\text { Sensitivity } \\
\text { (Iteration 2) }\end{array}$} & I find it unpleasant to have a lot going on at once & 4.64 & 1.567 & 0.698 & 0.487 & \multirow{5}{*}{0.805} & \multirow{5}{*}{56.877} & \multirow{5}{*}{0.722} \\
\hline & Changes in my life shake me up & 4.47 & 1.573 & 0.824 & 0.68 & & & \\
\hline & I get rattled when I have a lot to do in a short amount of time & 5.17 & 1.475 & 0.708 & 0.501 & & & \\
\hline & $\begin{array}{l}\text { I find myself needing to withdraw during busy days into bed or into } \\
\text { a darkened room or any place where I can have some privacy and } \\
\text { relief from stimulation }\end{array}$ & 4.25 & 2.008 & 0.788 & 0.622 & & & \\
\hline & $\begin{array}{l}\text { I'm easily overwhelmed by things like bright lights, strong smells, } \\
\text { coarse fabrics, or sirens close by }\end{array}$ & 3.09 & 1.925 & 0.745 & 0.555 & & & \\
\hline
\end{tabular}




\section{Appendix K: Final confirmatory factor analyses}

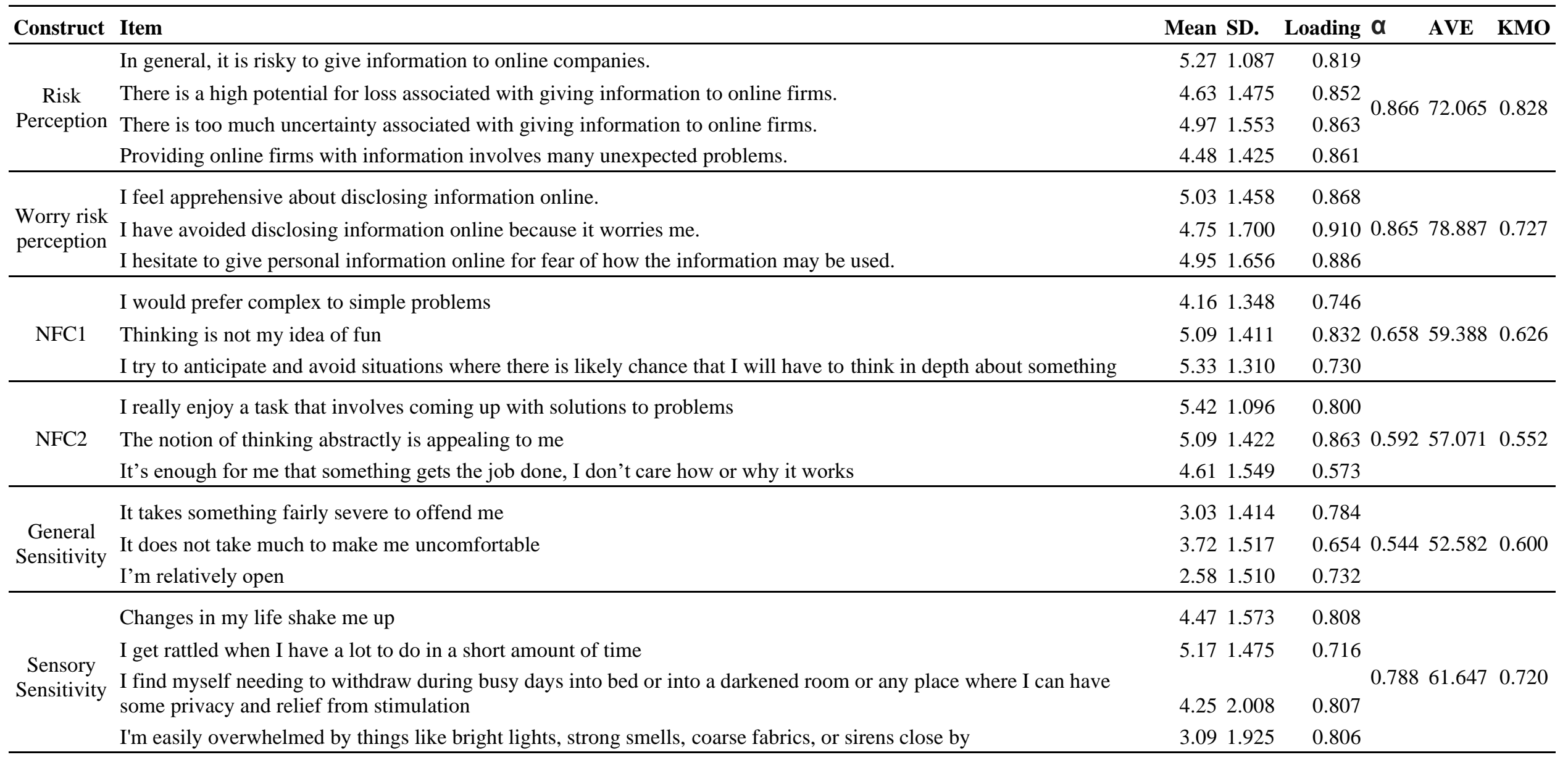




\section{Appendix L: Response latency between conditions}

\section{Independent t-test for response latency}

\begin{tabular}{|c|c|c|c|c|c|}
\hline Question & Manipulation & Mean & Deviation & $\mathrm{t}$ & Sig. (2-tailed) \\
\hline \multirow[t]{2}{*}{ What is your first name? } & 0 & 6.26 & 2.460 & -0.795 & 0.429 \\
\hline & 1 & 6.75 & 2.517 & & \\
\hline \multirow[t]{2}{*}{ What is your surname? } & 0 & 4.59 & 1.461 & -2.199 & 0.032 \\
\hline & 1 & 5.69 & 2.419 & & \\
\hline \multirow[t]{2}{*}{ What is your nationality? } & 0 & 8.88 & 4.979 & -0.325 & 0.746 \\
\hline & 1 & 9.33 & 6.044 & & \\
\hline \multirow[t]{2}{*}{ What is your favourite TV show? } & 0 & 16.70 & 13.301 & 1.221 & 0.227 \\
\hline & 1 & 13.29 & 8.518 & & \\
\hline \multirow[t]{2}{*}{ What was your last purchase you can remember? } & 0 & 16.87 & 12.805 & 0.508 & 0.613 \\
\hline & 1 & 15.40 & 10.119 & & \\
\hline \multirow[t]{2}{*}{ How often do you make online purchases? } & 0 & 12.19 & 8.336 & 1.212 & 0.230 \\
\hline & 1 & 10.25 & 3.581 & & \\
\hline \multirow[t]{2}{*}{ What are two websites you use most often? } & 0 & 9.92 & 5.409 & -1.017 & 0.313 \\
\hline & 1 & 11.69 & 8.265 & & \\
\hline \multirow[t]{2}{*}{ How often do you use social media? } & 0 & 7.64 & 3.432 & -1.926 & 0.059 \\
\hline & 1 & 10.12 & 6.400 & & \\
\hline \multirow[t]{2}{*}{ What is your occupation? } & 0 & 9.89 & 8.473 & 0.455 & 0.651 \\
\hline & 1 & 8.75 & 11.411 & & \\
\hline \multirow[t]{2}{*}{ What is your highest qualification? } & 0 & 13.94 & 7.790 & 1.026 & 0.309 \\
\hline & 1 & 11.86 & 8.437 & & \\
\hline \multirow[t]{2}{*}{ What is your relationship status? } & 0 & 8.78 & 6.695 & 0.614 & 0.541 \\
\hline & 1 & 7.74 & 6.809 & & \\
\hline \multirow[t]{2}{*}{ What amount is your student loan? } & 0 & 10.97 & 5.917 & 0.263 & 0.794 \\
\hline & 1 & 10.50 & 8.281 & & \\
\hline \multirow[t]{2}{*}{ Are you in any debt? (Excluding student loan) } & 0 & 5.55 & 3.212 & 1.101 & 0.275 \\
\hline & 1 & 4.83 & 1.863 & & \\
\hline \multirow[t]{2}{*}{ How many credit cards do you have? } & 0 & 4.52 & 2.942 & 0.454 & 0.651 \\
\hline & 1 & 4.24 & 1.891 & & \\
\hline \multirow[t]{2}{*}{ What is your yearly income? } & 0 & 18.73 & 12.534 & 0.949 & 0.346 \\
\hline & 1 & 15.46 & 14.939 & & \\
\hline \multirow[t]{2}{*}{ How much money do you save a month? } & 0 & 17.21 & 10.27 & 1.200 & 0.235 \\
\hline & 1 & 13.96 & 11.391 & & \\
\hline \multirow[t]{2}{*}{ What is your parent(s) yearly income? } & 0 & 14.75 & 8.984 & -1.803 & 0.076 \\
\hline & 1 & 23.41 & 25.644 & & \\
\hline \multirow[t]{2}{*}{ What is your political inclination? } & 0 & 18.52 & 17.028 & 1.344 & 0.184 \\
\hline & 1 & 13.52 & 12.351 & & \\
\hline \multirow[t]{2}{*}{ Who did you vote for last election? } & 0 & 10.36 & 7.192 & -0.126 & 0.900 \\
\hline & 1 & 10.61 & 8.806 & & \\
\hline How often do you smoke cigarettes? & 0 & 7.24 & 7.115 & 0.235 & 0.815 \\
\hline
\end{tabular}


How often do you consume alcohol?

Do you experience mental illness?

How many sexual partners have you had?

What is your email?

What is your address?

What is your mobile number?

$\begin{array}{rrrrr}1 & 6.90 & 3.606 & & \\ 0 & 11.29 & 9.362 & 0.989 & 0.326 \\ 1 & 9.43 & 5.054 & & \\ 0 & 9.96 & 8.883 & -2.201 & 0.031 \\ 1 & 17.26 & 16.529 & & \\ 0 & 8.00 & 8.416 & -0.823 & 0.414 \\ 1 & 11.56 & 23.033 & & \\ 0 & 9.72 & 2.825 & -0.306 & 0.761 \\ 1 & 10.01 & 4.452 & & \\ 0 & 13.90 & 8.636 & -0.048 & 0.962 \\ 1 & 14.07 & 18.847 & & \\ 0 & 7.02 & 4.028 & 0.351 & 0.727 \\ 1 & 6.72 & 2.679 & & \end{array}$

